
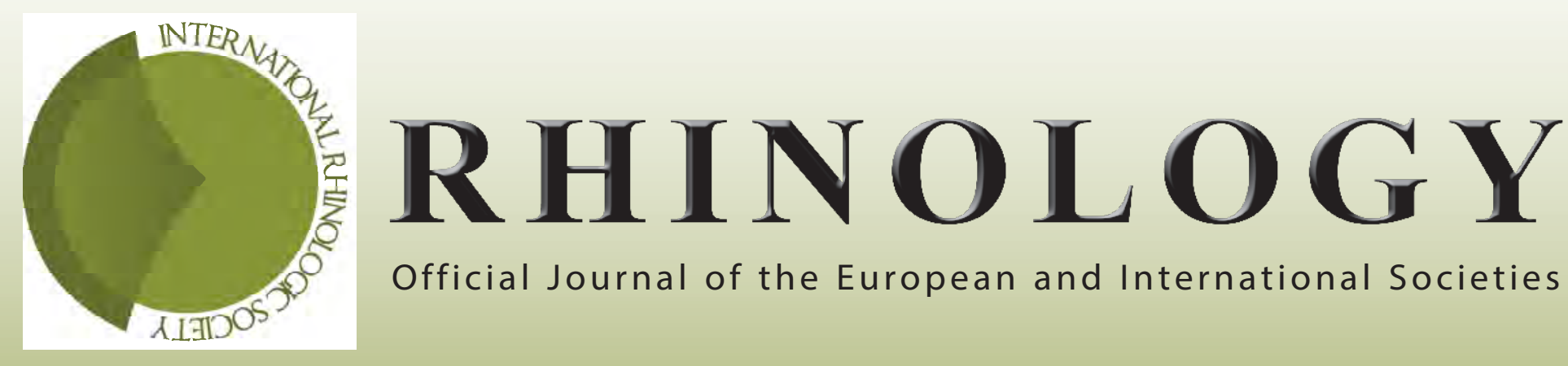

Official Journal of the European and International Societies

\title{
European position paper on diagnostic tools in rhinology
}

J. Rimmer, P. Hellings, V. Lund, I. Alobid, T. Beale, C. Dassi, R. Douglas, C. Hopkins, L. Klimek, B. Landis, R. Mosges, G. Ottaviano, A. Psaltis, P. Surda, P.V.Tomazic, J. Vent, W.J. Fokkens 
Editor-in-Chief

Prof W.J. Fokkens

\section{Associate Editor}

Prof P.W. Hellings

Managing Editor

Dr. W.T.V. Germeraad

Editorial Assistant and Secretary

Mrs J. Kosman

rhinologyassistant@amc.uva.n

Webmaster

Mr. S.H.O. Zwetsloot

rhinologywebmaster@gmail.com
Journal Rhinology, c/o AMC, Mrs. J. Kosman / A2-234, PO Box 22 660,

1100 DD Amsterdam, the Netherlands.

Tel: +31-20-566 4534

Fax: +31-20-566 9662

E-mail: rhinologysecretary@amc.uva.n

Website: www.rhinologyjournal.com
Rhinology (ISSN 0300-0729) is the official Journal of the European and International Rhinologic Societies and appears quarterly in March, June, September and December. Cited in Pubmed, Current Contents, Index Medicus, Exerpta Medica and Embase

Founded in 1963 by H.A.E. van Dishoeck, Rhinology is a worldwide non-profit making journal. The journal publishes original papers on basic research as well as clinical studies in the major field of rhinology, including physiology, diagnostics, pathology, immunology, medical therapy and surgery of both the nose and paranasal sinuses. Review articles and short communications are also pulished. All papers are peer-reviewed. Letters-to-the-editor provide a forum for comments on published papers, and are not subject to editorial revision except for correction of English language.

In-depth studies that are too long to be included into a regular issue can be published as a supplement. Supplements are not subject to peer-review.
All rights reserved. No part of this publication may be reproduced or transmitted in any form or by any means electronic or mechanical, including photocopying, recording or any information storage and retrieval system without prior permission in writing from the Publisher.

Submission of a manuscript for publication implies the transfer of the copyright from the author(s) to the publisher and entails the author's irrevocable and exclusive authorization of the publisher to collect any sums or considerations for copying or reproduction payable by third parties. 


\section{European Position Paper on Diagnostic Tools in Rhinology}

Joanne Rimmer ${ }^{1,2}$, Peter Hellings ${ }^{3,4,5}$, Valerie J. Lund ${ }^{6}$, Isam Alobid7, Timothy Beale $^{8}$, Camila Dassi ${ }^{9}$, Richard Douglas ${ }^{10}$, Claire Hopkins ${ }^{11}$, Ludger Klimek ${ }^{12}$, Basile Landis ${ }^{13}$, Ralph Mosges ${ }^{14,15}$, Giancarlo Ottaviano ${ }^{16}$, Alkis Psaltis ${ }^{17}$, Pavol Surda ${ }^{11}$, Peter Valentin Tomazic ${ }^{18}$, Julia Vent ${ }^{19,20}$, Wytske Fokkens ${ }^{5}$

' Department of Otolaryngology Head and Neck Surgery, Monash Health, Melbourne, Australia

2 Department of Surgery, Monash University, Melbourne, Australia

${ }^{3}$ Upper Airways Research Laboratory and ENT Department, University Hospital Ghent, Ghent, Belgium

${ }^{4}$ Department of Otorhinolaryngology - Head and Neck Surgery, University Hospitals Leuven, KU Leuven, Leuven, Belgium

${ }^{5}$ Department of Otorhinolaryngology, Amsterdam University Medical Centres, Amsterdam, The Netherlands

${ }^{6}$ Royal National Throat Nose and Ear Hospital, University College London Hospitals, London, UK

${ }^{7}$ Rhinology and Skull Base Unit, ENT Department, Hospital Clínic de Barcelona, Universidad de Barcelona, August Pi i Sunyer Biomedical Research Institute, Barcelona, Spain

${ }^{8}$ University College London Hospitals Foundation Trust, London, UK

${ }^{9}$ Department of Otolaryngology, Auckland City Hospital, Auckland, New Zealand

${ }^{10}$ Department of Surgery, The University of Auckland, Auckland, New Zealand

"Ear, Nose and Throat Department, Guys and St. Thomas' Hospital, London, United Kingdom

${ }^{12}$ Center for Rhinology and Allergology, Wiesbaden, Germany

${ }^{13}$ Rhinology-Olfactology Unit, Otorhinolaryngology Department, University Hospital of Geneva, Geneva, Switzerland

${ }^{14}$ Institute of Medical Statistics, Computational Biology (IMSB), Faculty of Medicine, University of Cologne, Cologne, Germany

${ }^{15}$ ClinNovis GmbH, Cologne, Germany

${ }^{16}$ Department of Neurosciences, Otolaryngology Section, University of Padova, Padova, Italy

${ }^{17}$ Department of Otolaryngology Head and Neck Surgery, University of Adelaide and Queen Elizabeth Hospital, Adelaide, South

Australia

${ }^{18}$ Department of Otorhinolaryngology - Head and Neck Surgery, Medical University of Graz, Graz, Austria

${ }^{19}$ Department of Otorhinolaryngology - Head and Neck Surgery, University of Cologne, Cologne Germany

${ }^{20}$ Medical Faculty Mannheim, University of Heidelberg, Mannheim, Germany

Rhinology supplement 28: 1-41,

2019

https://doi.org/10.4193/Rhin19.410 


\begin{abstract}
The accurate diagnosis of rhinologic disease depends on the clinical history, examination findings and, in many cases, further investigations. There are a wide variety of diagnostic tests available, the choice of which depends upon the condition being assessed. This position paper is intended to provide an up-to-date comprehensive description of the diagnostic tools available to rhinologists, allergists, general otolaryngologists and other physicians with an interest in sinonasal disease. The literature has been reviewed and evidence-based recommendations are included. The relevant history and examination techniques are described, including endoscopic assessment of the nose. General and disease-specific quality of life instruments are an important tool in assessing the impact of rhinologic disease and the response to treatment. Relevant blood tests are discussed, as well as the various methods of allergy testing. Techniques for collecting microbiological and tissue samples are described, as well as the use of more specialised tests such as nasal nitric oxide and those evaluating ciliary structure and function. Imaging techniques and their indications are included. Chemosensory (smell and taste) testing is explained, and the available techniques for objective measurement of nasal airflow and patency are reviewed. Prompt and accurate diagnosis allows appropriate management to be initiated; an understanding of the currently available diagnostic tools is a vital part of the assessment of rhinologic disease.
\end{abstract}

Key words: rhinology, sinusitis, rhinitis, diagnosis, investigation, nose, paranasal sinuses

To cite this article: Rimmer J, Hellings P, Lund V, Alobid I, Beale T, Dassi C, Douglas R, Hopkins C, Klimek L, Landis B, Mosges R, Ottaviano G, Psaltis A, Surda P, Tomazic PV, Vent J, Fokkens WJ. European Position Paper on Diagnostic Tools in Rhinology. Rhinology. 2019, Suppl. 28: 1-42. 


\section{Contents}

INTRODUCTION

HISTORY AND EXAMINATION

History

Examination

QUALITY OF LIFE INSTRUMENTS

Patient-rated outcome measures (PROMs)

Generic PROMs

Disease-specific PROMs

BLOOD TESTS

Epistaxis

Rhinitis

Granulomatous and vasculitic rhinological conditions Infectious conditions

Immunoglobulin deficiencies

Miscellaneous blood tests

4

5

7

7

7

9

9

9

9

10

10

10

ALLERGY TESTS

Skin tests

Provocation tests

In vitro allergy testing (IgE)

MICROBIOLOGY

Culture-dependent techniques

Culture-independent techniques

Outcomes

\section{CHEMOSENSORY ASSESSMENT}

Olfactory testing

Gustatory testing

Trigeminal testing

IMAGING

Techniques

Sensitivity and specificity or accuracy

Outcomes

NASAL SAMPLING FOR INFLAMMATORY MARKERS

Techniques

OBJECTIVE MEASURES OF NASAL AIRFLOW

AND PATENCY

Peak nasal inspiratory flow (PNIF)

Rhinomanometry

Acoustic rhinometry $(A R)$

Uses
11

11

11

13

14

14

15

15

16

16

18

19

19

20

22

24

25
NASAL NITRIC OXIDE 30

Technique 31

Diagnostic accuracy 31

Diagnostic use of nNO 31

TESTS OF MUCOCILIARY CLEARANCE 31

Techniques $\quad 32$

$\begin{array}{ll}\text { REFERENCES } & 33\end{array}$ 


\section{Introduction}

The European Academy of Allergy and Clinical Immunology (EAACI) recognised the importance of accurate investigation in the diagnosis of sinonasal disease with their 2011 position paper on Diagnostic Tools in Rhinology ${ }^{(1)}$. That document hoped to 'become outdated soon by new advances in the field' - this has indeed been the case in some areas, whilst others remain unchanged. This position paper is intended to provide an up-to-date comprehensive description of the diagnostic tools available to rhinologists, allergists, general otolaryngologists and other physicians with an interest in sinonasal disease. Some rhinologic conditions can be diagnosed on history and examination alone; others require further investigations to confirm or, in some cases, exclude a diagnosis. Blood tests, microbiology and histology, imaging, airflow assessment, allergy testing and more specialised investigations may all play a role. The accurate diagnosis of rhinologic disease is important for various reasons. Many sinonasal conditions have a significant negative impact on patients' quality of life (QOL), and prompt diagnosis will allow appropriate management at an early stage, with subsequent improvement in outcomes ${ }^{(2)}$. Inflammatory airway disease often starts in the nose and progresses to the lower respiratory tract, and there are several systemic conditions that may initially present with sinonasal symptoms, including cystic fibrosis, granulomatous and vasculitic conditions. Some systemic conditions are associated with significant potential long-term morbidity and even mortality which can be prevented or ameliorated by early accurate diagnosis and treatment. In some healthcare systems, objective evidence of disease and proof of benefit from treatment is increasingly required for funding purposes. This is particularly true for surgical intervention but also for newer, more expensive medical treatments such as monoclonal antibodies for asthma, nasal polyps and systemic vasculitides. Accurate diagnosis can be facilitated by appropriate investigations, remembering that not all the tests discussed below will be relevant to all patients. Some are freely available for all to use, others require more specialist equipment, and some remain more in the realm of research than clinical practice. Nonetheless, we must ensure that the available tools are used to facilitate prompt diagnosis and management of the multitude of sinonasal conditions that we see in our patients every day.

\section{History and examination}

\section{Rationale}

History taking and examination techniques are among the first clinical skills learned and remain the most important part of a consultation. A thorough history and rhinologic examination will suggest a differential diagnosis and, in some cases, may give an exact diagnosis. Certain rhinologic conditions, such as rhinosinusitis, have established diagnostic criteria, and treatment can be commenced based on the symptoms and clinical findings alone ${ }^{(3,4)}$.

There are a limited number of rhinological symptoms; when these are taken together with examination findings, a diagnosis may be made. If that is not possible, the investigations required to confirm (or exclude) a disease can be determined. Several studies have assessed the correlation between symptoms, examination findings and imaging results in chronic rhinosinusitis (CRS) ${ }^{(5-7)}$. If symptom criteria are met there is a high sensitivity but low specificity for correctly diagnosing CRS. If endoscopy is included, the specificity and diagnostic accuracy increase significantly ${ }^{(6,7)}$.

\section{Objectives}

To establish the nature, duration and severity of symptoms, and to interpret them in conjunction with examination findings, with the aim of making a diagnosis and initiating appropriate treatment. If an exact diagnosis cannot be reached then further investigations may be indicated, depending on the symptoms and clinical findings.

\section{History}

Patients should be asked to describe their symptoms, and further questions can then define their nature. Common sinonasal symptoms are listed in Box 1. It is useful to identify any precipitating or relieving factors, including any response (or lack of) to treatment so far ${ }^{(8)}$.

Nasal obstruction or congestion is the most common rhinologic symptom, reported in up to $80 \%$ of patients ${ }^{(9)}$. It may be unilateral or bilateral, fluctuating, alternating or constant, and is a very subjective symptom. The nature of the obstruction can suggest the underlying aetiology, for example unilateral constant nasal obstruction is often due to septal deviation, whilst alternating fluctuating obstruction is more typical of rhinitis. Nasal discharge (rhinorrhoea) may be anterior or posterior, with many patients describing 'postnasal drip'; this may simply be an awareness of the normal passage of mucus posteriorly from the nose into the pharynx but may represent an abnormal volume or consistency of mucus. It may be clear and watery, as commonly seen in rhinitis, although unilateral watery rhinorrhoea should raise the suspicion of a CSF leak. Discharge may be coloured, although this does not always correlate with an infective aetiology. Blood-stained discharge may simply be due to underlying inflammation or infection but a neoplastic or vasculitic process must be considered.

Facial pressure or pain may be related to underlying sinonasal disease, particularly acute exacerbations, but many so-called 
'sinus headaches' are not sinogenic in nature ${ }^{(10)}$. A negative correlation has been found between headache or facial pain as the predominant symptom and positive endoscopic and radiological findings ${ }^{(11)}$. Facial pain rather than pressure, a throbbing quality, headaches and photophobia have been shown to be negatively predictive for CRS ${ }^{(12)}$.

A change in sense of smell may be a reduction (hyposmia) or complete loss (anosmia). Associated nasal obstruction may point to a conductive loss, such as in nasal polyps, but a history of trauma, infection and underlying neurological conditions need to be included. A foul smell (cacosmia) can be real or may represent an olfactory hallucination (phantosmia); these may be idiopathic, but an underlying pathology needs to be excluded. Hyposmia is positively predictive for a diagnosis of CRS but rarely found in rhinitis ${ }^{(12)}$.

Additional factors, including a history of asthma, any other comorbidities, previous sinonasal surgery, current medications, sensitivity to non-steroidal anti-inflammatory drugs (NSAIDs) and known allergies should also be recorded.

The symptoms of rhinitis are nasal obstruction and discharge, with sneezing often a feature of allergic rhinitis ${ }^{(13)}$. It is important to elicit the frequency and duration of symptoms in allergic rhinitis, and their impact on daily life, as this allows further classification into 'intermittent' or 'persistent' and 'mild' or 'severe' as per the Allergic Rhinitis and its Impact on Asthma (ARIA) guidelines ${ }^{(14)}$. Allergic rhinitis most commonly begins in early childhood, and nasal conditions that begin in adulthood are less likely to have an allergic cause.

The European Position Paper on Rhinosinusitis and Nasal Polyps (EPOS 2012) defines rhinosinusitis based on symptoms, endoscopic and/or computed tomography (CT) changes ${ }^{(3)}$. Two or more symptoms are required, one of which must be either nasal blockage/obstruction/congestion or nasal discharge, with or without facial pain/pressure or a reduction or loss of smell. Acute rhinosinusitis (ARS) is defined as symptoms lasting for less than 12 weeks, while CRS persists for more than 12 weeks. The American Academy of Otolaryngology-Head and Neck Surgery Foundation Clinical Practice Guidelines for rhinosinusitis have the same symptom requirements for a diagnosis of CRS but define ARS slightly differently, namely up to four weeks of purulent (not clear) nasal drainage accompanied by nasal obstruction, facial pain/pressure/fullness or both ${ }^{(4)}$. Thus the history is vital in making a diagnosis of rhinosinusitis.

\section{Examination}

A thorough head and neck examination should be considered the gold standard for any patient complaining of sinonasal symptoms; here the relevant rhinological components are discussed.

Observe the patient, looking for mouth breathing and/or dynamic collapse of the nasal side walls. Assess the external nose for deformity, which may cause functional problems and/ or cosmetic concerns. Cottle's manoeuvre is often performed to assess nasal valve collapse as a cause of nasal obstruction: the cheek skin lateral to the nasolabial fold is pulled laterally, increasing tension in the lateral nasal wall and thereby widening the nasal valve ${ }^{(15)}$. The result is positive if the patient reports improved breathing as a result of this. However, there is little evidence to support the specificity of Cottle's manoeuvre and it has never been validated. No difference was found in septoplasty outcomes for those with a positive versus a negative Cottle's manoeuvre, suggesting it is not particularly helpful as an isolated assessment ${ }^{(15)}$.

Anterior rhinoscopy is performed using a Thudichum's, Cottle's or Killian's speculum and a head light or mirror (Figure 1). It allows assessment of the caudal septum, anterior ends of the inferior turbinates and the anterior nasal airway in general. It may be possible to see the middle turbinates. Caudal septal deviation is more likely to be associated with nasal obstruction than more posterior deviations or spurs ${ }^{\left({ }^{9}\right)}$. There may be inferior turbinate hypertrophy and oedematous, pale or purplish nasal mucosa in rhinitis ${ }^{(13)}$. Large nasal polyps may be easily visible and the diagnostic accuracy of anterior rhinoscopy in CRS has been shown in older studies to be $66 \%-77 \%$ when combined with the history ${ }^{(5,10)}$. However, it is generally accepted that anterior rhinoscopy is useful but not diagnostic in many cases ${ }^{(3,14)}$. Nasal endoscopy allows a more comprehensive examination of the nasal cavity, middle meatus, sphenoethmoidal recess and postnasal space, and is an essential part of the rhinological examination ${ }^{(3)}$. It allows identification of oedema, pus and/or polyps, assessment of sinus cavities following surgery and facilitates postoperative debridement or microbiological sampling when needed ${ }^{(16)}$. It can be used to evaluate the response to both medical and surgical treatment and allows photo/videodocumentation. It is a useful educational tool for both junior staff and patients, and is generally well-tolerated.

The standard three-pass technique for rigid nasendoscopy was originally described using a $4 \mathrm{~mm} 30$ degree endoscope, but it can be performed with a $2.7 \mathrm{~mm}$ endoscope and/or a zero degree endoscope instead ${ }^{(17,18)}$. The patient should be upright, and topical decongestant/anaesthetic spray may be used if necessary. The first pass is made along the floor of the nose to the nasopharynx, looking at the general anatomy, septum, inferior turbinates and nasal mucosa (Figure 2). The second pass runs above the inferior turbinate to the middle meatus then medial to the middle turbinate into the sphenoethmoidal recess (Figure 3). The third pass is made as the endoscope is withdrawn, when it may be possible to roll it laterally into the middle meatus (Figure 4) ${ }^{(17)}$. Flexible endoscopes can be used instead, and are particularly useful if the larynx and pharynx need to be assessed as well, but additional procedures cannot be performed ${ }^{(19)}$. Endoscopy improves diagnostic accuracy compared to anterior 


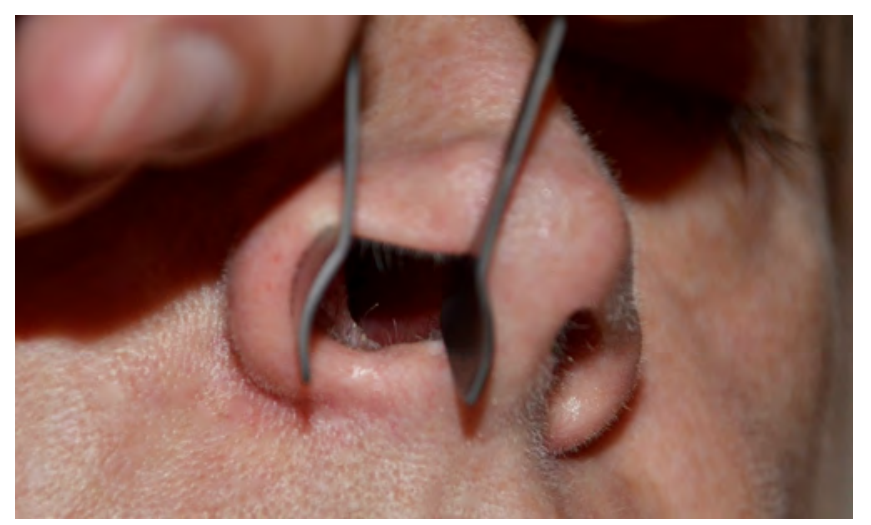

Figure 1. Anterior rhinoscopy using a Thudichum's speculum.

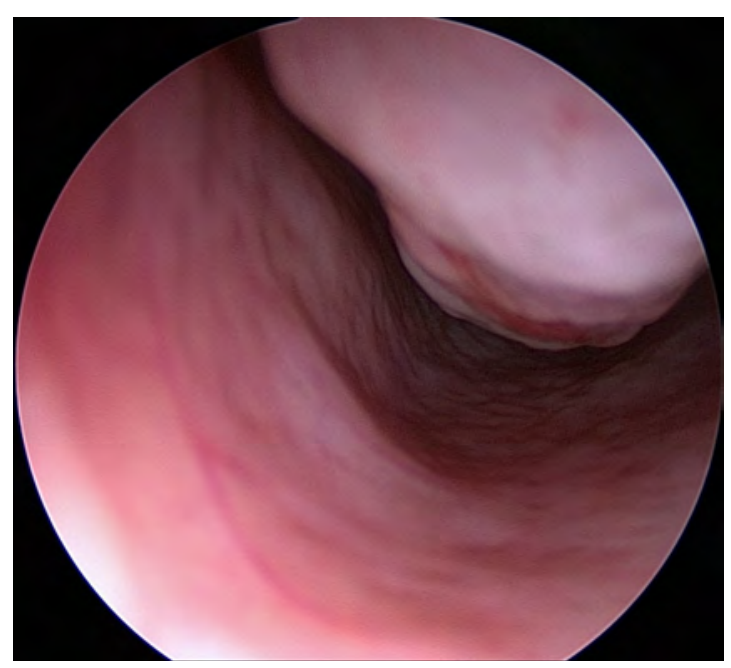

Figure 2. First pass with rigid (0 degree) endoscope.

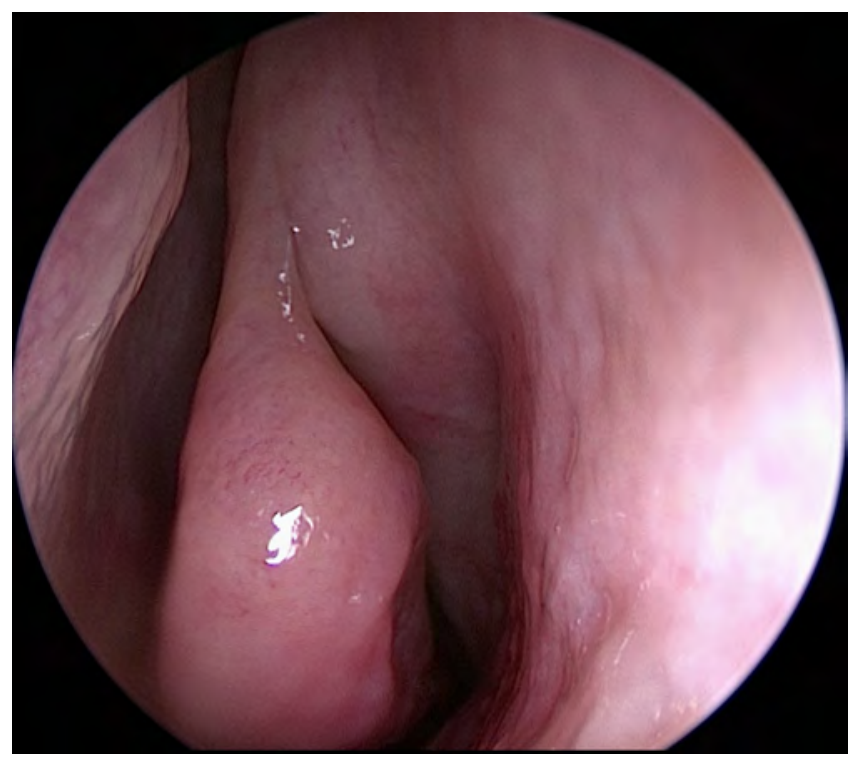

Figure 4. Third pass with rigid (0 degree) endoscope.
Box 1. Common sinonasal symptoms.

Nasal congestion/obstruction
Nasal discharge
Facial pain/pressure or headache
Change in sense of smell
Sneezing/itching
Bleeding

Nasal congestion/obstruction

Nasal discharge

Facial pain/pressure or headache

Change in sense of smell

Bleeding

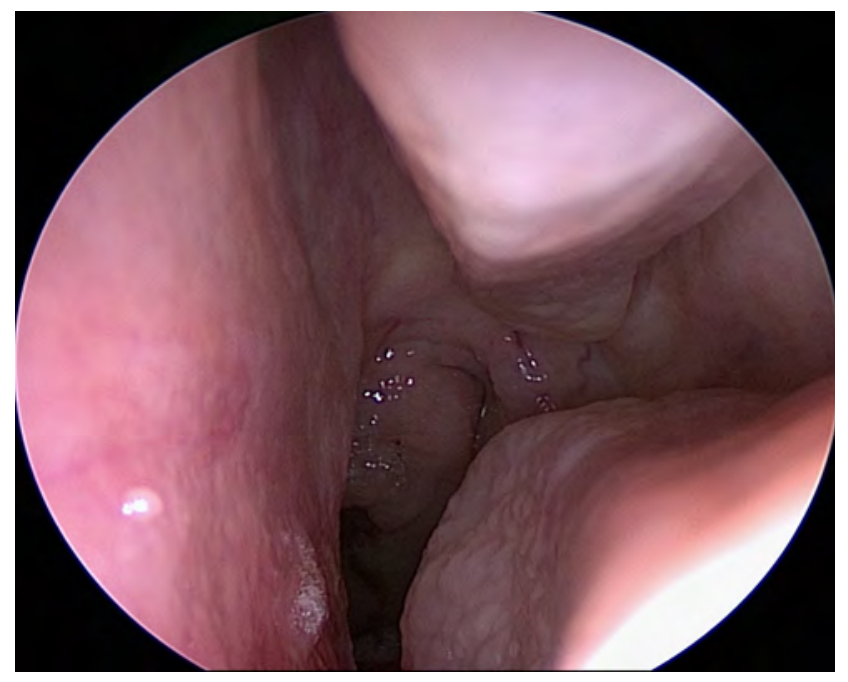

Figure 3. Second pass with rigid (0 degree) endoscope.

rhinoscopy alone, up to $69.1 \%-85 \%{ }^{(5,6)}$. It is highly specific, with several studies reporting specificities of up to $95 \%(6,7,20)$. It is less sensitive, ranging from $30 \%$ to $73 \%{ }^{(5-7)}$. Various endoscopic scoring systems have been described, such as the Lund-Kennedy system and modifications thereof ${ }^{(21,22)}$. Inter-rater reliability is variable, with some aspects of the examination scoring highly and others less so, although overall inter-rater agreement is $\operatorname{good}^{(23-27)}$.

Posterior rhinoscopy and diaphanoscopy have been superseded by endoscopy and imaging.

\section{Recommendations}

A thorough history should be used in combination with a complete rhinological examination, of which endoscopy is a vital part. This allows a systematic approach to be used to determine the differential diagnosis, whether further investigations are required, and to plan appropriate management for the individual patient. 


\section{Quality of life instruments}

\section{Rationale}

Sinonasal diseases can have a significant impact upon patients' QOL. This affects physical and mental health and may translate into absenteeism or presenteeism. The effects on daily functioning, work, leisure and school as perceived by the patient are considered an important characteristic of disease severity ${ }^{(28,29)}$. Therefore, assessment of QOL is one of the standard outcome measures that is increasingly important to improving patientcentred care and optimising healthcare delivery.

Patients seek medical care in order to alleviate symptoms of disease and their impact on QOL. It seems intuitive that doctors would wish to measure whether they are successful in achieving these treatment aims, whether from surgical or medical intervention. Medical therapy is often the mainstay of treatment for sinonasal disease, but if this fails or complications arise, surgery is considered. Therefore, patients have several treatment options which may change and evolve throughout their disease progression. The degree of health-related QOL impairment has been demonstrated to drive patient choice between treatment options ${ }^{(30)}$. Application of different outcome measures is essential to improve the quality of care. Moreover, assessment of $\mathrm{QOL}$ is one of the standard outcome measures in clinical trials, acknowledging the fact that the classical outcome variables may only partially characterize the disease of the patient.

\section{Objectives}

To evaluate the degree of QOL impairment due to rhinological disease, to help guide treatment and to monitor the response to medical and/or surgical management. Additional benefits to measuring surgical outcome are listed in Box 2.

\section{Patient-rated outcome measures (PROMs)}

Quality of life is measured using one of a growing number of validated 'instruments'; typically these are questionnaires, but in some cases visual scales or grading systems can be used. These allow quantitative assessment of otherwise subjective results. So why not simply ask the patients if they are satisfied with their treatment? Although this is easy to do, patient satisfaction is influenced by many variables, such as the availability and convenience of healthcare, the 'bedside manner' of the doctor, affability of the extended team and perceived cleanliness of the hospital (31). While these are all important, they complicate evaluation of clinical outcome. To avoid this, the questionnaires require the patient to rate the impact of their disease across a number of specified 'domains' or areas of interest. Individual questions are scored according to severity or impact of disease, and then scores are combined to produce an overall score. Scores can be used to follow patients with chronic disease, or compared before or after an intervention at an individual patient level, or across different groups of patients, thus quantifying the amount of change.

Some patient-rated outcome measures (PROMs) have been developed for particular conditions or treatments (diseasespecific) while others are designed for use in all patient groups or healthy individuals and measure the patient's perception of their general health (generic measures).

\section{Generic PROMs}

General QOL instruments are based on standard survey techniques but are not specific to the population being surveyed and therefore do not assess the improvement in disease-specific symptoms. They allow the impact on QOL of different diseases to be evaluated and compared, and when linked with economic evaluations may allow the comparison of the relative 'value' of interventions across different conditions.

The short form 36 (SF-36) is a multipurpose, 36-item survey that measures eight domains of health: physical functioning; role limitations due to physical health; bodily pain; general health perceptions; vitality; social functioning; role limitations due to emotional problems; and mental health. It has been widely used in many medical conditions and in over 5000 publications, with normative values available for the general population. Using the SF-36, CRS has been shown to have a negative impact on several aspects of QOL, and has a greater impact on social functioning than chronic heart failure, angina or back pain ${ }^{(32)}$.

The EQ-5D is a generic measure of a patient's preference for living in a particular health state. It has been recently validated in the CRS population and provides health state utility values capable of generating quality-adjusted life-years ${ }^{(33,34)}$. The EQ-5D contains five attributes: mobility; self-care; usual activity; pain/ discomfort; and anxiety/depression. Each attribute has three possible states, which provides 245 possible health states. Utility scores were measured for each health state using the time trade-off technique ${ }^{(34,35)}$.

Generic QOL instruments should be used with caution to assess changes in health-related QOL and are less effective with mild disease ${ }^{(36)}$. For example, when applied to cataract surgery, a pilot study found that although the majority of patients reported that their vision was better following cataract surgery, there was no change in the EQ-5D ${ }^{(37)}$. Similar results have been shown in patients with conductive hearing loss ${ }^{(38)}$. This is of concern if such measures are used for demand management to ration healthcare. Furthermore, application of these different instruments in the same patient group can yield significantly different results ${ }^{(39)}$.

\section{Disease-specific PROMs}

There are a number of disease-specific QOL instruments that have been developed to assess the most important symptoms for patients and quantify the severity of all commonly associa- 
Box 2. Additional benefits to measuring surgical outcome.

Allows individual surgeons to judge and improve their practice

Allows refinement of surgical techniques by comparing procedures

Helps patients to make informed choices about their care, allowing comparison between medical and surgical treatments, or between different procedures

Provides greater public transparency and accountability

Enables quality assurance of operations

Facilitates comparison between healthcare providers

Provides data for healthcare commissioners when making funding decisions, as may allow comparison of the impact of treatments across different specialities

Has or will become an essential component of revalidation in the UK, the USA, the Netherlands and other healthcare systems

ted symptoms. As a result, they help focus the consultation and provide a useful clinical record; they may facilitate the patient's visit and reduce consultation time. They can help define the aims of treatment and are likely to be more sensitive to small but clinically relevant changes in outcome than global measures. Although they are based on subjective patient symptoms, the instruments themselves are objective in that they have gone through an extensive process of validation and reproducibility testing.

Any textbook is unable to keep up with the development of new PROMs, but some of the key areas in rhinology are briefly reviewed below.

\section{Chronic rhinosinusitis}

A recent systematic review performed by Rudmik et al. ${ }^{(40)}$ identified 15 PROMs validated for adults with CRS. Of these, the Sinonasal Outcome Test (SNOT-22), the Questionnaire of Olfactory Disorders (QOD) and the Sinusitis Control Test (SCT) contained the highest quality of development and psychometric properties. These three PROMs also evaluated different aspects of CRS including health-related QOL and symptoms (SNOT-22), olfaction (QOD) and disease control (SCT). Morley and Sharp ${ }^{(41)}$, based on their appraisal of the available measures, concluded that the SNOT-22 was the most suitable tool in terms of reliability, validity, responsiveness and ease of use. An earlier systematic review ${ }^{(42)}$, before the SNOT-22 was validated, recommends either the RhinoQOL or the 31-Item Rhinosinusitis Outcome Measure (a longer version of the SNOT-22) for rhinosinusitis.
The SNOT-22 is an outcome measure validated for use in patients with CRS and applicable to both medical and surgical treatments, with a score range of $0-110$. It is derived from the SNOT-20 with two questions added to measure nasal blockage and sense of taste/smell. Patients rank the severity of 22 symptoms using a six-point Likert scale. The SNOT-22 was used to prospectively collect the outcomes of 3,128 patients undergoing a range of surgical procedures for CRS who were recruited by the National Comparative Audit of Surgery for Chronic Rhinosinusitis and Nasal Polyposis ${ }^{(43)}$. This is the largest published outcomes study to date in CRS, and therefore provides useful benchmarking data against which future studies may be compared. Psychometric validation has been completed, suggesting excellent internal consistency, test-retest reliability and discriminant ability, and has established that the minimally important change for an individual with CRS is nine points ${ }^{(44)}$.

\section{Rhinitis}

The mini-Rhinoconjunctivitis Quality of Life Questionnaire (miniRQLQ) was primarily developed and validated to assess QOL in allergic rhinitis and includes 14 questions divided into five subdomains assessing daily activities, practical issues, and nasal and ocular symptoms ${ }^{(45)}$. In contrast to the well-known significant impairment of QOL in allergic rhinitis, the degree of impairment in QOL in non-allergic rhinitis remained unknown for a long time, due to the lack of a validated questionnaire. Recently, a validation of the mini-RQLQ questionnaire in non-allergic rhinitis patients was performed, followed by an assessment of 
QOL in non-allergic rhinitis patients compared to allergic rhinitis patients and healthy controls ${ }^{(46)}$.

\section{Nasal obstruction and septal surgery}

The Nasal Obstruction Septoplasty Effectiveness (NOSE) questionnaire is a validated five-item instrument for use in patients with nasal obstruction, and has been used to measure improvements in QOL after septoplasty, functional septorhinoplasty and nasal valve surgery ${ }^{(47)}$. The SNOT-22 has also been used in septoplasty, although it has not been validated in this patient group $^{(48}$.

\section{Rhinoplasty and facial appearance}

Perhaps more so than in any other aspect of rhinology, patient satisfaction and QOL must be the measure against which successful aesthetic facial plastic surgery should be judged. A recently published study identified 47 patient-reported instruments targeted to facial plastics ${ }^{(49)}$. Three of these pertained to rhinoplasty (Glasgow Benefit Inventory, Facial Appearance Sorting Test ${ }^{(50)}$ and the Rhinoplasty Outcomes Evaluation (ROE)) (51). The ROE is the only QOL instrument designed specifically for rhinoplasty and has been fully validated. There are few published studies including patient-rated satisfaction following rhinoplasty. Two studies show significant improvement in ROE scores following rhinoplasty ${ }^{(51,52)}$.

\section{Skull base surgery}

A disease-specific instrument has been designed and validated for those undergoing resection of anterior skull base tumours (53). The Anterior Skull Base Questionnaire (ASBQ) has a total of 35 items including generic questions and items drawn from head and neck questionnaires, and also includes more detailed questions regarding altered taste, smell, appearance, epiphora, nasal secretions and visual disturbances ${ }^{(53)}$.

\section{Recommendations}

Patients now rightly expect their doctors to record outcomes of clinical care. Clinical measures are becoming more sophisticated, and the equipment required to make such measures is now widely available. Routine collection of PROMs is likely to become mandatory for healthcare providers. We should embrace this opportunity and use this patient-rated information to enhance the doctor-patient relationship and focus communication. Careful use in cohort studies or within randomised trials may identify important differences in outcomes between treatments or providers, although it is still important to recognise the limitations of the outcome tools.

\section{Blood tests}

\section{Rationale}

Blood tests are required for some patients with rhinological conditions. However, before tests are requested, it should be asked whether they are likely to be materially helpful in the diagnosis and management of the patient. If tests with imperfect accuracy are requested for patients with a low pre-test probability of having the condition, then more diagnostic confusion can be created by false positive results than diagnostic clarity by true positive results.

\section{Objectives}

To provide additional support for or against the diagnosis of certain rhinological conditions, and to monitor disease severity, progression and/or response to treatment where appropriate.

\section{Epistaxis}

A full blood count, serum ferritin and coagulation studies may be included in the investigation of recurrent or severe epistaxis.

\section{Rhinitis}

\section{Allergic rhinitis}

Diagnostic tests for allergies must be considered when the clinical presentation indicates a high suspicion of immunoglobulin E (IgE)-mediated disease (see section on 'Allergy tests'). It is important to highlight that allergy testing demonstrates sensitization to a specific allergen, which does not always imply clinical manifestations of that sensitization ${ }^{(54,55)}$. Despite their relatively high cost compared to skin prick tests (SPT), tests that measure serum levels of allergen specific lgE are a valuable alternative for patients with a high risk of anaphylaxis, severe eczema or other dermatologic diseases, or when the interruption of anti-histamines is contraindicated ${ }^{(56)}$.

\section{Non-infectious non-allergic rhinitis}

The investigation of systemic conditions such as pregnancy, thyroid pathologies and autoimmune diseases should be considered in appropriate clinical contexts.

\section{Granulomatous and vasculitic rhinological conditions} Vasculitic diseases with sinonasal manifestations usually, but not always, involve multiple organs. Rhinitis, sinusitis, septal perforation and epistaxis are the most common nasal features related to these diseases ${ }^{(57)}$.

\section{Granulomatosis with polyangiitis (GPA, formerly Wegener's granulomatosis)}

Patients with granulomatosis with polyangiitis (GPA) affecting the sinonasal cavity usually have persistent bleeding, crusting and obstruction, and may develop a septal perforation. 
Sometimes the manifestations of this vasculitic condition are limited to the sinonasal cavity. GPA is strongly associated with anti-neutrophil cytoplasmic antibodies (ANCA), and the more widespread and severe the presentation, the more likely the serum ANCA is to be positive ${ }^{(58)}$. The combination of clinical features, positive ANCA serology, necrotizing vasculitis and granulomatous inflammation on biopsy establish the diagnosis (59). However, nasal biopsies often do not have enough features specific to this condition to confirm the diagnosis, and so biopsies from other involved organs may be required.

It is important to highlight that a positive ANCA serology is not required for diagnosis if the clinical and histological findings are consistent with GPA. The sensitivity of this test is lower for localized as opposed to generalised GPA. False positive ANCA results can also occur. The cytoplasmic antigen towards which ANCAs are directed is proteinase-3 (PR3), and the detection of PR3 antibodies in serum by enzyme-linked immunosorbent assay (ELISA) is used in conjunction with ANCA immunofluorescent testing to improve diagnostic accuracy ${ }^{(60,61)}$.

\section{Eosinophilic granulomatosis with polyangiitis (EGPA, formerly} Churg-Strauss syndrome)

Eosinophilic granulomatosis with polyangiitis (EGPA) is a necrotizing vasculitis of small and medium-sized vessels. Among a wide spectrum of non-pulmonary symptoms, nasal and sinonasal features are common and part of the diagnostic criteria for EGPA ${ }^{(62)}$. This condition typically develops in patients with adult onset asthma and the sinonasal manifestation is CRS with eosinophilic nasal polyps.

Like GPA, EGPA is associated with positive ANCA serology. The most common pattern of immunofluorescence seen is a perinuclear (as opposed to a cytoplasmic) pattern. The antigen to which the antibodies are most commonly directed in EGPA is myeloperoxidase (MPO), and serum ELISAs for MPO are positive in about $40 \%-50 \%$ of patients with this disease ${ }^{(63)}$.

\section{Sarcoidosis}

Sarcoidosis is a complex disease with manifold clinical manifestations. Diagnosis of sarcoidosis is based on clinical and radiological evidence, plus histological confirmation of non-caseating granulomas. Serum soluble interleukin-2 (sIL-2R), angiotensin converting enzyme (ACE) and lysozyme levels have become useful tools in the diagnosis of sarcoidosis and for evaluating disease activity, in addition to fluorodeoxyglucose-positron emission tomography (FDG-PET). Serum ACE is the most widely used laboratory test for the investigation of sarcoidosis ${ }^{(64)}$. Elevated serum levels of ACE, sIL-2R and lysozyme are usually associated with more aggressive disease and multiple organ involvement ${ }^{(65)}$.
Infectious conditions

Diagnostic tests for human immunodeficiency virus (HIV), tuberculosis, syphilis and hepatitis should be considered in patients with high-risk exposure to infectious diseases.

\section{Immunoglobulin deficiencies}

Patients with hypogammaglobulinaemia often present with a combination of upper and lower respiratory tract infections and inflammation. Hypogammaglobulinaemia may be primary, of which the most common cause likely to be seen by a rhinologist is common variable immunodeficiency. This usually begins in adulthood, and results in the patient developing sinusitis and pulmonary infections. The most common secondary cause is chronic lymphocytic leukaemia.

The diagnosis is made by the determination of low levels of serum IgG. These are usually associated with low levels of the other classes of immunoglobins. Sometimes, the significance of slightly low levels of lgG are not clear, and so functional assays in which the response mounted after administration of certain vaccine challenges is measured. Pneumococcal vaccines have been used for this purpose, but the interpretation of adequate response is a matter for conjecture.

Sometimes, when the serum IgG level is normal but a humoral immune deficiency is suspected, serum IgG subclasses are requested. IgG has four variants, each with a slight difference in its action. The clinical significance of subclass deficiency is not clear, and it is generally advisable for rhinologists to manage patients with hypogammaglobulinaemia in combination with a clinical immunologist.

\section{Miscellaneous blood tests \\ Periostin}

Periostin is both an extracellular matrix protein and matricellular protein that is capable of activating cells by linking integrin molecules to cell receptors, promoting tissue remodelling. It may be an important biomarker for type 2 immunity and airway allergic inflammation exacerbations. Up-regulated expression of periostin is correlated with CRS with nasal polyps (CRSwNP) and Th2-type asthma ${ }^{(66-68)}$. Serum periostin levels also appear to be higher in patients with NSAID intolerance than in those without it ${ }^{(67)}$.

\section{Aspirin sensitivity}

Oral provocation test is the most common investigation used to identify hypersensitivity reactions to aspirin. However, for those patients who have a higher risk of severe reactions, flow cytometry-assisted basophil activation testing (FAST) and functional-eicosanoid-test (FET) can be helpful tools to elucidate the diagnosis, if they are available ${ }^{(69,70)}$. 


\section{Recommendations}

Many patients with nasal conditions are managed with clinical evaluation including endoscopy and imaging, without the requirement for blood tests. However, for some presentations laboratory tests are very helpful.

\section{Allergy tests}

\section{Rationale}

Allergic rhinitis in most cases is triggered by allergen-specific $\lg \mathrm{E}$ that initializes the immune response and inflammatory process. If an allergic reaction is IgE-mediated, it is called a type I hypersensitivity reaction. The presence of specific lgE can be demonstrated either in vivo (skin tests, organ provocation) or in vitro by detecting allergen-specific $\lg E$ in serum or airway secretions. The presence of specific lgE alone (sensitization) does not necessarily imply their causative relationship to the patient's symptoms (IgE-mediated allergic disease). Many individuals are sensitized but not clinically allergic ${ }^{(71)}$. The prevalence of positive skin prick or serum allergy tests are significantly higher than the prevalence of allergic rhinitis, so testing patients with a low pretest probability of having this condition will generate false positive results.

\section{Objectives}

To demonstrate both the presence and functional relevance of $\lg \mathrm{E}$ antibodies in allergic rhinitis.

\section{Skin tests}

In patients with upper airway allergies, skin tests such as SPT and intracutaneous tests (ICT) are the most commonly used in vivo methods to diagnose lgE-mediated allergic reactions ${ }^{(72-76)}$. A recent EAACl task force survey investigating the current practice of allergy diagnosis in Europe found that in almost twothirds of all types of allergic diseases and in $90 \%$ of respiratory allergies the diagnosis relies on skin tests as the first option ${ }^{(77)}$. A number of manufacturers offer commercial allergen test extracts for skin testing called diagnostic allergens (DAs). The composition and standardization of DAs is crucial to the sensitivity, specificity and reproducibility of test results ${ }^{(75,78)}$. In the European Union (EU), allergens used for diagnostic tests or therapy have been defined as medicinal products by EU Directives 89/342/EEC and 2001/83/EC ${ }^{(78)}$. As such, DAs that are produced by an industrial process to be used in the $\mathrm{EU}$ are required to obtain a marketing authorisation in EU member states. For this, the documentation to be provided by the applicant has to follow the European Pharmacopoeia as well as specific guidelines such as those developed by the European Medicines Agency and the International Council for
Harmonisation of Technical Requirements for Pharmaceuticals for Human Use ${ }^{(75,78)}$. For allergen products, the Guideline on Allergen Products: Production and Quality Issues is of high importance ${ }^{(79)}$. The approval of DAs has enabled the use of qualitatively and quantitatively standardized extracts ${ }^{(75,78)}$, however it also increased the costs for and has led to a reduction in commercially available DAs ${ }^{(75,78,80)}$.

\section{Skin prick test (SPT)}

The primary diagnostic tool to detect type I hypersensitivity reactions in the upper airways is SPT, since it is reproducible, inexpensive, safe, minimally invasive and results are immediately available ${ }^{(74,81-84)}$. SPT interpretation utilizes the presence and degree of cutaneous reactivity as a surrogate marker for sensitization within target organs and allows several different allergens to be tested simultaneously. A large GA2LEN study in 14 countries set a standard allergen panel for SPT ${ }^{(83,85)}$. The allergen is presented to perivascular mast cells in the dermis; the volar side of the forearm is the preferred site ${ }^{(86)}$, but modifications exist for special applications ${ }^{(87)}$. The test site should be marked so that individual reactions can be readily attributed to test preparations and sufficient distance should be left between test sites. Negative (normal saline) and positive (histamine) control preparations are also used. Mediators released by the mast cells trigger a reaction clinically equivalent to the triple response of Lewis caused by the injection of histamine ${ }^{(86)}$ :

- local redness due to vasodilation

- dermal oedema caused by increased capillary permeability - erythema in the surrounding area due to axonal reflexes. Redness (erythema) and wheal (urticaria) peak within 15-20 minutes following histamine or allergen application ${ }^{(88)}$. Latephase reactions may appear within hours to several days after SPT.

\section{Intracutaneous test (ICT)}

Using a 21-gauge needle, $0.02-0.05 \mathrm{ml}$ of the test solution is injected intracutaneously ${ }^{(86)}$; the injected volume should form a wheal approximately $3 \mathrm{~mm}$ in diameter. The test solution must be sterile and both approved and suitable for intracutaneous use ${ }^{(89)}$. ICT may have higher sensitivity but lower specificity compared with SPT and require different allergen test solution concentrations ${ }^{(90-93)}$. Thus, ICT may be indicated even in the presence of a negative SPT ${ }^{(90-93)}$.

\section{Provocation tests}

\section{Nasal allergen challenge}

The EAACl guidelines for nasal allergen challenge testing aim to unify the conduction of provocation tests and their interpretation ${ }^{\left({ }^{94}\right)}$. The main recommendations are a bilateral 
challenge with standardized allergens using a spray device offering $0.1 \mathrm{~mL}$ per puff. A systematic catalogue for positivity criteria is given for the variety of established subjective and objective assessment methods as well as a schedule for the challenge procedure.

\section{Conjunctival provocation test (CPT)}

Most patients with allergic rhinitis also suffer from allergic conjunctivitis, with symptoms of itchy eyes, redness and tearing ${ }^{95}$. The conjunctival provocation test (CPT), also known as conjunctival allergen challenge (CAC), is a well-established diagnostic procedure to assess the severity of the allergic reaction in rhinoconjunctivitis and to show the efficacy of immunotherapy in dose-finding studies. Several different challenge protocols have been described in the literature, but the general procedure is similar.

First, $0.5 \mathrm{ml}$ of a control solution is instilled into the lower conjunctival sac of one eye and $0.5 \mathrm{ml}$ of a test solution is instilled into the other eye (Figure 5). The compositions of the control solution and the test solution are the same, except that the first contains no allergen extract and should therefore not induce an allergic reaction. After 15 minutes, the allergic reaction is assessed according to a standardized scoring system, of which there are several in use (Tables 1-3). If the CPT is positive, the eye is rinsed with lukewarm water and drops containing topical antihistamines or nonpharmacological agents are applied for symptom relief. If the threshold of the scoring system is not reached, the CPT is repeated with a higher allergen concentration, for example increased by a factor of 10 (Figure 5). The CPT is considered negative if no reaction occurs after the highest concentration has been administered.

The total ocular symptom score (TOSS) (Table 1) is calculated by adding up the individual scores and is positive if the sum is greater than five ${ }^{(96)}$.

Riechelmann et al. ${ }^{(97)}$ established an adapted version of the scoring system described by Gronemeyer ${ }^{(98)}$ by comparing the CPT with the nasal provocation test (NPT), SPT, IgE assays and the patient's allergic history (Table 2). The allergic reaction is classified as stages 0-IV; stage II or higher is considered positive. In comparison with the NPT, the CPT assessed with the Gronemeyer score was shown to be more consistent with

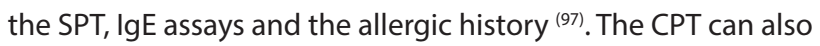
be used in patients with allergic rhinitis but no conjunctival symptoms.

The culture-independent assessment of the CPT (CIA-CPT) is applied to the separate allergic symptoms of the CPT, assessing them on a 0-3 scale (Table 3), and was successfully used in a recent dose-finding study ${ }^{(99)}$.

The information obtained depends on the quality of the allergen solution. It is recommended to use only highly standardized and lyophilized allergen extracts and a fluid containing only one allergen ${ }^{(96)}$. Depending on the manufacturer, definitions for the concentration of the allergen mixture differ widely, such as index of reactivity/ml (Stallergenes Greer, Antony, France), histamine equivalent prick/ml (Laboratorios LETI S.L. Unipersonal, Madrid, Spain) or standardized quality units (SQ-

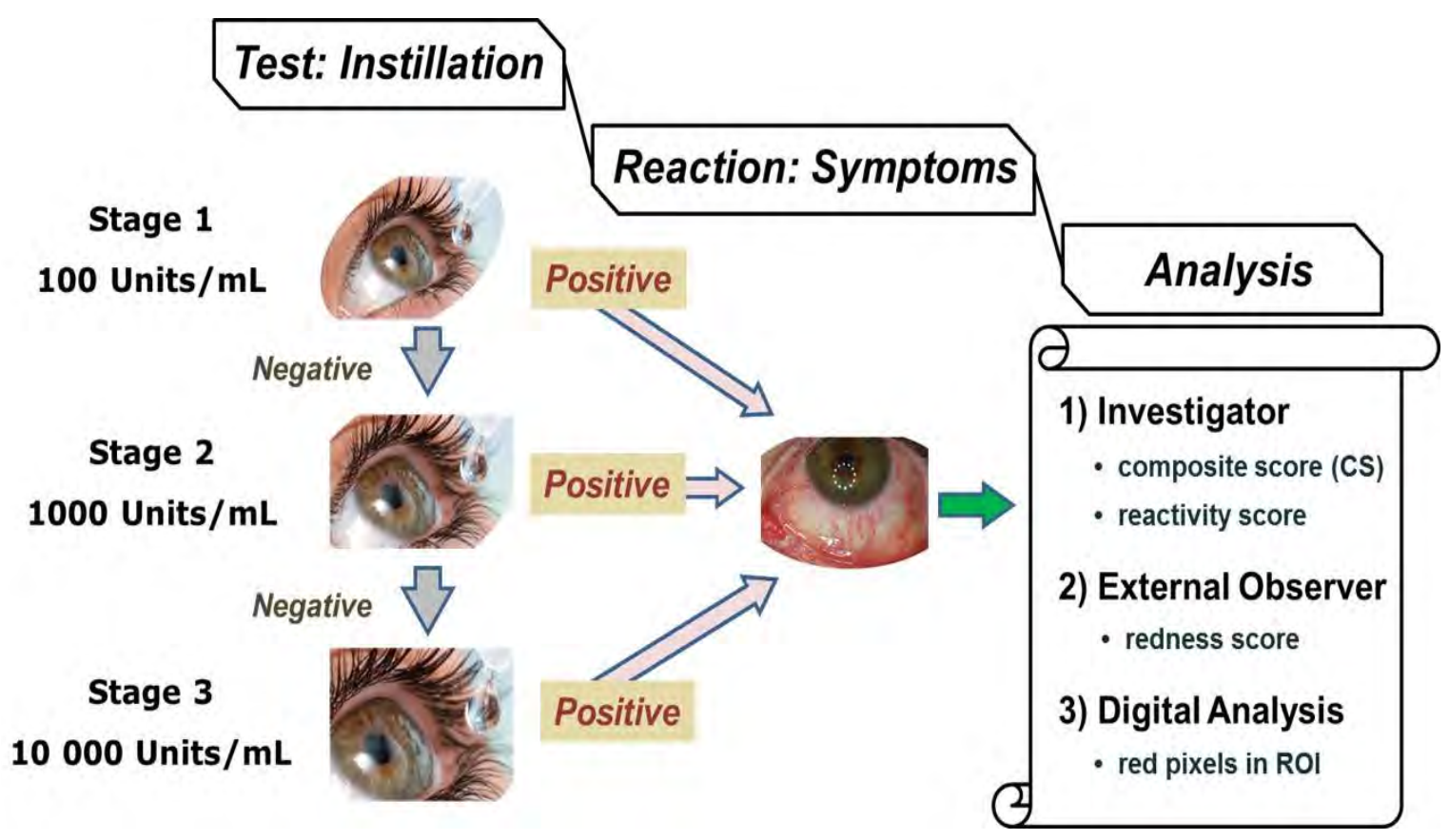

Figure 5. The conjunctival allergen challenge. (ROI: region of interest) 
Table 1. Total ocular symptom score (TOSS) (96).

$\begin{array}{ll}\text { Symptom } & \text { Severity (score) } \\ & 0 \text { - none } \\ & 1 \text { - mild } \\ & 2 \text { - moderate } \\ & 3 \text { - severe } \\ & 4 \text { - incapacitating } \\ \text { Itching } & 0 \text {-none } \\ & 1 \text { - mild } \\ & 2 \text { - moderate } \\ & 3 \text { - severe } \\ & 0 \text { - none } \\ \text { Redness } & 1 \text { - mild } \\ & 2 \text { - moderate } \\ & 3 \text { - severe } \\ & 0 \text { - none } \\ \text { Tearing } & 1 \text { - mild } \\ & 2 \text { - moderate } \\ & 3 \text { - severe } \\ \end{array}$

Table 3. Culture-independent assessment of the CPT (CIA-CPT) ${ }^{(99)}$.

\begin{tabular}{|c|c|}
\hline Symptom & Severity (score) \\
\hline \multirow{4}{*}{ Itching } & 0 - no itching \\
\hline & 1 - mild itching, but not annoying \\
\hline & $\begin{array}{l}2 \text { - moderate, annoying itching or urge to rub } \\
\text { the eye sometimes }\end{array}$ \\
\hline & $\begin{array}{l}3 \text { - severe, very annoying itching or urge to rub } \\
\text { the eye frequently. }\end{array}$ \\
\hline \multirow{4}{*}{ Irritation } & 0 - no irritation \\
\hline & $\begin{array}{l}1 \text { - dry eye or another unusual feeling in the eye, } \\
\text { but not annoying }\end{array}$ \\
\hline & $\begin{array}{l}2 \text { - annoying sandy feeling or feeling of a foreign } \\
\text { object in the eye, or urge to rub the eye }\end{array}$ \\
\hline & $\begin{array}{l}3 \text { - very annoying burning or pain in the eye, or } \\
\text { difficulty in keeping the eye open, or urge to rub } \\
\text { the eye frequently. }\end{array}$ \\
\hline \multirow{4}{*}{ Tearing } & 0 - no watery eye \\
\hline & 1 - watery eye, but no tears and not annoying \\
\hline & $\begin{array}{l}2 \text { - annoying watery eye with some tears, or urge } \\
\text { to wipe the eye sometimes }\end{array}$ \\
\hline & $\begin{array}{l}3 \text { - very annoying watery eye with some tears, or } \\
\text { urge to wipe the eye frequently. }\end{array}$ \\
\hline \multirow{4}{*}{ Redness } & 0 - no redness \\
\hline & 1 - redness in conjunctiva bulbi \\
\hline & 2 - redness in conjunctiva bulbi and tarsi \\
\hline & $\begin{array}{l}3 \text { - redness in conjunctiva bulbi and tarsi, and } \\
\text { oedema }\end{array}$ \\
\hline
\end{tabular}

Table 2. Adapted version of the Gronemeyer scoring system (97).

\begin{tabular}{ll|}
\hline Stage & $\begin{array}{l}\text { Symptom } \\
\text { No subjective or visible reaction } \\
\text { Itching, reddening, foreign body } \\
\text { sensation }\end{array}$ \\
\hline II & $\begin{array}{l}\text { Stage I plus tearing, vasodilation } \\
\text { of conjunctiva bulbi }\end{array}$ \\
III & $\begin{array}{l}\text { Stage II plus vasodilation and } \\
\text { erythema of conjunctiva tarsi, } \\
\text { blepharospasm }\end{array}$ \\
IV & $\begin{array}{l}\text { Stage III plus chemosis, lid } \\
\text { swelling }\end{array}$ \\
\hline
\end{tabular}

U)/ml (ALK-Abello A/S, Hørsholm, Denmark). Furthermore, the availability of high-quality allergen extracts varies in the EU due to the enormous cost of the registration process and authorizations in each country granting them ${ }^{(78)}$.

\section{In vitro allergy testing (IgE)}

$\operatorname{lgE}$ antibodies are the major contributors in type 1 allergic diseases, but as such are also a marker of disease. Serological tests for allergen-specific lgE antibodies have been in clinical use for several decades ${ }^{(100-102)}$. In general, the correlation between a strongly positive response to a skin test and the detection of serum-specific lgE, and between a negative response to a skin test and the lack of detection of serum-specific lgE, is very good. As with skin tests, the presence or absence of specific lgE in the serum does not automatically imply a clinically relevant allergy. The composition and quantity of antigens within an allergenic extract strongly affects the result of traditional extract-based IgE assays ${ }^{(103)}$. Commercial IgE assays produced by different companies may therefore generate different quantitative levels and non-concordant qualitative results ${ }^{(101)}$.

Rationales supporting the targeted use of allergen molecules include increased test sensitivity, particularly when important allergens are underrepresented or lacking commercial extracts, improved test selectivity/analytical specificity, possible crossreactivity and primary (species-specific) sensitization. Allergenspecific IgE tests identifying allergenic antigens at a molecular basis are thus considered a more precise and informative option compared to tests based on allergenic extracts ${ }^{(104)}$. This analytical approach is called "component resolved diagnosis" (CRD) and allows detailed molecular profiling of the polyclonal $\operatorname{lgE}$ repertoire of the allergic patient ${ }^{(101,104-107)}$. Several single molecular allergens of clinical relevance have been identified, characterized and produced for commercial in-vitro assays and will allow for precision medicine approaches ${ }^{(108,109)}$. Databases of allergenic molecules help allergists to handle and interpret CRD data ${ }^{(110,111)}$. Today, IgE microarrays exist that measure more 
than 100 individual allergenic molecules in a single analysis ${ }^{(112)}$. Allergenic molecules still need to be cloned or purified to make them useable for diagnostic purposes, but wider possibilities will also increase costs ${ }^{(108)}$.

\section{Total IgE}

IgE antibodies are normally found in much lower concentrations in serum than other Ig classes such as IgG. In normal subjects, IgE levels increase from birth to adolescence and then decrease to reach a plateau after the age of 20-30 years. The standard curve for total IgE refers to the third World Health Organisation (WHO) standard and allows absolute determinations of unbound IgE concentrations ( $2.4 \mathrm{ng} / \mathrm{ml}=1 \mathrm{IU} / \mathrm{ml}=1 \mathrm{kU} / \mathrm{l}){ }^{(113)}$. Indications for measuring total $\lg \mathrm{E}$ may be if atopic disease is suspected, as an interpretation aid when judging specific IgE concentrations, or to correctly dose anti-lgE medication such as omalizumab.

Total IgE maybe increased in conditions other than atopy such as smoking and autoimmune, neoplastic or parasitic diseases. In patients with atopic diseases total lgE may be moderately $(>100 \mathrm{kU} / \mathrm{l})$ to severely $(>10,000 \mathrm{kU} / \mathrm{l})$ increased. Substantially increased levels ( $>20,000 \mathrm{kU} / \mathrm{ml}$ ) should prompt diagnostic workup for cellular immune deficiencies, hypereosinophilia syndrome and lymphoma.

It has been suggested that some patients may have a local IgE immune response without elevated systemic $\lg \mathrm{E}^{(114)}$. In a subset of patients the presence of specific lgE in the nasal mucosa has been demonstrated ${ }^{(115)}$, but the measurement of IgE in nasal secretions is currently not routinely performed.

\section{Basophil activation test (BAT)}

The basophil activation test is based on the fact that mast cells and basophil granulocytes share the same pathway for allergic degranulation after crosslinking of the high affinity receptor for $\lg \mathrm{E}$ (FcERI) by lgE and allergen on the cell surface ${ }^{(108,116)}$. Individual basophils with allergic degranulation can be identified and distinguished from marginally activated basophils by upregulation of CD63 on activated basophils ${ }^{(117)}$. Basophil reactivity has been shown to correlate with symptoms. Some advantages of the BAT may increase its use in the future, including that the patient does not need to be exposed to the allergen, a number of single allergen molecules can be tested simultaneously as only $75-100 \mu \mathrm{l}$ blood is required for a single test, allergen components can be combined to mirror real-life exposure, and CD63 upregulation is a precise marker of allergic degranulation and thus has the potential to reflect the severity of the allergic reaction ${ }^{(117)}$.

\section{Recommendations}

The clinical history helps to identify the need for allergy testing. Skin tests are easy to perform and in widespread use, as are in vitro measurements of IgE. Provocation tests are a simple and safe method for diagnosis and therapy monitoring but remain underused in daily practice. It is important to remember that a positive test does not necessarily imply a clinically relevant allergy.

\section{Microbiology}

\section{Rationale}

Microbial sampling of the nasal cavity and paranasal sinuses is a well-established practice. It forms a common part of the diagnostic work-up of patients with rhinosinusitis. Its utility in the management of acute bacterial rhinosinusitis (ABRS) is well recognized, with a generalized acceptance of the importance of microbes in the aetiology of this condition. The role of microbes in the aetiopathogenesis of CRS remains less clear. This is in part due to the disparity of published microbiological studies in CRS and in part due to the absence of convincing evidence that antimicrobial treatment affects long term outcomes in this condition ${ }^{(3)}$.

The past decade has seen a renewed interest in the microbiology of CRS. Significant technological advances have enabled culture-independent detection of microbes. Sophisticated microscopy techniques and immunofluorescent labelling have allowed the visualization of microbial biofilms and intracellular bacteria, both of which have been consistently associated with more severe disease and worse treatment outcomes. Next generation sequencing has facilitated even greater characterization of the intricate microbial ecology of the paranasal sinuses by allowing the detection of previously unculturable bacteria.

This section will provide an overview of historical and current microbial sampling techniques as well the rationale for their use. In addition, sampling techniques presently in the research realm but likely to be accessible soon, will also be discussed.

\section{Objectives}

To identify pathological microbes within the nose and sinuses, allowing culture-based antimicrobial treatment where appropriate, and to facilitate our understanding of the complex multifactorial aetiopathogenesis of inflammatory sinonasal disease.

\section{Culture-dependent techniques}

Nasal blown secretions

Culturing of nasally blown secretions is commonly utilized in the primary care setting and for paediatric patients. This is largely to circumvent the discomfort or inconvenience of nasal swabs. Patients are asked to nasally expel mucus which is then sent for microbiological testing. Although commonly used, 
only a few comparative studies exist comparing this to standard culture swab techniques. These studies suggest that a high concordance rate (>90\%) exists for the detection of common upper airway pathogens when nasal secretions are present. In the absence of obvious secretions, this rate reduces to less than $50 \%{ }^{(118,119)}$.

\section{Sinus aspirates}

For many years maxillary sinus taps (MST) were considered the gold standard technique for obtaining sinus cultures ${ }^{(120)}$. MSTs were thought to provide a more accurate representation of sinus contents and limited the influence of nasal contamination on the results obtained. This procedure can be performed in the office under local anaesthesia via a trocar inserted directly into the maxillary sinus via the inferior meatus or canine fossa. Despite its advantages, it does however remain an invasive procedure associated with local tissue trauma, discomfort and the possible risk of orbital, dental and nerve injury. Furthermore, it provides no information on the microbiology of the other sinuses. Numerous comparative studies have demonstrated a high concordance between MSTs and endoscopically directed middle meatal (EDMM) culture swabs and an equivalent, if not superior, sensitivity of EDMM swabs for the culturing of sinus pathogens ${ }^{(121)}$. For these reasons, MSTs have fallen out of favour in recent times.

\section{Nasal/sinus lavage}

Nasal lavage is not considered an accurate technique for the culturing of sinus contents. This is because of the minimal sinus penetration that occurs in an unoperated patient as well as the inherent issues with nasal flora contamination. Direct sinus lavage and culture of the aspirated contents through an endoscopically placed maxillary sinus catheter does however circumvent these issues and may enable the practitioner to selectively collect the sinus efflux with less contamination. Studies comparing direct sinus lavage to EDMM swabs have demonstrated higher bacterial yields and increased recovery of anaerobic pathogens ${ }^{(122,123)}$, making some believe them to be more sensitive for the detection of fastidious and less abundant bacteria. The clinical relevance of these organisms and their treatment remains to be studied. Recently developed balloon catheter technology appears to lend itself well to this sampling technique, as many such devices have inbuilt catheters that can be used for lavage drainage and antibiotic irrigation. Targeted culture and treatment of isolated infected sinuses with such therapy may prove useful, although again remains to be studied.

\section{Nasal swabs}

Nasal swabs remain the most commonly used modality to sample the nasal cavity. Swabs are easy to perform, non-invasive and generally well tolerated without the need for topical anaesthesia. Studies however have consistently demonstrated a poor correlation between non-directed nasal/nasopharyngeal and EDMM swabs. This is largely due to contamination of the swab with micro-organisms from the nasal vestibule and nasal cavity. In contrast, EDMM swabs show a high concordance with maxillary sinus aspirates and sinus cultures ${ }^{(120,121)}$ and thus have become the mainstay of microbial sampling in patients with rhinosinusitis. The middle meatus is considered the watershed area for the anterior sinuses, draining the frontal, anterior ethmoid and maxillary sinuses. Although the correlation of swabs between the middle meatus and maxillary sinus is well established, little research exists on how representative middle meatal swabs are of the remaining sinuses. Although not a direct comparative study, a recent retrospective study by Miller et al. ${ }^{(124)}$ demonstrated different pathogens in two or more of the swabs of $40 \%$ of patients undergoing multiple sinus cultures. Although only $5 \%$ of the patients in this study received clinical benefit from changing the antibiotic, it does suggest that bacterial cultures from the middle meatus may not be truly representative of all the sinuses.

\section{Culture-independent techniques \\ Next generation sequencing}

Next generation sequencing techniques have allowed for the identification of micro-organisms previously unidentifiable on routine culture studies. Samples can be obtained using guarded, flocculated microbial swabs or by tissue biopsy with high concordance noted between the two ${ }^{(125)}$. DNA is extracted from the obtained specimens and sequenced using primers specific for conserved genetic regions within bacterial or fungal micro-organisms. Sophisticated bio-informatic pipelines that reference known microbial libraries then allow for the identification and relative quantification of all the microbial organisms present. Although previously confined to the research setting, such technology is now commercially available and accessible for clinical use. Studies comparing culturedirected analysis with next generation sequencing have shown significant discordance, with sinus culture poorly predicting resident microbiota ${ }^{(126)}$. This may in part explain the oftenpoor treatment response despite culture-directed antibiotic therapy. It is possible that the incorporation of modern cultureindependent techniques into clinical practice may improve treatment outcomes, but further research is required.

\section{Outcomes}

There is no evidence that microbiological assessment of nasal or sinus samples has any impact on outcomes in rhinosinusitis. Although a recently published systematic review offers moderate evidence that antibiotics provide a small but significant benefit for clinical outcomes in immunocompetent patients with uncomplicated ABRS, $80 \%$ of individuals with 
ABRS typically improve within two weeks without treatment (127). Furthermore, there is no evidence showing superiority of culture-directed antibiotic therapy over empiric treatment for this condition. For this reason, microbial sampling for uncomplicated ABRS is not routinely recommended ${ }^{(3)}$. The European guidelines for the treatment of $A B R S$ do however suggest that $A B R S$ non-responsive to empirical antimicrobial treatment and topical nasal steroids, and complicated ABRS, should be referred to an ENT specialist. At that time, further diagnostic procedures including microbiology may be required (3).

Although low-level evidence suggests a possible role for culture-directed antibiotic therapy in the treatment of acute exacerbations of CRS, no high-level evidence studies exist supporting the use of antibiotics in CRS. Furthermore, there is a paucity of literature comparing outcomes of culturedirected versus empirical antibiotic treatment for this condition. Prospective trials are needed to examine the relevance of routine microbiologic cultures and antibiotic treatment in CRS patients before sound recommendations can be made.

\section{Recommendations}

Microbiological assessment is not routinely recommended in the diagnosis of rhinitis/rhinosinusitis. ABRS non-responsive to empirical antimicrobial treatment and topical nasal steroids should be referred to an ENT specialist where further diagnostic procedures, including microbiology, should be performed. The role of microbial sampling in CRS remains unclear. Culturedirected antibiotic therapy may be of some benefit in symptom reduction in acute exacerbations, although long-term outcomes are likely to be unaffected.

\section{Chemosensory assessment}

\section{Rationale}

For some senses it is sufficient to ask whether the person thinks that there is a dysfunction. This makes screening of that sense easy and asking about the function is reliable. Several studies have shown that this is not the case for olfaction ${ }^{(128)}$. The self-evaluation of olfactory function does not correlate with measured olfactory function, meaning that impaired sense of smell can be totally unnoticed by the patient and the doctor if it is not measured ${ }^{(128,129)}$. Even in patients declaring that they have an olfactory impairment, the extent of dysfunction is constantly misevaluated ${ }^{(130,131)}$. Only in patients with total anosmia does there seem to be a match between subjective smell loss and measured absence of olfactory function ${ }^{(130,132)}$. As a consequence, olfactory function needs to be measured if this parameter is intended to be part of any kind of study, measure of surgical success or clinical follow up of conservative treatment in rhinology. Simply asking about olfactory function is not enough. The same is true for gustatory function ${ }^{(133)}$. As for any sensory modality, testing can be done psychophysically or objectively. For this section the focus will be on psychophysical tests with a short mention of the available objective tests. Routine clinical testing is done in the overwhelming majority of cases by psychophysical tests since they are quick and easy to use. The main shortcoming of psychophysical tests is the need for adequate patient cooperation. In small children, malingerers or patients with advanced dementia, testing becomes unreliable. This section is not meant to establish rules for which test should be used, but intends to familiarize the physician with the aspects of psychophysical testing that should be considered and the tests available $^{(134)}$.

\section{Objectives}

To measure chemosensory function by formally testing olfactory, gustatory and trigeminal function, through psychophysical and objective tests.

\section{Olfactory testing}

Olfactory tests can be roughly divided into three categories.

\section{Olfactory identification}

The overwhelming majority of olfactory testing is olfactory identification. This consists of presenting strong, suprathreshold concentration odours for the patient to identify. Although this sounds easy, four things should be considered. First, if the patient is not given a choice of answers, the likelihood that the results fail to reflect the true olfactory function is relatively high ${ }^{(135)}$. This is due to most people's inability to associate odours to a single odour identity without being given verbal help. If, for example, the odour presented is cinnamon, the patient needs to be offered a choice of descriptor items such as vanilla, chocolate, cinnamon and coffee (Figure 6). Second, this kind of testing is biased by cultural background. If cinnamon is presented in a region of the world where cinnamon is rarely used, even subjects with normal olfactory function will have poor results. This is probably the main reason for the number of different tests available, often with country- or cityrelated names (Table 4) ${ }^{(134,136-138)}$. Third, the patients should be forced to choose one of the four descriptors (Figure 6). This forced choice sets the chance level for a descriptor to be chosen as $25 \%$. A patient with no sense of smell at all (total anosmia) would still score some 'correct' answers if several odour presentations are done this way. Using a forced choice paradigm may thus help to identify malingering patients ${ }^{(139)}$. Finally, the number of odours used improves the validity of the test result. The more odours are used in a forced choice identification test, the better the result assigns a patient to anosmia, hyposmia or 
normosmia (Figure 7). Considering the normal distribution for people with normal and absent smell function, if a forced choice identification test is done with six odours the interpretation of results in between becomes very difficult. This ambiguity can be avoided if 12 or more odours are used; it adds a little extra test time but considerably displaces both normal distributions and allows for clearer definition of the hyposmia range. This is why the most prevalent olfactory identification tests include at least 20 items ${ }^{(136,138,140,141)}$.

\section{Olfactory threshold}

Threshold testing is the second most common test method. It is fundamentally different in that it uses only one odour that is presented in different dilutions from physiologically not detectable to very concentrated. The task is to detect the presence of the odour, not identify it. The odours are presented to the patient in gradually increasing concentrations to the point where the patient reliably detects the odour. The concentration is then decreased again until the patient is no longer able to detect it. This up and down ('stairway') procedure is repeated several times until a reliable threshold is established. Threshold testing is more time-consuming than identification tests but has the advantage of reliably detecting subtle olfactory loss, as is often the case in sinonasal disease ${ }^{(134)}$. In CRS patients

Table 4. Common validated olfactory psychophysical test. Taken from Hummel et al., with permission ${ }^{(134)}$.

\begin{tabular}{|c|c|}
\hline Psychophysical test & $\begin{array}{l}\text { Olfactory components } \\
\text { assessed }\end{array}$ \\
\hline "Sniffin' Sticks" (original version) & $\begin{array}{l}\text { Threshold, discrimination, } \\
\text { identification }\end{array}$ \\
\hline $\begin{array}{l}\text { Connecticut Chemosensory Clinical } \\
\text { Research Center Test }\end{array}$ & Threshold, identification \\
\hline T \& T Olfactometer & Threshold, identification \\
\hline $\begin{array}{l}\text { University of Pennsylvania Smell Identifi- } \\
\text { cation Test (UPSIT) }\end{array}$ & Identification \\
\hline Smell Diskettes Test & Identification \\
\hline Cross-Cultural Smell Identification Test & Identification \\
\hline Pocket Smell Test & Identification \\
\hline San Diego Odor Identification Test & Identification \\
\hline Scandinavian Odour Identification Test & Identification \\
\hline Smell Threshold Test & Threshold \\
\hline Olfactory Perception Threshold Test & Threshold \\
\hline Barcelona Smell Test (BAST-24) & $\begin{array}{l}\text { Odour detection, } \\
\text { identification, memory }\end{array}$ \\
\hline Odourized Marker Test & Identification \\
\hline Snap \& Sniff Olfactory Test System & Threshold \\
\hline Open Essence & Identification \\
\hline
\end{tabular}

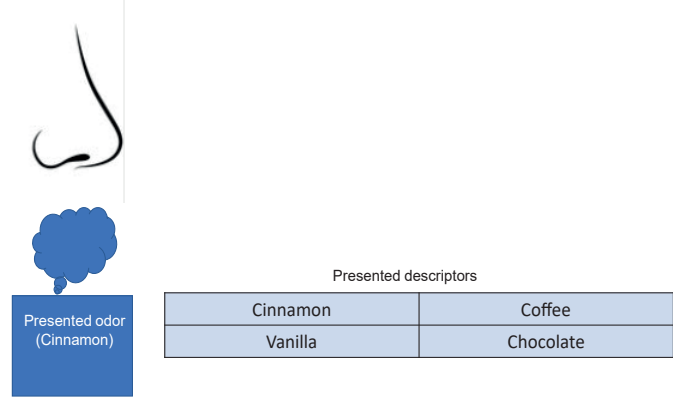

Figure 6. Basic principle of olfactory identification tests: one presented odour and a choice of possible answers (descriptors) from which one has to be chosen.

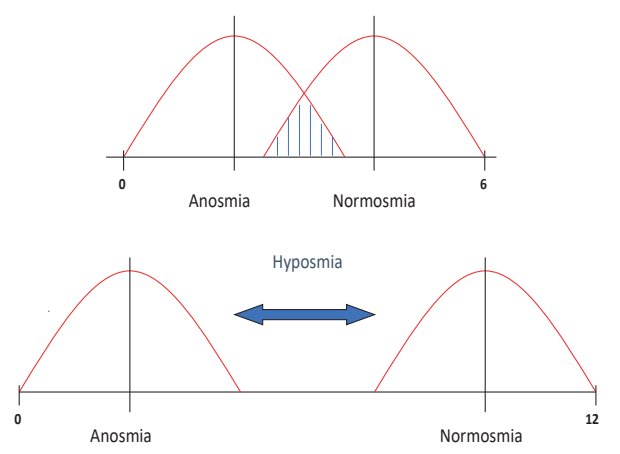

Figure 7. Illustration of how the use of more odours in an identification test increases the diagnostic accuracy.

it is not unusual to see a typical pattern of normal olfactory identification with impaired thresholds ${ }^{(142)}$. The disadvantage of threshold testing is that it is done with a single odour. As humans have slightly different olfactory receptor ranges ${ }^{(143)}$, patients with isolated weakness for the odour used might falsely be considered hypo- or anosmic. Some of the widely used olfactory tests offer commercially available prefabricated thresholds whereas $n$-butanol and phenylethylalcohol (PEA, rose odour) are the most prevalent threshold tests ${ }^{(137,144-146)}$.

\section{Olfactory discrimination}

This method consists of presenting three supra-threshold concentrated odours where two odours are the same and one is different. The goal is to identify the dissimilar odour. Like the identification test, this can be repeated several times and becomes more accurate the more odour triplets are used.

\section{Retronasal olfactory testing}

Odour molecules reach the olfactory epithelium via the nose (orthonasally) or retronasally (Figure 8) ${ }^{(147)}$. Retronasal olfactory perception is often taken to be taste perception by patients, but actually reflects the olfactory part of the flavour ${ }^{(148)}$. Testing retronasal olfactory function alone may give valuable 
information in patients with sinonasal inflammatory conditions that tend to obstruct the anterior rather than the posterior airflow to the olfactory cleft ${ }^{(149,150)}$. Retronasal testing has also been used in malingerers or patients trying to exaggerate their situation ${ }^{(151)}$. The literature on retronasal olfactory tests is not abundant and there is currently no commercial test available. All published tests ${ }^{(150,152,153)}$ are self-made and are identification tests based on the same principle as the orthonasal identification test described above (Figure 9).

These diverse methods test different aspects of olfactory function. Threshold testing reflects more peripheral changes such as those seen in sinonasal diseases, whereas identification and discrimination reflect more cognitive aspects of olfactory function ${ }^{(154,155)}$. Other, more rarely used techniques are the odour memory test ${ }^{(156)}$ that specifically addresses the capacity to memorize previously presented odorants, and the sniff magnitude test ${ }^{(157)}$ or olfactory respirometry ${ }^{(158)}$ that use sniff or inhalation pattern changes to draw conclusions about the perceived odour stimulation.

Testing olfactory function in children is more challenging as they may not always be familiar enough with odours or simply lack patience to do a full-length adult test. Some identification tests have recently been validated for use in a young population, but below the age of five years the classical identification testing paradigm is not helpful and other paediatric-specific tests should be used ${ }^{(159-162)}$.

Two very recent publications have addressed the biases that the classical psychophysical tests have, such as the genetic variability of odour sensitivity and cultural influences ${ }^{(163,164)}$. The authors propose the use of mixtures instead of single odours for both identification and threshold testing, suggesting that this can overcome these biases. It is too early to see the impact this change will have but it might herald a new design for olfactory psychophysical tests.

\section{Objective olfactory testing}

Objective olfactory testing, using event related potentials (ERPs), was first described over 30 years ago by Kobal and co-workers (165) and can be considered a validated clinical tool that is no longer restricted to research. Unfortunately, the recording of ERPs is time consuming and the olfactometers very costly. This means that ERPs are only in routine use in a handful of clinics and are mainly reserved for insurance cases ${ }^{(166,167)}$.

\section{Gustatory testing}

Although taste seems to be the much simpler sense in terms of complexity, its assessment is far behind that of olfaction. Human taste comprises the modalities sweet, sour, salty, bitter, umami (or monosodium-glutamate) and, as recently identified, water ${ }^{(168,169)}$. Whereas testing the first four modalities has been

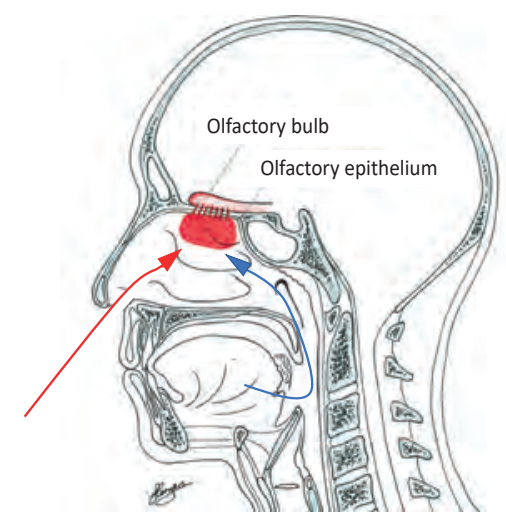

Figure 8. Orthonasal (red) and retronasal (blue) olfactory routes. Illustration adapted with permission from Landis et al. ${ }^{(147)}$.
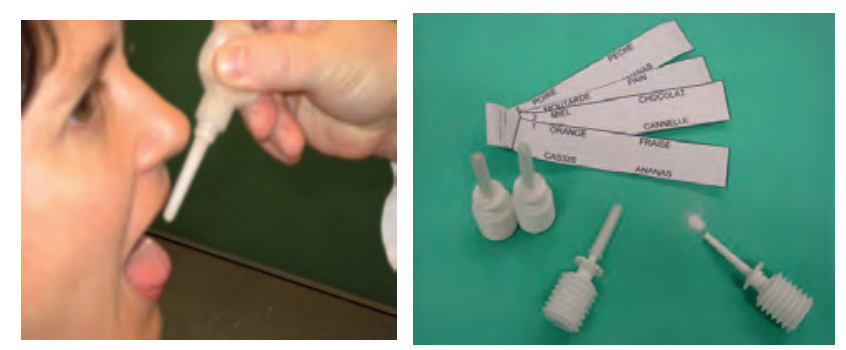

Figure 9. A retronasal test device based on food powders. The powders are applied by means of squeezable vials onto the subject's tongue.

done for decades, there is still no routine testing of umami in a clinical setting. One reason is verbal confusion between taste modalities. In normal subjects without any taste problems, more than $20 \%$ would name the impression they had after the presentation of citric acid (sour) as bitter or salty. With the exception of sucrose (sweet), which is reliably identified by more than $95 \%$ of subjects, psychophysical taste testing is associated with a high degree of verbal confounders ${ }^{(170)}$.

There are two psychophysical ways of testing gustatory function. One is chemical testing with substances such as sucrose, citric acid, quinine or sodium chloride; the other is electrical stimulation of the gustatory areas of the tongue and oral cavity (electrogustometry) ${ }^{(171)}$. The first method has the advantage of selectively stimulating the taste fibres since activation is taste-receptor specific. The disadvantage is that it is time-consuming. Electrogustometry is quick and easy to perform. The disadvantage is that electrical stimulation not only elicits activation of gustatory fibres but also of free trigeminal (somatosensory) fibres. The result is a mixed taste-trigeminal perception that has the character of 'sour-stinging-prickling' ${ }^{\prime(172)}$. Gustatory testing has become more prevalent since commercially available tests with a longer shelf-life have become available. This is managed by drying the taste substance on diverse supporting agents such as candies ${ }^{(173)}$, 
cellulose disks ${ }^{(174)}$ or filter paper ${ }^{(175)}$. The development and validation of taste strips ${ }^{(175,176)}$ now allows easy and quick bedside testing of gustatory function (Figure 10). However, only identification tests are currently available, with no gustatory threshold testing available.

\section{Objective testing}

Objective gustatory evaluation by ERPs has been shown to be feasible ${ }^{(177)}$ but has not yet found its way into routine clinical practice $^{(178,179)}$.

\section{Trigeminal testing}

The trigeminal nerve provides the oral and nasal cavity mucosa with somatosensory innervation. As such it is part of the chemical senses via a series of TRP channels that recognize volatiles and molecules such as menthol and capsaicin. The three chemical senses (taste, olfaction and trigeminal) interact and influence each other in health and disease ${ }^{(180-183)}$ and full chemosensory investigation should include measurement of trigeminal function. Currently the investigation tools in this field are poor, although recent studies suggest that intranasal trigeminal function has an influence on how humans perceive airflow and is possibly linked to the sensation of nasal

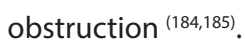

Psychophysical trigeminal testing can be done by three methods. The first is to establish thresholds using volatile molecules that primarily stimulate the trigeminal system, such as eucalyptol or menthol, and create dilution series. The problem with thresholds is that olfactory sensitivity is far higher than trigeminal sensitivity so the measured threshold would reflect the olfactory rather than the trigeminal threshold of the substance. To overcome this requires subjects to disregard the odorous properties of the substance and to focus on trigeminal properties such as coolness, pricking or stinging ${ }^{(186)}$. The second method is to use a lateralization device. This test takes advantage of the fact that the olfactory system is unable to locate the source of stimulation whereas the trigeminal system can $^{(187)}$. The third, most recently developed device uses the summation properties of the trigeminal system and analyses the concentration a subject is able to bear over time when exposed to a trigeminal stimulus such as carbon dioxide ${ }^{(188,189)}$. There is a need for better intranasal trigeminal testing since none of these methods has yet found its way into routine rhinology workup.

\section{Objective testing}

In contrast to psychophysical testing, objective trigeminal evaluation by means of ERPs is well established. It has been developed in parallel to objective olfactory testing and is available in any clinic that offers objective olfactometry with ERPs ${ }^{(190)}$. Unfortunately, it has the same shortcomings of being costly and time-consuming.

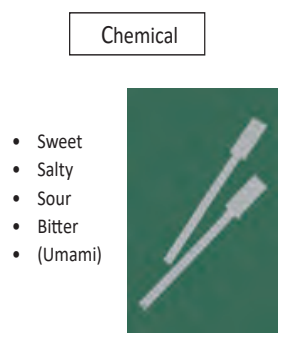

Taste strips
Electrical

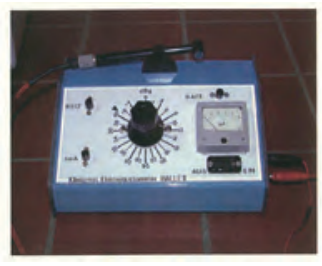

Electrogustometry
Figure 10. Two methods of gustatory testing: chemical testing by means of taste substances impregnated on a filter paper e.g. Taste Strips (left) and electrical testing by means of electrical stimulation of the tongue (right).

\section{Recommendations}

It is crucial to test rather than to ask. More extensive tests increase the diagnostic accuracy but are more time-consuming. For general practitioners, a simple identification test is sufficient. Specialized olfactory clinics require validated tests with a large database of normative data available ${ }^{(134)}$.

\section{Imaging}

\section{Rationale}

Imaging accurately visualises areas beyond the naked eye and endoscope. It is used to provide an accurate assessment of the anatomy, a corroboration of clinical symptoms and endoscopic findings and facilitates an objective evaluation of pathology both in terms of diagnosis and extent of disease ${ }^{(191,192)}$. However, how and when the scan is done will influence the results. Computed tomography (CT) and magnetic resonance imaging (MRI) are amongst our most important diagnostic tools, and if a specific diagnosis is not possible based on the imaging, a differential diagnosis is usually provided. Furthermore, extent of disease can be defined and semi-quantified and MRI in particular allows soft tissue characterisation.

Pre-operative CT is mandatory for sinus surgery in most countries and should be available to the surgeon in the operating theatre. This became the standard of care with the advent of endoscopic sinus surgery ${ }^{(193,194)}$ and now often augments an appreciation of the anatomy through navigation systems and other techniques such as fusion of CT and MRI. Imaging also has a major role in follow-up, where serial MRI may be undertaken without radiation exposure.

\section{Objectives}

To demonstrate anatomy and anatomical variants (Figures 11 and 12), to define the pathology, both the diagnosis (Figures 1317) and extent, as well as monitoring for disease recurrence. 


\section{Techniques}

Neither plain x-ray nor ultrasonography are routinely used in modern rhinologic practice ${ }^{(3,195)}$.

\section{Computed tomography (CT) and cone beam CT (CBCT)}

The technology and processing abilities of multi-detector CT (MDCT) scanners have continued to evolve and improve. There has been a drive to reduce radiation dose whilst preserving image quality by shortening the scan time and using postprocessing techniques ${ }^{(196,197)}$. Cone beam CT (CBCT), historically used for dental imaging, is also being utilised in sinonasal imaging producing high resolution images, but the longer scan time, subsequent susceptibility to motion artefact and the lack of soft tissue differentiation can be a drawback.

The high resolution of both MDCT and CBCT provide high quality coronal and sagittal reformatted images which are required for clear assessment of the ostiomeatal complex (OMC) (Figure 11), frontal and sphenoethmoidal recesses and the anterior skull base, and to accurately delineate important anatomical variants such as frontoethmoidal and sphenoethmoidal air cells and their relation to the mucociliary drainage pathways. The study should also be reconstructed using a soft tissue algorithm in order to assess the orbits, postnasal space and the pre- and retroantral tissues. The reformatted images are best visualised interactively. By placing a marker on the area of interest (for example the uncinate process), its relationship to adjacent structures can be highlighted simultaneously in all three planes. The use of detailed three planar reconstruction has significantly improved our appreciation of the complex anatomy, particularly in the frontal recess, and led to international efforts to agree a classification of the area ${ }^{(3,192)}$ (Figure 12). Three-dimensional (3D) reconstructions are helpful when surgically planning complex facial trauma or craniofacial anomaly cases. 3D models can be made from the $\mathrm{CT}$ data using $3 \mathrm{D}$ printing techniques in order to plan or practice the surgery in advance and can be used to design bespoke prostheses.

More complex multi-planar reformatting, for example in curved planes for an orthopantomogram of the upper jaw, may be particularly useful when assessing dentition.

\section{Magnetic resonance imaging (MRI)}

MRI is recommended for soft tissue characterisation; it is useful in patients with complicated inflammatory sinus disease extending beyond the boundaries of the sinonasal cavities and is the modality of choice in patients with suspected neoplasms. On MRI, sinonasal tumours are usually of intermediate signal on $\mathrm{T} 1$ and $\mathrm{T} 2$ weighting and can be differentiated from the high $\mathrm{T} 2$ signal of inflammatory secretions. There are some $\mathrm{T} 2 \mathrm{high}$ signal sinonasal tumours such as some salivary neoplasms,

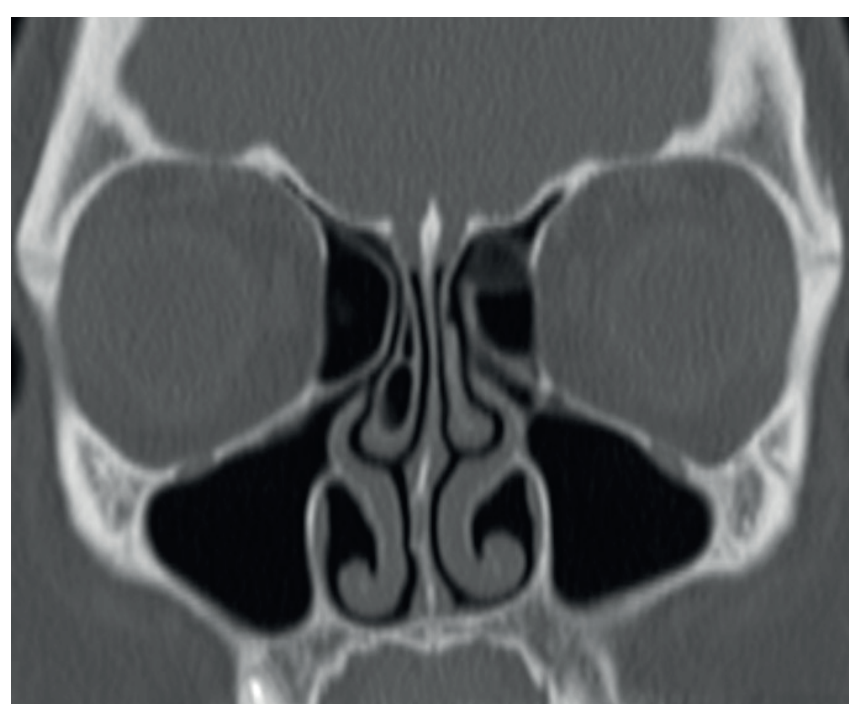

Figure 11. Coronal CT showing normal anatomy through the ostiomeatal complex including right concha bullosa.

chondrosarcomas and neuromas where differentiation will depend on the post-contrast sequences.

Sinonasal MRI is helpful in assessing the extent of vasculitic, granulomatous, IgG4-related and fungal disease as unlike CT it can clearly differentiate the above pathologies from the normal high $\mathrm{T} 2$ signal and non-enhancing fluid/oedema characteristic of inflammatory mucosal thickening. Fungal disease has a variable T1 signal, but on T2 images there is marked signal loss that can mimic an aerated sinus (Figure 13). The low signal is due to the low mucin content and the paramagnetic metals that are concentrated by fungal organisms. GPA and IgG4related conditions have a characteristic relatively low $\mathrm{T} 2$ signal, probably due to the increased cellularity and fibrosis. In anosmia/hyposmia, MRI can not only demonstrate the extent of any sinonasal disease, but can visualise the olfactory pathway, measure the size of the olfactory bulbs and identify any intracranial cause.

MRI is required for the assessment of the superior nasal cavity "polyp", in particular where there is an overlying anterior skull base defect, in order to identify any meningo- or meningoencephalocoele or unsuspected neoplasia (Figure 14). T1, T2 and STIR protocols are the routine sequences used, although volume sequences that can be reformatted in any plane are increasingly utilised. Gadolinium contrast is required for assessing suspected sinonasal neoplasia or intracranial and orbital extension of disease and is usually combined with fat saturation in at least one plane to more clearly identify involvement of intraorbital, pre- and retroantral (pterygopalatine fossa and infratemporal) fat and the fatty marrow within the central and anterior skull base. Post-contrast imaging is essential for assessing perineural extension of disease which often markedly alters the management pathway. 


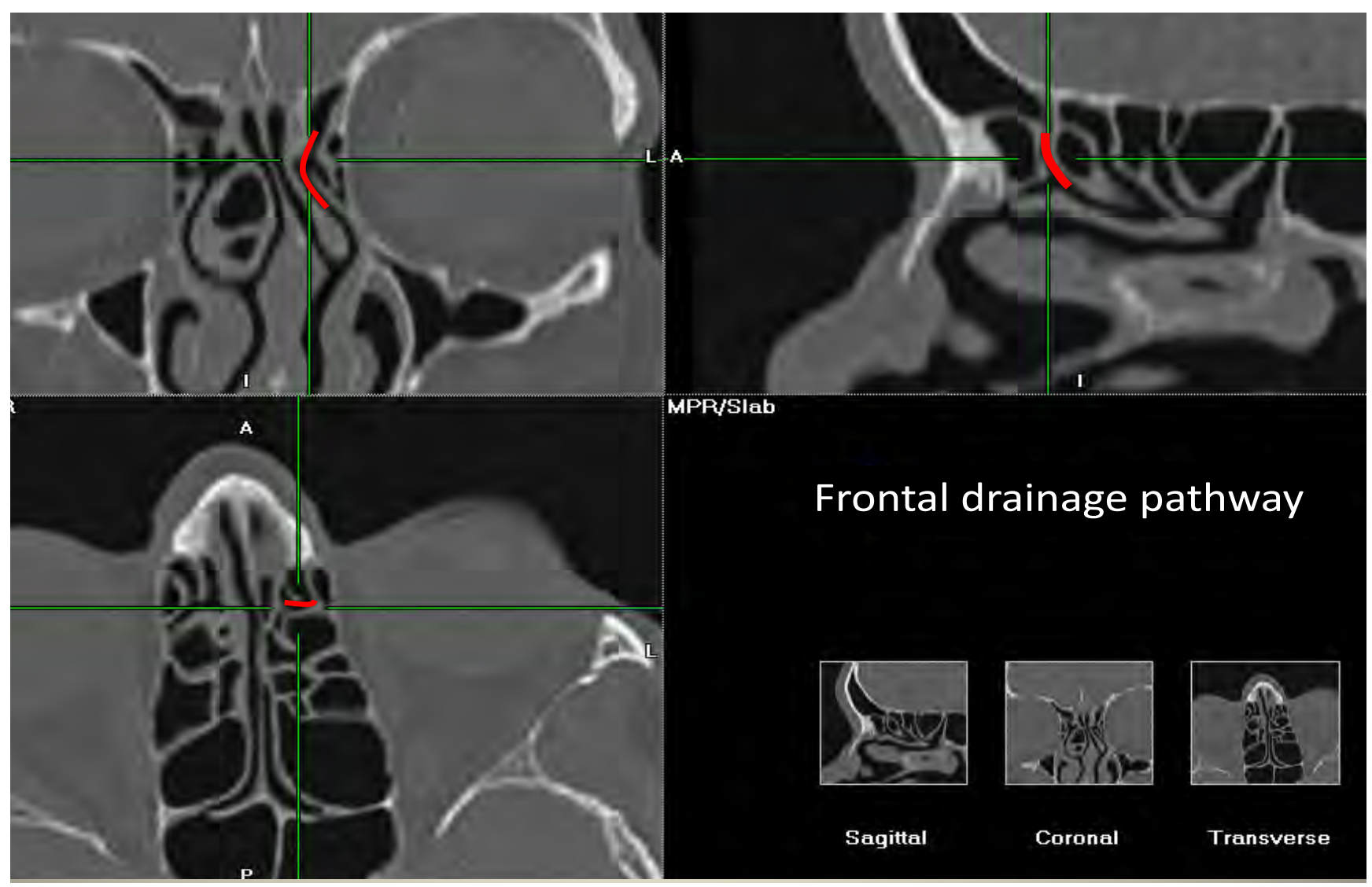

Figure 12. Three planar CT (coronal, axial, sagittal) showing frontal sinus drainage pathway (solid red line) in normal scans.

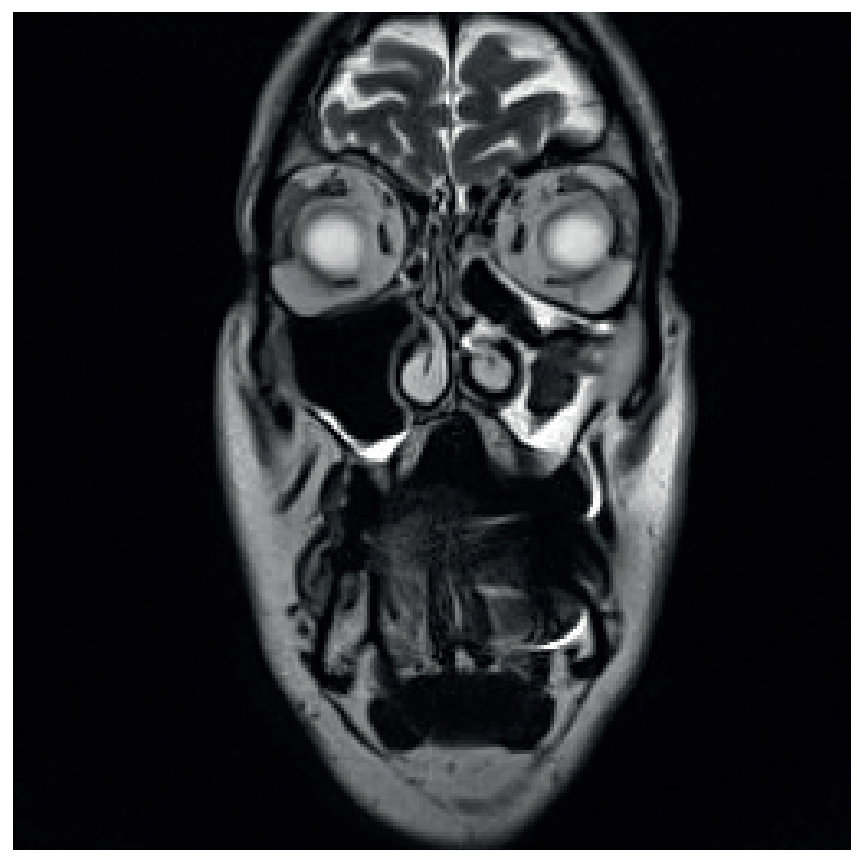

Figure 13. Coronal MRI (T2 sequence) showing high signal mild inflammatory change in both maxillary sinuses, worse on left with central low density fungal ball.
$\mathrm{CT}$ and MR are often both required and are complementary, notably when assessing skull base or orbital extension. The following newer imaging techniques are still evolving, but some show promise.

Diffusion weighted imaging (DWI) is especially useful in the head and neck region for helping to differentiate posttreatment scarring from tumour and can be used in some sinonasal neoplasia such as squamous cell carcinoma for highlighting areas of concern. Post-treatment studies are difficult to interpret due to distortion of the normal anatomy, but foci of restricted diffusion can help the radiologist identify suspicious areas that can then be reviewed on other ( $\mathrm{T} 1 / \mathrm{T} 2$ and post-gadolinium) sequences and by direct inspection. DWI has been used to identify those tumours that are responding to chemoradiotherapy. Imaging can be performed during treatment to assess response and may in the future have a role in adjusting the treatment regime ${ }^{(198)}$.

Dynamic contrast enhanced MRI (DCE-MRI) and intravoxel incoherent motion (IVIM) are two MRI techniques that have been shown to effectively differentiate between benign and malignant sinonasal lesions, although biopsy is still required to identify the exact pathology ${ }^{(199)}$.

There are some contraindications to MRI imaging such as 


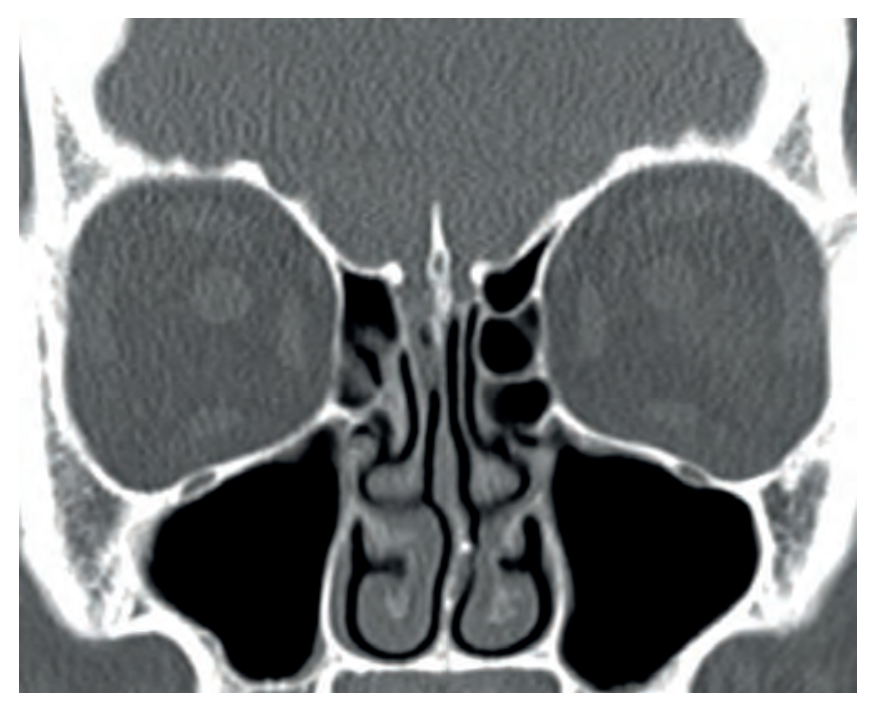

Figure 14a. Coronal CT showing right skull base dehiscence and small meningocoele in superior nasal cavity.

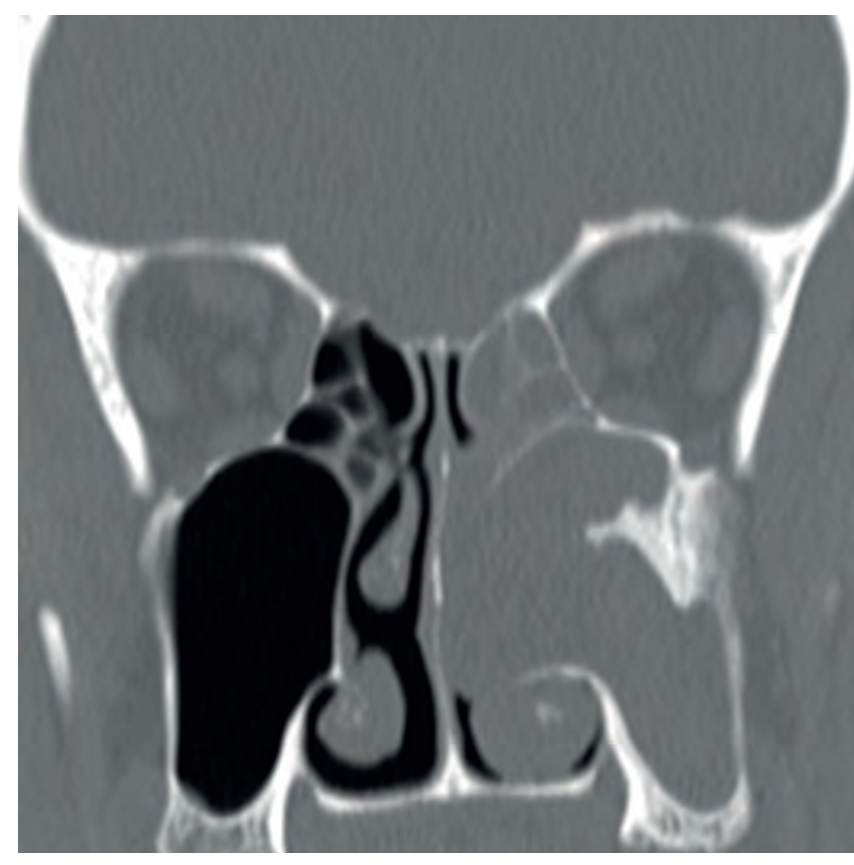

Figure 15a. Coronal CT showing mass extruding into left nasal cavity with unilateral opacification of left maxillary sinus and posterior ethmoids. There is hyperostosis on the lateral wall highly suggestive of an inverted papilloma.

cardiac pacemaker, implanted cardiac defibrillator, aneurysm clip and some cochlear implants and prostheses. The main restriction however is claustrophobia even with "open" scanners as a head and neck coil is still required for sinonasal imaging. Positron emission tomography-CT (PET-CT) or PET-MR are occasionally used pre-treatment to exclude distant disease, during treatment to measure the response to chemotherapy (for example in sinonasal sarcomas), or post-treatment to differentiate post-treatment appearances from residual/

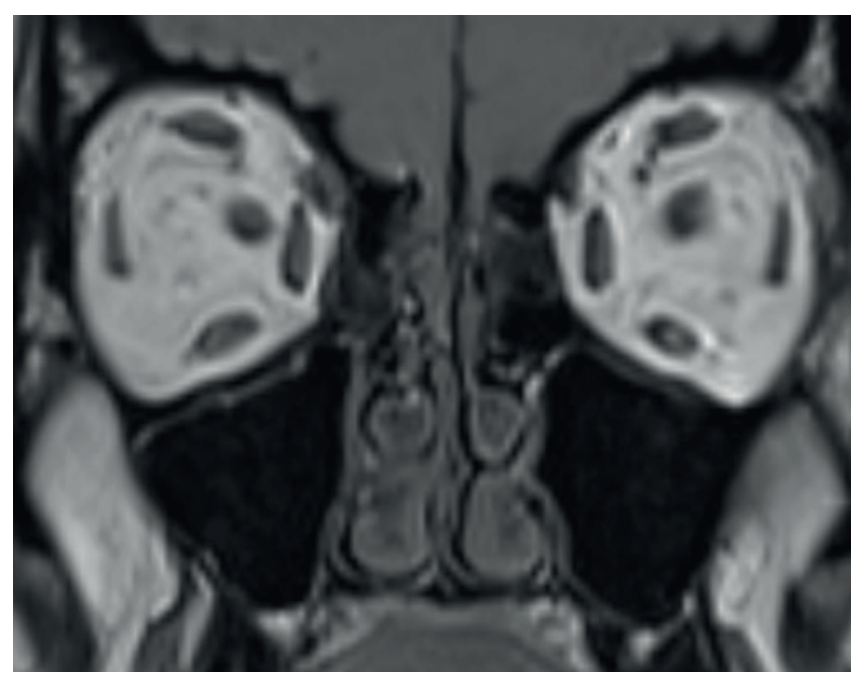

Figure 14b. Coronal MRI confirming presence of meningocoele.

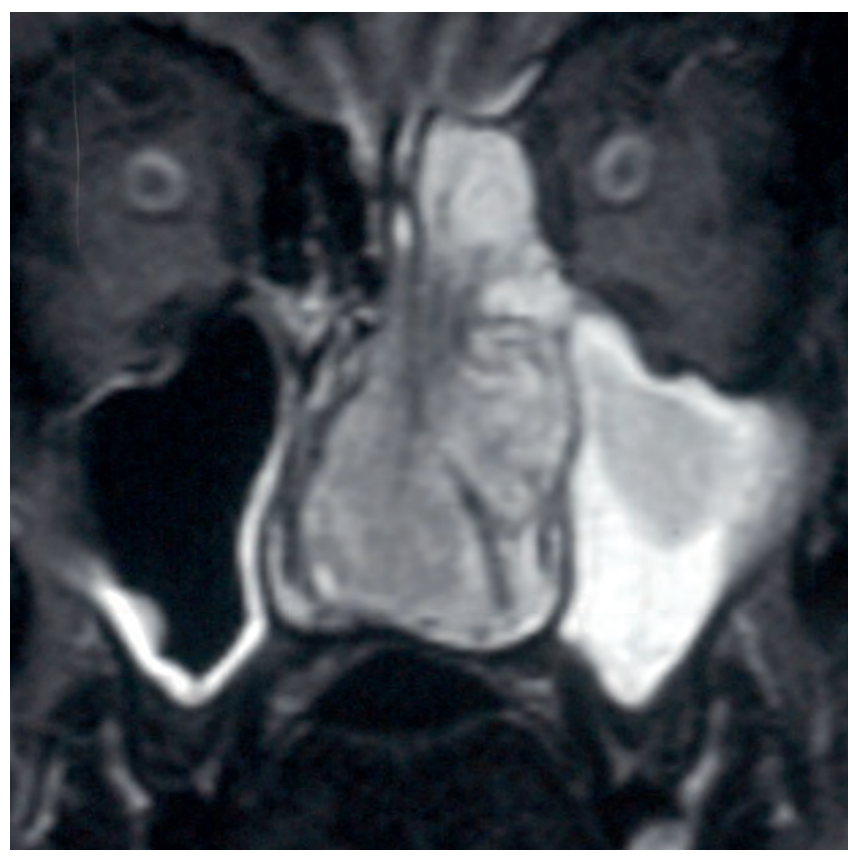

Figure 15b. Coronal MRI showing cerebriform nature of mass, pathognomonic of inverted papilloma, together with inflammatory change and fluid in maxillary sinus.

recurrent disease.

Sensitivity and specificity or accuracy

Studies comparing symptoms with CT and endoscopic findings have shown good correlation between $\mathrm{CT}$ and endoscopy but not between symptoms and CT. When comparing concordance between endoscopy and CT staging in CRS, the correlation was $65 \%$ for positive and $71 \%$ for negative results ${ }^{(200)}$.

Many attempts have been made to semi-quantify the changes 


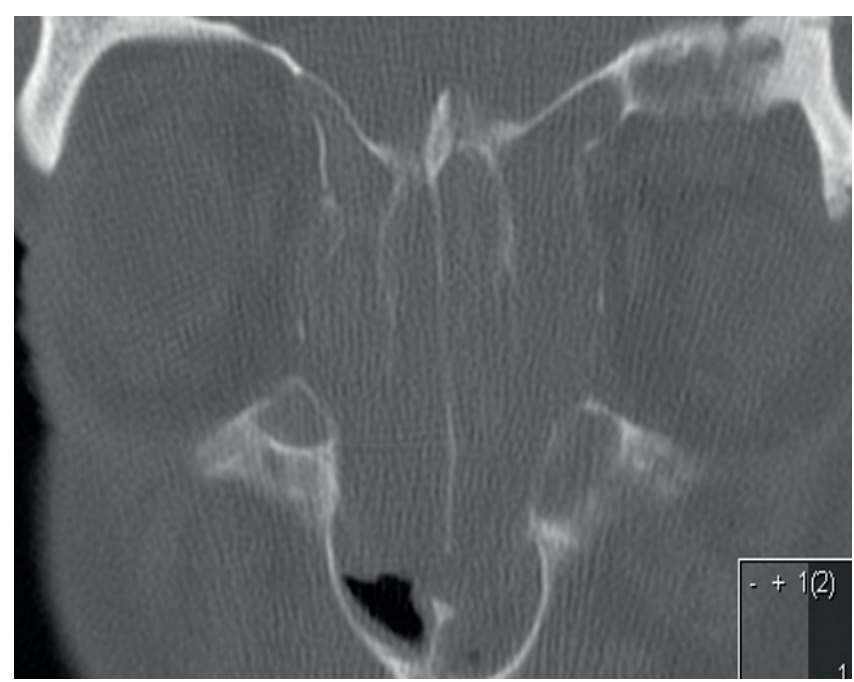

Figure 16a. Coronal CT showing widespread bilateral opacification with expansion of the ethmoids and erosion of the lamina papyracea in CRSWNP.

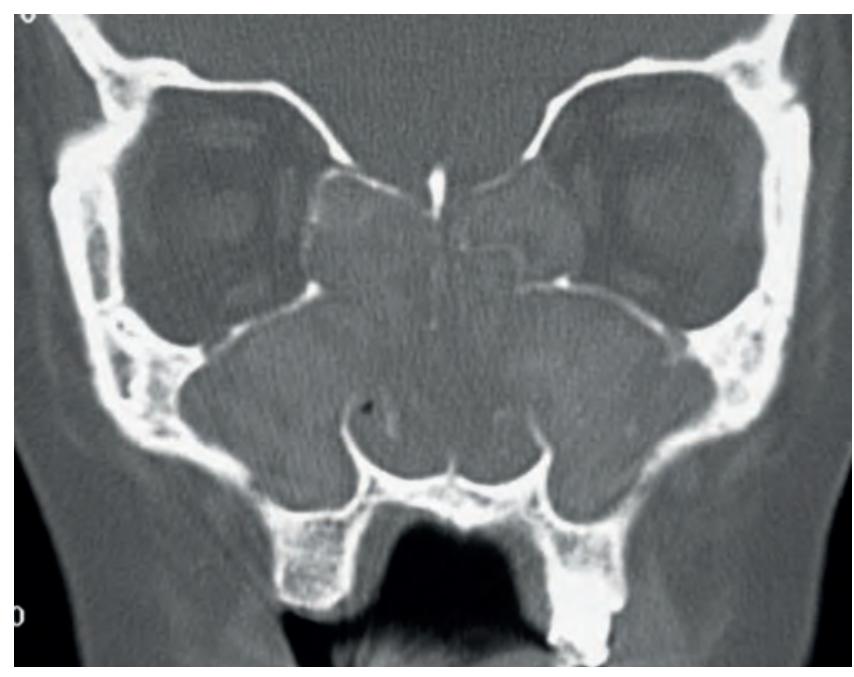

Figure 17a. Coronal CT showing pan-opacification of the sinuses with heterogeneity suggestive of eosinophilic fungal rhinosinusitis. There is expansion of the ethmoids with erosion of the lamina papyracea and thinning of the skull base particularly on the left.

observed on CT scan using scoring and staging systems of varying complexity. The most commonly used of these is the Lund-Mackay system which is based on the degree of opacification of the maxillary, anterior and posterior ethmoids, frontal and sphenoid sinuses (0-none; 1-partial; 2-complete) and OMC ( 0 or 2 ) giving a maximum score of 24 or 12 per side ${ }^{(201)}$. This scoring system has been validated in several studies (202,203) but does not significantly correlate with symptom severity scores.

$\mathrm{CT}$ and MRI are extremely sensitive in demonstrating 'abnormalities' in the sinonasal region. A wide range of

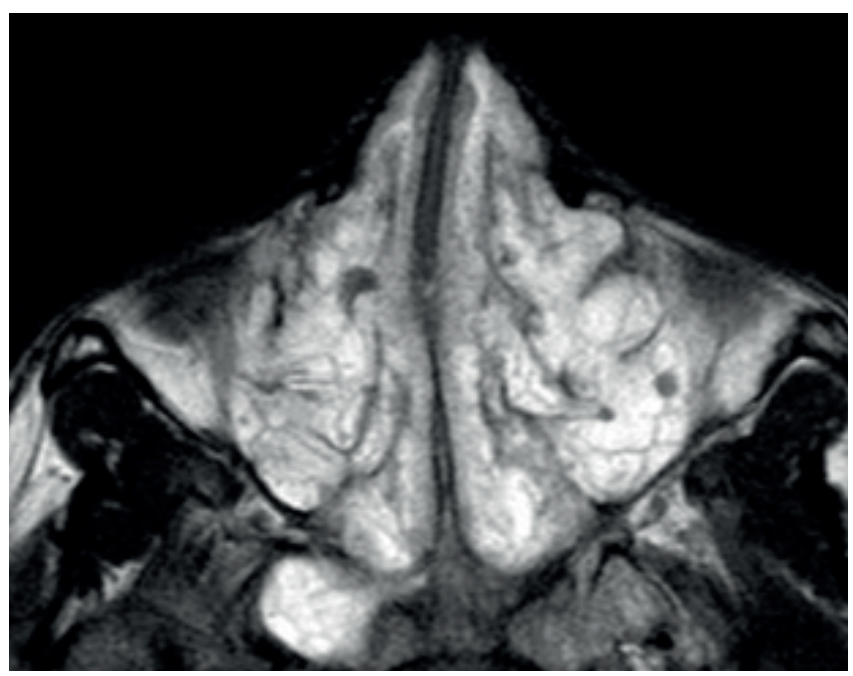

Figure 16b. Axial MRI (T2 sequence) showing CRSwNP.

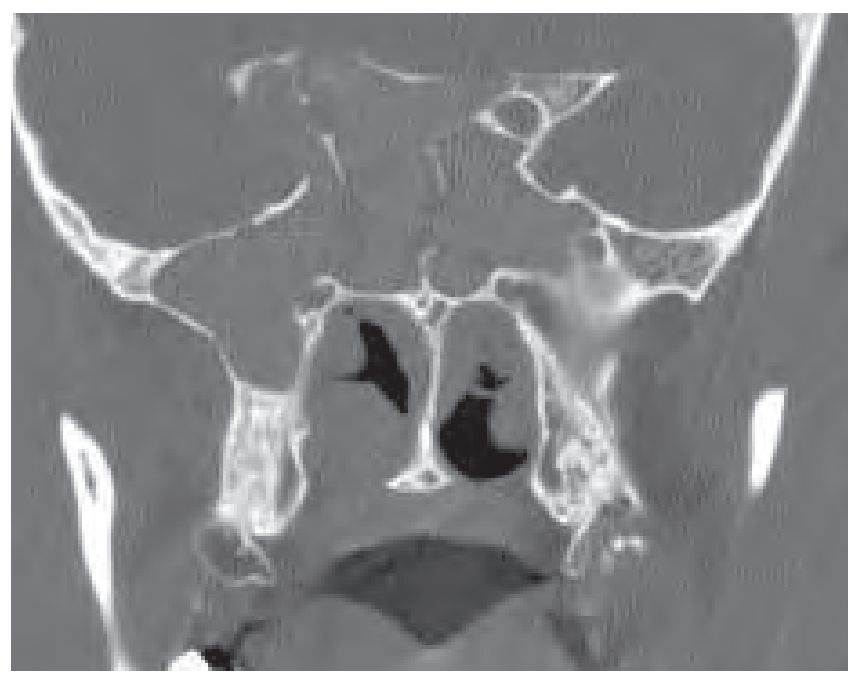

Figure 17b. Coronal CT in same case showing heterogenous opacification filling both sphenoid sinuses with erosion of the right lateral wall and planum sphenoidale.

anatomic variations are observed which are generally unrelated to the development of disease ${ }^{(204,205)}$ but are highly significant for 'safe' surgery, such as the presence of a sphenoethmoidal cell. The development of the frontal and sphenoid sinuses during childhood to early adulthood has been demonstrated by imaging ${ }^{(191,206)}$.

Marked inflammatory changes may be observed following a viral cold which can persist for a number of weeks ${ }^{(207,208)}$ which probably accounts for the high percentage of normal asymptomatic adults who have evidence of mild mucosal thickening on CT ( 18\% ) ${ }^{(204)}$. 
Thus on CT a 'normal' Lund-Mackay score (LMS) for adults is $4.26(95 \% \mathrm{Cl}, 3.43 \text { to } 5.10)^{(209)}$ and for children it is $2.81(95 \%$ confidence interval, 2.40 to 3.22 ), with only $19.3 \%$ having a score of $0^{(210)}$. The LMS can also be applied to MRI and does not appear to overstage inflammatory disease ${ }^{(211)}$.

Conversely more than $40 \%$ of patients who fulfil the symptombased diagnosis of CRS may have normal CT and endoscopy results ${ }^{(3)}$. The accuracy of CT in the diagnosis of CRS was tested, comparing CT scores with histopathologic grade of inflammation and including a control group without CRS utilizing well designed criteria. By using the ROC method, the sensitivity of CT was found to be $94 \%$ and specificity $41 \%$ using a LMS score cut-off value for CRS of greater than two. If the value of 'normal' LMS scores (greater than 4) was applied, specificity increased to $59 \%$. Using the same method in paediatric rhinosinusitis, taking an LMS of at least five to indicate real disease, CT sensitivity was $86 \%$ and specificity $85 \%$. Thus, LMS of two or less have an excellent negative predictive value, and LMS of five or more have an excellent positive predictive value, strongly indicating true disease. By comparison plain sinus radiographs have shown poor sensitivity and specificity, so that even low irradiation does not justify their use. Correlation of CT scans with plain sinus radiographs for maxillary sinusitis was reasonable (78\%), but was only $52 \%$ for the ethmoids ${ }^{(212)}$. The pattern of inflammation may also be important. A central radiological pattern of mucosal disease is likely associated with inhalant allergen sensitization - the so-called 'black halo' sign ${ }^{(213)}$. The radiological pattern defined by centrally limited changes in all of the paranasal sinuses was associated with allergy status and predicted atopy with $90.82 \%$ specificity, $73.53 \%$ positive predictive value, likelihood positive ratios of 2.16 and diagnostic odds ratio (OR) of 4.59 .

In the management of tumours, specific diagnostic features may be found, for example erosion of the upper medial pterygoid plate in juvenile angiofibroma ${ }^{(214)}$ or the likely diagnosis and site of origin in inverted papilloma (Figure 15) ${ }^{(194,215)}$. In malignant tumours treated by craniofacial resection, it has been possible to assess the accuracy of both CT and MRI compared with histological findings. With a dedicated head and neck radiologist CT versus histology was $85.2 \%$ accurate, whereas MRI with gadolinium DTPA correctly predicted the histology in $98.3 \%$ but even today still fails to determine microscopic involvement of the orbital periosteum and dura (216).

Imaging of the olfactory bulb has become an area of increasing importance as interest has increased in olfaction in general and in particular the recognition of the role of olfactory loss in neurodegenerative disorders ${ }^{(217,218)}$.

\section{Outcomes}

In the diagnosis and management of most rhinologic conditions, CT remains the gold standard. However, with the exception of neoplasia, extent of disease does not necessarily equate with prognosis.

In a multicentre prospective study of patients undergoing surgery for CRSwNP (Figures 16 and 17) and CRS without nasal polyps (CRSsNP), the LMS was correlated with a range of parameters in 1840 CT scans ${ }^{(219)}$. This showed unsurprisingly that the higher the score, the higher the grade of polyp and the more extensive the surgery. The score also correlated with symptom reduction (coeff $=0.24, p=0.02$ ), complication rate (OR $1.08,95 \%$ confidence interval $(\mathrm{CI}) 1.06-1.1)$ and revision rates (OR 1.03, 95\% Cl 1.001-1.06) but showed no correlation with SNOT-22 scores. In contrast, a more recent study ${ }^{(220)}$ showed that the preoperative LMS in 665 patients with medically recalcitrant CRS correlated significantly with preoperative extranasal and rhinologic symptom severity on the SNOT-22 and that the LMS was an indicator of postsurgical QOL outcomes.

Nonetheless it seems that the LMS measures a different aspect to 'subjective' symptom scores as it correlates well with other markers of disease severity, the nature of surgery offered and its outcome. Its main value lies in diagnosis, determining extent of disease and providing inclusion criteria for studies. However, it cannot be used as an outcome measure due to ethical issues with post-therapeutic scanning with additional radiation exposure.

Other radiologic features such as the degree of neoosteogenesis in CRS may have important prognostic implications ${ }^{(221,222)}$.

\section{Recommendations}

In most current consensus documents ${ }^{(3,195)} \mathrm{CT}$ is the modality of choice in the radiologic evaluation of rhinologic disease, notably CRS. However, in ARS, the diagnosis is made on clinical grounds and $\mathrm{CT}$ is not recommended ${ }^{(191)}$ unless the condition persists despite treatment or a complication is suspected, when contrast is used if there is no contraindication ${ }^{(223)}$. However, a recent study from Spain suggested that CT continues to be over-used in this context ${ }^{(224)}$.

In CRS, CT imaging is the primary modality but is not normally recommended until after an appropriate course of medical therapy has failed ${ }^{(3,195)}$ and without an intervening acute episode. It is mandatory prior to surgical intervention when three planar CT is advisable, particularly for assessment of frontal sinus drainage. It should be noted that, radiation exposure aside, other studies suggest that early CT scanning may be more cost-effective as compared to extended courses of antibiotics given empirically ${ }^{(7,225)}$. This is especially pertinent in patients with rhinitis or atypical facial pain ${ }^{(226-228)}$ and may be facilitated by the availability of lower radiation protocols and/ or CBCT. 
A combination of $\mathrm{CT}$ and MRI are generally recommended to assess the extent of tumours with sequential MRI utilised for long-term follow-up ${ }^{(229,230)}$.

\section{Nasal sampling for inflammatory markers}

\section{Rationale}

The measurement of inflammatory and other biological markers in nasal secretions and cells can potentially provide diagnostic and therapeutic information regarding different sinonasal disease processes. In general, the most common techniques for nasal sampling are nasal lavage fluid, nasal suctioning, inserting nasal packs, nasal brushing or scraping, and biopsies. The most important determining factor for which method to use is whether inflammatory markers, nasal cells for cytology or culture, or a combination of both are required.

\section{Objectives}

To obtain appropriate nasal secretions, fluid and/or cells to allow measurement of relevant biological markers, to aid in the diagnosis, treatment and understanding of the pathophysiology of rhinologic disease processes.

\section{Techniques}

\section{Nasal blown secretions}

The easiest method to collect nasal secretions is by simply blowing the nose and collecting the mucus in sterile containers directly or by letting the participants blow in tissues ${ }^{(118)}$. This method is especially helpful in children. The biggest disadvantage is the small quantities of mucus obtained with this method.

\section{Nasal lavage}

Lavage fluid is introduced into the nose for a certain amount of time and then recollected, with its associated nasal secretions. It is easy to perform and well tolerated. Various techniques are used, mainly differing in the amount of lavage fluid used and the time left inside the nose. The lavage fluid consists of $0.9 \%$ sodium chloride $(\mathrm{NaCl})$ at body temperature and is instilled via a syringe. It is important to instruct the patient not to swallow the fluid while the head is reclined. After the appropriate waiting time the head is bent forward and the lavage fluid collected in sterile containers. Usually $2-10 \mathrm{~mL}$ of $\mathrm{NaCl}$ are introduced for approximately 10 seconds ${ }^{(231,232)}$. The 'rule of $10^{\prime}$ can be applied for facilitating the protocol: use a $10 \mathrm{~mL}$ syringe to instil $10 \mathrm{~mL}$ of $\mathrm{NaCl}$ for 10 seconds in each nostril. To reduce the volume of fluid inserted into the nose to $1-5 \mathrm{~mL}$ one can use nasal sprays with iso- to mildly hypertonic saline $(0.9-1.8 \%)^{(232)}$. Variations of nasal lavage have been described, including inserting a paediatric tracheostomy tube into the nostril and inflating the cuff after the patient bends forward, so as not to lose lavage fluid and be able to standardize volumes better ${ }^{(233)}$. A disadvantage of the nasal lavage techniques is that by instilling $\mathrm{NaCl}$ the mucosa is stimulated, which may bias the results.

\section{Nasal suctioning}

Nasal suction devices are sterile and contain a reservoir where nasal secretions can be trapped (Figure 18). For post-processing it is important to weigh the reservoir prior to application to avoid bias through minimal weight differences of the product. The exact weight of the sample can then be determined. The mucus can be suctioned out and directly frozen at -80 to $-90^{\circ} \mathrm{C}$ before further processing or a known quantity of phosphate buffered saline (PBS) or similar agents can be applied immediately after suctioning and before freezing. The advantage of this may be to stop chemical activity such as proteolysis in the mucus ${ }^{(234)}$. This technique is well tolerated and has the advantage of minimal stimulation and/or trauma to the mucosa. Moreover, certain areas of the nose can be directly suctioned under endoscopic control, for example the middle meatus or the olfactory cleft ${ }^{(235)}$.

\section{Nasal packing}

Nasal packing in a variety of commercially available forms can be used to soak up nasal secretions. The packs can be placed in different areas of the nasal cavity from where secretions are specifically required (e.g. inferior or middle meatus). They must be weighed before and after insertion into the nose to measure the quantity of absorbed secretions. The packs are left in situ for five minutes and are then placed in a conical tube, washed in $\mathrm{NaCl}$ and mechanically squeezed out (e.g. with a syringe), then washed again and centrifuged at $1500 \mathrm{~g}$ for $10 \mathrm{~min}$ at

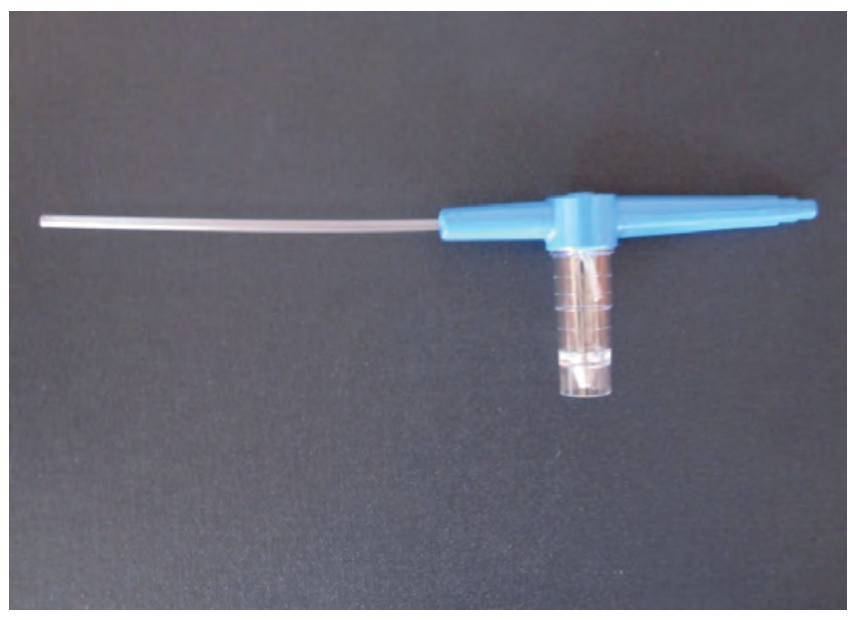

Figure 18. Standard nasal suction with mucus trap. 
$4^{\circ} \mathrm{C}$ to obtain all secretions ${ }^{(236)}$. An advantage of this method is clear discrimination of sides as compared to lavage techniques. However, disadvantages include patient discomfort, irritation of the mucosa and that nasal secretions might be retained in the pack despite thorough squeezing and washing. Moreover, if nasal secretion at baseline is low, a limited amount of material would be collected (e.g. in a study control group). Another technique uses reticulated polyurethane foam packs (at 60 and 110 pores per inch (PPI)) that perhaps absorb secretions better than standard packs with less stimulation of the mucosa ${ }^{(237)}$.

\section{Nasal brushing}

Nasal brushing can be performed with a soft sterile brush in the middle or inferior meatus with a gentle circular movement (Figure 19). The brushes are then immersed in tubes containing an appropriate growth medium depending on the subsequent processing. The tubes are vortexed for five minutes and intermittently the brushes are gently rubbed by forceps to remove the sample from the brush hairs. The tube is then centrifuged at $400 \mathrm{~g}$ for 10 minutes. Depending on further experiments the supernatant can be discarded or the mucus it contains may be used for further analysis ${ }^{(238)}$. With this method pure cytology can also easily be performed. The advantage is to be able to obtain both mucus and enough cells for cell culture. A disadvantage is the discomfort for the patient as well as trauma to the mucosa which may contaminate the sample with blood. Nasal scraping may also be used for cytology but probably yields less cells for cell culture. Nasal scrapings have been shown to be more reliable than swabbing ${ }^{(239)}$.

\section{Nasal biopsy}

The nose is the most accessible part of the respiratory tract and is therefore an invaluable source of respiratory tissue. Biopsy of intranasal tissue can help in the investigation and diagnosis of local nasal disease or systemic conditions affecting the nose. Nasal biopsies can be performed in an outpatient clinic under local anaesthesia or in the operating theatre. The choice depends on a number of factors including the reason for performing the biopsy and the size of the biopsy required. For research purposes, the biopsy must be easily performed, painless and with a minimal complication rate. For clinical diagnosis the need for sufficient sample size has to be balanced with the burden for the patient. It is important that the biopsy is not crushed. This can be achieved with specific Fokkens forceps (Figure 20) ${ }^{(240)}$ or more general fenestrated punch forceps ${ }^{(241)}$, or in the operating theatre with scissors ${ }^{(242)}$.

Small biopsies for research purposes can be taken from the inferior turbinate after local anaesthesia. We place cotton-wool with 50 to $100 \mathrm{mg}$ of cocaine and three drops of epinephrine (1:1000) under the inferior turbinate without touching the area from which the biopsy specimen is taken, but a small pledget of cotton wool with $50 \mathrm{mg}$ of cocaine resting on the floor of the nose between the inferior turbinate and the septum has also been described ${ }^{(241)}$. Especially in research, when repetitive biopsies have to be taken, it is essential that the procedure is painless and does not cause bleeding. This is difficult to achieve with less potent local anaesthetics such as lidocaine. For light microscopic evaluation, the biopsy specimens can be embedded in Tissue-Tek II OCT compound in a gelatin capsule and frozen immediately. The minimum number of sections required to give a sufficient number of fields to assure acceptable accuracy (5\%) was determined to be two on the basis of a summation average graph ${ }^{(243)}$. In general cells can be evaluated more reliably in biopsies than in nasal brushings

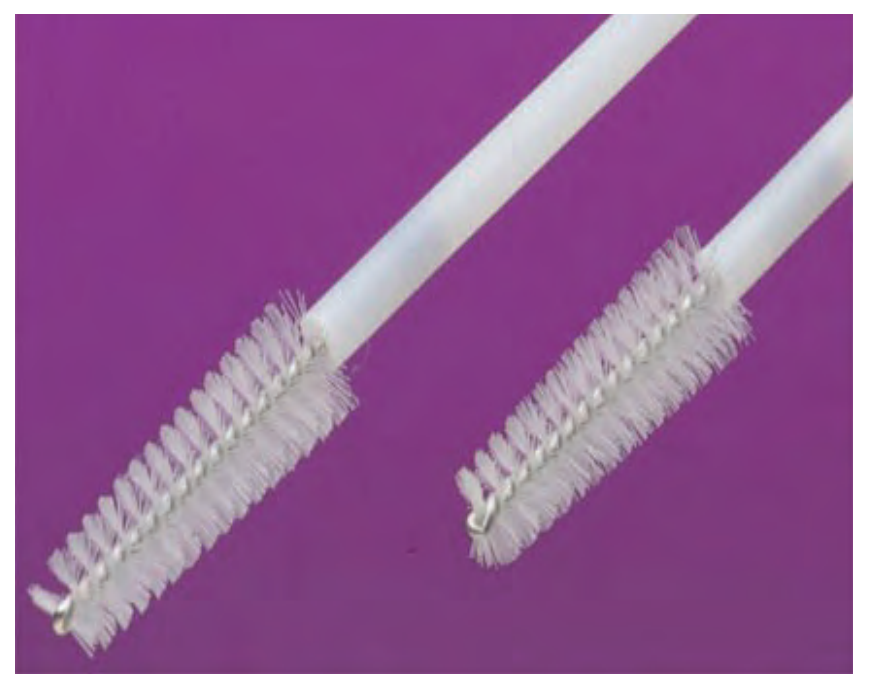

Figure 19. Standard brushes used for nasal mucosal cell sampling

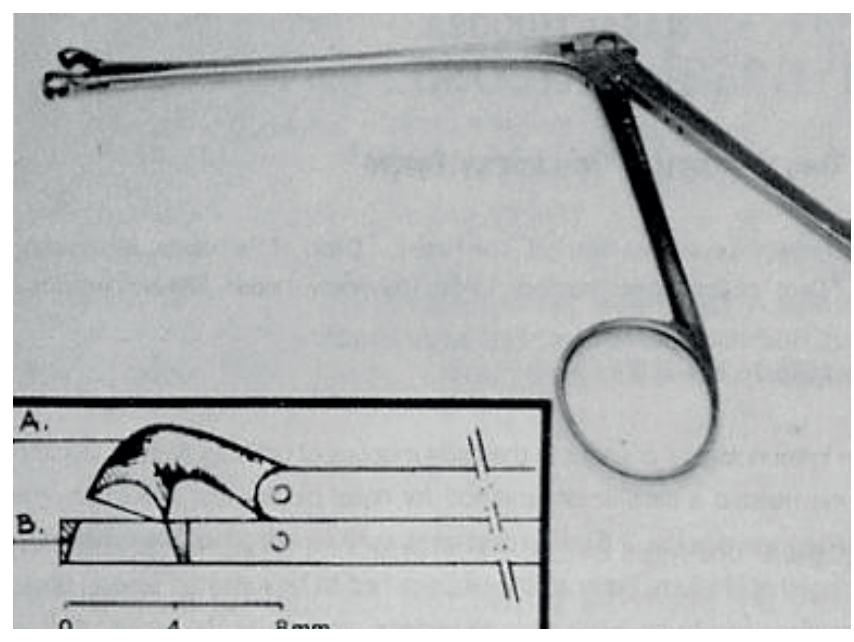

Figure 20. Fokkens forceps for nasal biopsy. 
or swabs ${ }^{(244)}$. This might be especially important when the inflammatory response is not always obvious, as in non-allergic rhinitis ${ }^{(245)}$. It has been shown that biopsies can safely be taken from the olfactory mucosa without affecting nasal function or the sense of smell ${ }^{(246)}$.

\section{Recommendations}

Nasal sampling can be undertaken when measurement of specific inflammatory or other biological markers is required but it remains predominantly a research tool at present. The technique used depends on the type of sample required (mucus, mucosa, cells) and the marker to be studied.

\section{Objective measures of nasal airflow and patency}

\section{Rationale}

Nasal obstruction is a common complaint in many nasal conditions and affects $\mathrm{QOL}{ }^{(247)}$, so its objective measurement is very important ${ }^{(248,249)}$. Many authors have shown that the correlation between the subjective sensation of nasal obstruction and its objective measurement is low or absent (250-252). However, others have reported a correlation, both in adults ${ }^{(253-259)}$ and children ${ }^{(260)}$. In the lower airways, symptoms are assessed and monitored by pulmonary function tests (261). Similarly, nasal obstruction assessment with objective measures should become part of routine clinical testing ${ }^{(262,263)}$. Objective measures such as peak nasal inspiratory flow (PNIF), rhinomanometry (RM) and acoustic rhinometry (AR) assess different aspects of nasal obstruction and provide complementary information ${ }^{(264)}$. RM and AR are the most commonly used methods and have shown good correlation with each other ${ }^{(254,265-267)}$. PNIF has shown a moderate to strong correlation with both AR and RM ${ }^{(268)}$. Van Spronsen et al. proposed the GRADE system (Grading Recommendations Assessment, Development and Evaluation) to evaluate studies of different tools used to assess nasal obstruction and concluded that RM and PNIF were good for assessing the presence and severity of obstruction ${ }^{(269)}$. In this section, these methods will be analyzed and discussed in detail.

\section{Objectives}

To provide objective measurements of nasal airflow and patency to assist in the diagnosis and assessment of nasal obstruction, and to monitor response to treatment, both medical and surgical.

\section{Peak nasal inspiratory flow (PNIF)}

PNIF is an inexpensive, fast, portable and simple technique which does not depend on computers to analyze the data. PNIF uses a facemask with an airtight seal over the nose and mouth, attached to a peak flow monitor (Figure 21). The patient, sitting upright, exhales fully then holds the mask in place and inspires through the nose as hard and fast as they can, keeping the mouth closed ${ }^{(264)}$. Usually three satisfactory maximal inspirations are obtained and the highest of these results is taken as the PNIF value ${ }^{(270)}$. PNIF strongly decreases with age ${ }^{(270-273)}$, is higher in males than females and increases with height, albeit with a large variability ${ }^{(270)}$. This variability can perhaps in part be explained by the correlation of PNIF and pulmonary function, specifically peak expiratory flow rate (PEFR) ${ }^{(274,275)}$. Normal PNIF values are available for adults and children ${ }^{(270,273,276-279)}$ (Table 5). Unilateral normal PNIF values are available for adults ${ }^{(280)}$.

Given its portability and simple technique, PNIF can be easily used by the patient in the workplace to evaluate environmental effects on nasal airflow ${ }^{(281)}$ and can be used at home to investigate the day-to-day effects of therapy on nasal airflow ${ }^{(282,283)}$. PNIF has good reproducibility ${ }^{(284,285)}$ with a correlation coefficient up to $92 \%{ }^{(286)}$.

Despite the potential for valve collapse at high flow rates (287) and the need to pay attention to the nasal valve area especially when unilateral measurements are taken ${ }^{(288,289)}$, PNIF has been used to study nasal valve collapse ${ }^{(290)}$ and to evaluate the effect of nasal dilators ${ }^{(291-295)}$ and surgery for nasal valve insufficiency $(296,297)$.

\section{Rhinomanometry (RM)}

RM is the simultaneous measurement of nasal airflow and the pressure gradient required to achieve that flow from which nasal airway resistance (NAR) can then be calculated ${ }^{(298)}$. RM

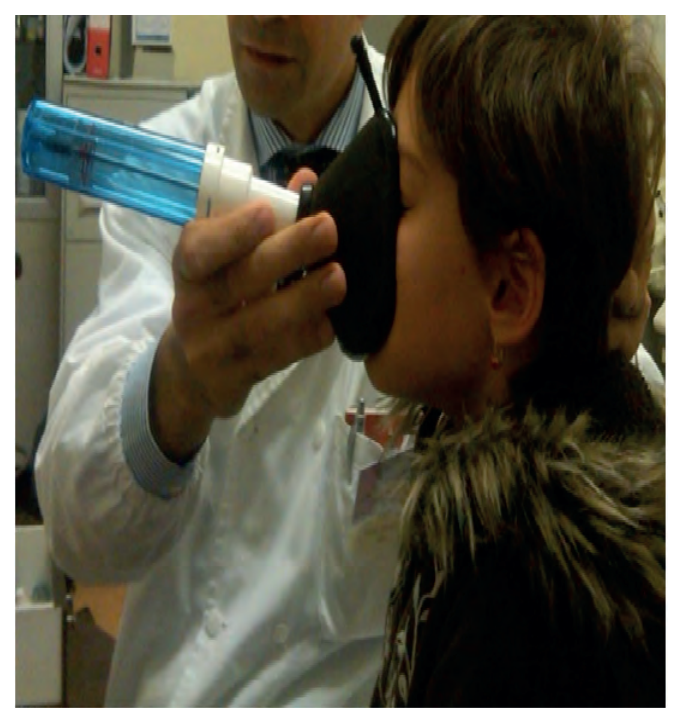

Figure 21. A young patient performing peak nasal inspiratory flow. 
can be anterior or posterior, active or passive. In anterior active rhinomanometry (AAR), the most commonly used method of RM ${ }^{(299)}$, a mask is attached to the device that measures the transnasal pressure and flow and interfaces with a computer. The pressure sensor is placed in one nostril with a total seal created by taping off the nostril (Figure 22) ${ }^{(299)}$. NAR is the ratio of pressure to flow and is reported in $\mathrm{Pa} / \mathrm{cm}^{3} / \mathrm{sec}^{(300,301)}$. Simultaneous display of the pressure-flow curve is provided. The more obstructed the airway, the greater the pressure required to generate a certain flow. The International Committee on Rhinomanometric Standards previously described calculating NAR at a fixed pressure gradient of $150 \mathrm{~Pa}$ (P150) in classic AAR ${ }^{(298)}$. More recent consensus guidelines recommend the use of four-phase rhinomanometry (4PR), where NAR is calculated using hundreds of resistances continuously recorded during the whole breathing cycle ${ }^{(299,302)}$. In 4PR the parameters considered are: 1) vertex resistance (VR), defined as the resistance measured at the highest point of the flow curve during quiet breathing, and its logarithmic value (LVR); 2) the effective resistance of the entire breath (Reff); and 3) the effective resistance during inspiration (Reffln) and expiration (ReffEx) and their logarithmic values (LReff, LReffIn and LReffEx). VR has been found to best correlate with the symptom of nasal obstruction ${ }^{(303)}$. Despite the differences in measurement techniques, 4PR and AAR have not been shown to significantly differ in outcomes ${ }^{(304)}$. More studies comparing these methods should be performed in the future. Rhinomanometry can be carried out in children; NAR decreases with age and is lower for girls than boys ${ }^{(305)}$. Reference values are available for children and adults (Table 5) ${ }^{(260,306,307)}$. Normal values for 4PR have also been reported ${ }^{(308,309)}$.

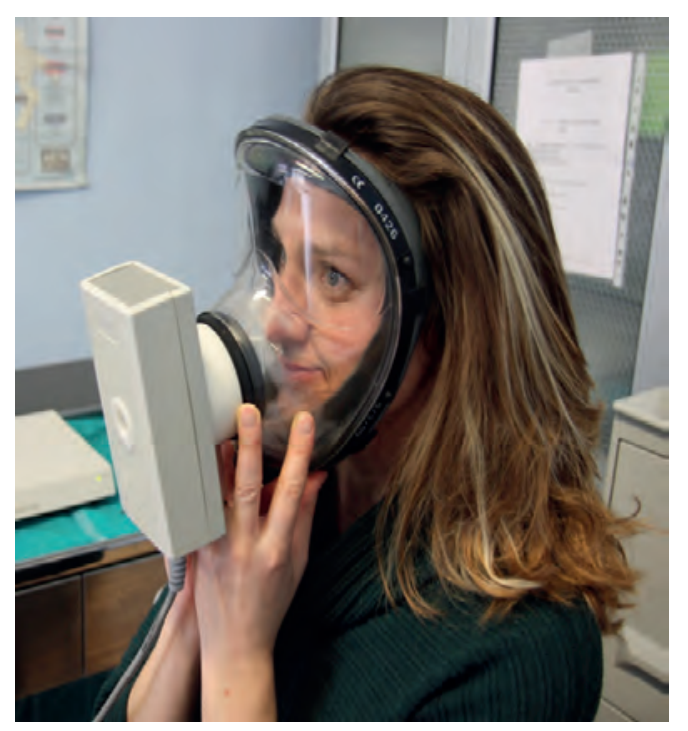

Figure 22. A patient performing anterior active rhinomanometry.

\section{Acoustic rhinometry (AR)}

AR aims to explore the geometry of the nasal cavity. It uses the acoustic reflection of a sound wave that travels along the nasal cavity to measure areas and volumes at different points in the nose. Jackson et al. developed the fundamentals of AR in 1977 (Figure 23) ${ }^{(310)}$. The size and pattern of the reflected sound waves provide information on the structure and dimensions of the nasal cavity, with the time delay of reflections correlating with the distance from the nostril. The conversion of these measurements to nasal volume and area requires mathematical calculations and theoretical assumptions, and is done by the computer connected to the recording device.

The patient sits in an upright position, cleans the nose and places the nosepiece into the nostril with an airtight seal (Figure 24). The room should be standardized in terms of temperature and humidity. Silence during measurement is

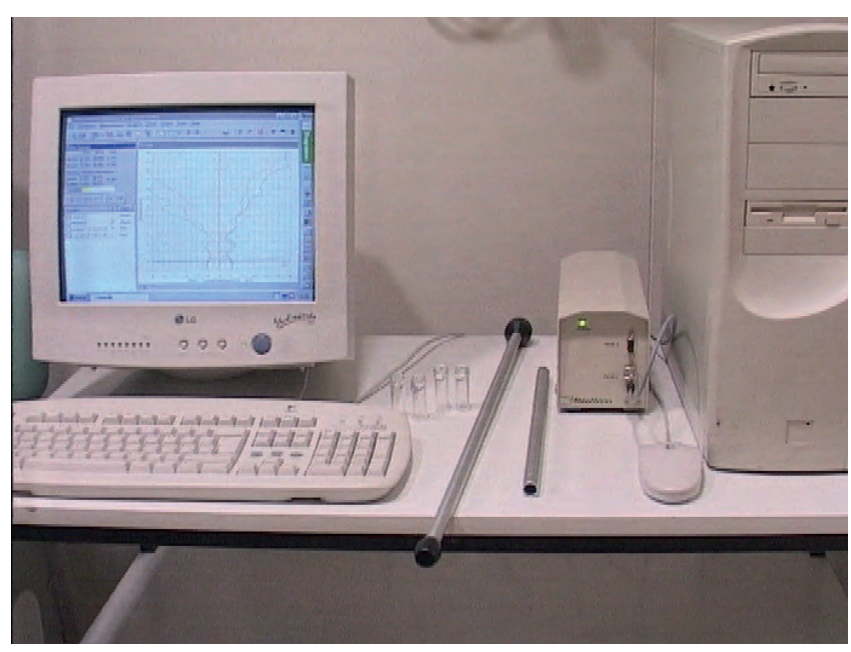

Figure 23. Acoustic rhinometry equipment.

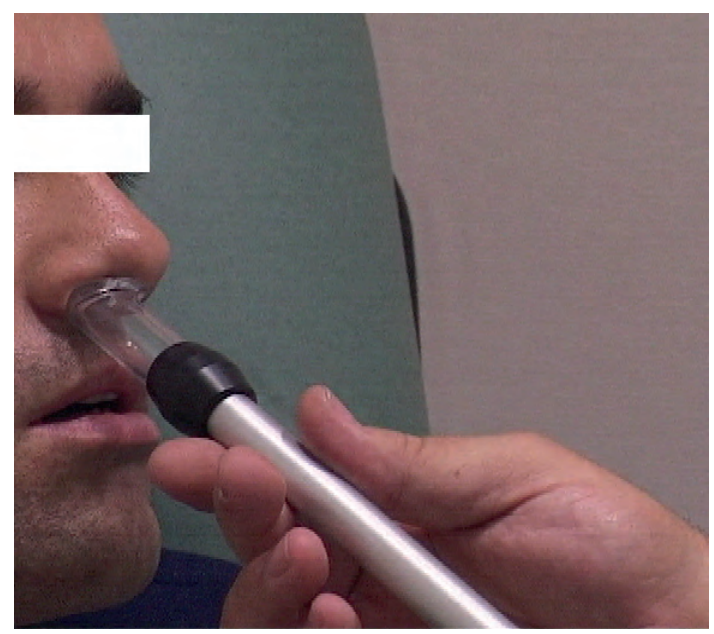

Figure 24. Nosepiece in acoustic rhinometry fits the nostril, ensuring an airtight seal. 
Table 5. Normal values for peak nasal inspiratory flow (PNIF) ${ }^{(279,281)}$ and anterior active rhinomanometry (AAR) ${ }^{(308)}$.

\begin{tabular}{|c|c|c|}
\hline & PNIF & AAR \\
\hline Measurement & Maximal nasal inspiratory flows & Nasal resistance at $150 \mathrm{~Pa}$ \\
\hline Normal values for adult males (Caucasian) & $143 \pm 48.6 \mathrm{~L} / \mathrm{min}$ & $0.24 \mathrm{~Pa} / \mathrm{cm} 3 / \mathrm{s}(95 \% \mathrm{Cl} 0.09-0.39)$ \\
\hline Normal values for adult females (Caucasian) & $121.9 \pm 36 \mathrm{~L} / \mathrm{min}$ & $0.26 \mathrm{~Pa} / \mathrm{cm} 3 / \mathrm{s}(95 \% \mathrm{Cl} 0.08-0.44)$ \\
\hline Normal values for children (8 years) & $80 \pm 25 \mathrm{~L} / \mathrm{min}$ & $\begin{array}{c}0.24 \mathrm{~Pa} / \mathrm{cm} 3 / \mathrm{s}(95 \% \mathrm{Cl} 0.11-0.37 \text { ) } \\
\text { (after nasal decongestion) }\end{array}$ \\
\hline
\end{tabular}

essential. Measurements are performed during breath holding. Nosepieces should either be disposable or treated with appropriate hygienic precautions in order to avoid transmission of infectious diseases ${ }^{(311)}$.

AR was standardized in 2005 by the Standardization Committee on Objective Assessment of the Nasal Airway of the European Rhinologic Society ${ }^{(312)}$. The distance from the nostril is calculated by the running time of the incident and reflected sound waves. Derived parameters include nasal cavity volume, and minimal cross-sectional area (MCA) at the nasal valve and the anterior end of the inferior turbinate. Two notches, representing specific areas in the nose, are seen on the AR graph (Figure 25). The first notch, or l-notch, is generally thought to be at the nasal valve. Since it has no precise anatomical correlation, it is strictly accepted as an AR measure. The absence of nasal mucosa at this point means that it will not be modified by vasoconstrictors ${ }^{(313)}$. The second notch, or C-notch, is located a mean distance of $1.83 \mathrm{~cm}$ from the nostril, with an average cross-sectional area of $0.56 \mathrm{~cm}^{2}$ in a non-decongested nasal cavity, and is anatomically correlated with the head of the inferior turbinate. In healthy Caucasians, MCA corresponds to the second notch and is the AR measure of greatest clinical value; MCA less than $0.4 \mathrm{~cm}^{2}$ correlates with nasal obstruction ${ }^{(314)}$. Volume values can be obtained in the nasal passages at various distances from the nostril; the volume between $2 \mathrm{~cm}$ and $5 \mathrm{~cm}$ in the nasal cavity is the most sensitive measurement for showing changes in the nasal airway after decongestion of the nasal mucosa ${ }^{(315)}$. It is difficult to define a'normal' nasal fossa. Countless variables must be taken into account in the context of mid-facial growth and development, as well as aspects linked to ethnic/racial characteristics, age, weight and the tools used. Separate left and right anatomical nose adaptors probably provide better results than measurements obtained with a common adaptor for both sides. Incorrect positioning and inclination of the sonic tube are the major source of errors ${ }^{(249)}$.

Septal perforation influences the results of AR. Mishima et al. studied this effect before and after closing a septal perforation by thin cotton patches ${ }^{(316)}$. The authors reported a decrease in MCA and volumes after closure. Compared to CT scan, AR measurements have been shown to accurately reflect the geometry of nasal cavity volumes in patients with nasal polyps, with a better assessment in the anterior part of the nasal cavity (317).

Uses

All three tests can be used for the objective evaluation of nasal obstruction associated with CRS (301,317-323) and allergic rhinitis ${ }^{(323-331)}$. Pre- and post-decongestion testing can distinguish between nasal obstruction due to soft tissue and that due to fixed structural deformity ${ }^{(249,332,333)}$ (Table 6). This can be useful in the appropriate selection of surgical procedures ${ }^{(314,334)}$ as well as in the evaluation of nasal surgery outcomes (288,289,334-341). Patients who have objective evidence of nasal obstruction do significantly better after nasal surgery than those who do not (314,342).

They can also be used to study the nasal cycle ${ }^{(343,344)}$ and hormonal influences on the nasal mucosa ${ }^{(345,346)}$ as well as in nasal provocation testing ${ }^{(328,347-351)}$. AR is reportedly better than AAR for the nasal provocation test, since it measures the MCA and volume of the nasal passages quickly, directly and with high sensitivity and specificity. The nasal provocation test is considered positive if the MCA and/or the nasal volume between $2 \mathrm{~cm}$ and $5 \mathrm{~cm}$ decrease by at least $25-30 \%{ }^{(352-354)}$.

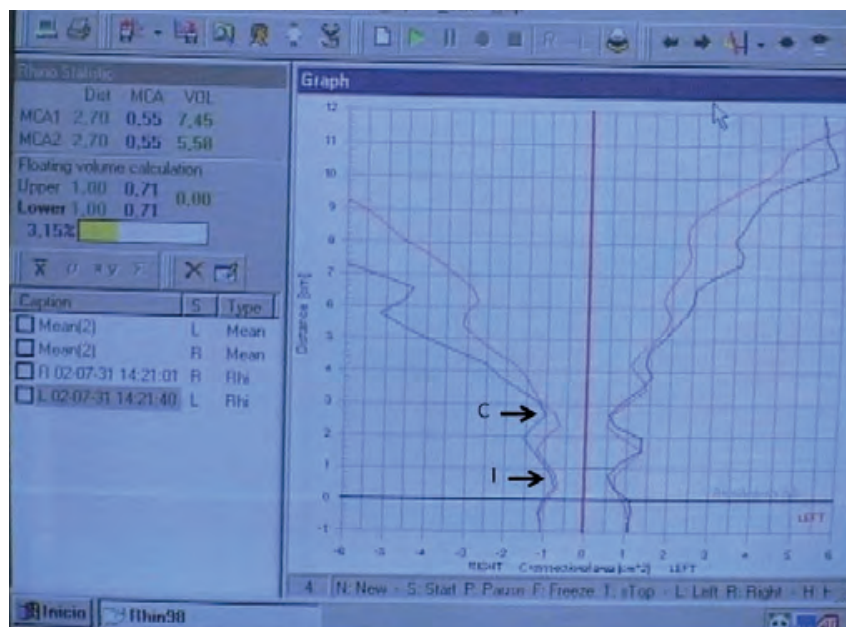

Figure 25. Acoustic rhinometry of right and left nose before (red line) and after (blue line) decongestion, demonstrating the I notch (nasal valve) and $C$ notch (head of inferior turbinate). 
Table 6. Advantages and disadvantages of different techniques for objective airway measurement.

\begin{tabular}{|c|c|c|}
\hline Test & Advantages & Disadvantages \\
\hline Peak nasal inspiratory flow (PNIF) & $\begin{array}{l}\text { Easy to use } \\
\text { Operator not required after short training } \\
\text { session } \\
\text { Can be used in children } \\
\text { Good correlation with subjective nasal } \\
\text { congestion } \\
\text { Cheap } \\
\text { Portable } \\
\text { Reproducible }\end{array}$ & $\begin{array}{l}\text { Patient cooperation required } \\
\text { Affected by lung function } \\
\text { Not possible if complete alar collapse on } \\
\text { inspiration }\end{array}$ \\
\hline Rhinomanometry (RM) & $\begin{array}{l}\text { Minimal patient cooperation } \\
\text { Can be used in children } \\
\text { Unilateral information } \\
\text { Reproducible }\end{array}$ & $\begin{array}{l}\text { Operator required } \\
\text { Affected by nasal cycle } \\
\text { Weak correlation with subjective nasal } \\
\text { obstruction } \\
\text { Not possible if complete obstruction } \\
\text { Not suitable for home monitoring } \\
\text { Relatively expensive equipment }\end{array}$ \\
\hline Acoustic rhinometry (AR) & $\begin{array}{l}\text { Easy to use } \\
\text { Minimal patient cooperation } \\
\text { Can be used in children } \\
\text { Unilateral information } \\
\text { Reproducible }\end{array}$ & $\begin{array}{l}\text { Non-physiological measure } \\
\text { Operator required } \\
\text { Affected by nasal cycle } \\
\text { Weak correlation with subjective nasal } \\
\text { obstruction } \\
\text { Not possible in septal perforation } \\
\text { Not suitable for home monitoring } \\
\text { Relatively expensive equipment }\end{array}$ \\
\hline
\end{tabular}

\section{Recommendations}

Objective testing can show those patients in whom airflow restriction corresponds to obstructive symptoms and those in whom it does not. PNIF, RM and AR are the most studied techniques. Although assessing different aspects of the nasal airway, they have been shown to roughly correlate with each other and can be used individually or in combination to provide objective information on nasal function. The choice of what method to use depends on the situation.

\section{Nasal nitric oxide}

\section{Rationale}

Nitric oxide (NO) is a colourless, odourless gas that is present in air exhaled through the mouth or nose. NO is produced from arginine and oxygen by nitric oxide synthase (NOS). Constitutively expressed neuronal and endothelial forms exist as well as an induced form, iNOS, which appears to be upregulated within the respiratory tract in response to pro-inflammatory signals. NO came to prominence for its role in vasodilatation and subsequently as a neurotransmitter and inflammatory mediator ${ }^{(355)}$. The role of NO in the airways is complex, possibly including antibacterial effects, pro-inflammatory effects and regulation of blood flow and ciliary beat frequency. Exhaled NO (eNO) levels are raised in eosinophilic asthma and measurement of this has become a standardised, but not yet widespread, tool in the diagnosis and management of asthma ${ }^{(356)}$. It can potentially provide a rapid, low cost objective measure of lower airway inflammation. Most NO is produced in the sinuses, far less by the nasal mucosa and the lower respiratory tract ${ }^{(355)}$.

\section{Objectives}

Measurement of nasal NO ( $\mathrm{nNO}$ ) may represent a useful tool for research purposes as well as for screening for primary ciliary dyskinesia (PCD). Nasal NO may be normal, raised or lowered in disease states; measurement may therefore be a useful tool in the diagnosis and management of patients with CRS, nasal polyps and cystic fibrosis (CF), as well as in the diagnosis of PCD. Measuring both bronchial and nasal NO may assist in the combined management of upper and lower airways.

\section{Nasal NO}

High levels of $\mathrm{NO}$ are produced constitutively within the paranasal sinuses of normal individuals by calcium-independent NOS ${ }^{(355)}$. Additionally, $\mathrm{NO}$ is also formed in the respiratory mucosa by iNOS in response to inflammation. NO and its metabolites are toxic to micro-organisms and likely form part of 
the innate defence mechanism of the respiratory tract. NO may also stimulate ciliary beat frequency within the epithelium and regulate nasal vascular tone.

\section{Technique}

As with eNO, nNO can also be measured by chemiluminescence, using non-invasive techniques, providing immediate results.

Several different techniques have been used to ensure sampling from the upper airways only, including breath holding and breathing against resistance. Guidelines for measurement have been published ${ }^{(357-359)}$.

\section{Diagnostic accuracy}

Nasal NO can be measured in either nostril and shows no diurnal variation. The measurement is quick, reproducible, feasible and best accepted with an aspiration flow of $700 \mathrm{ml} / \mathrm{min}$ during breath-holding for 10 seconds ${ }^{(360)}$. Humming during $\mathrm{nNO}$ measurement initially increases levels considerably in healthy subjects ${ }^{(361)}$. If low values are obtained, measuring nNO during humming can increase the specificity of the measurement ${ }^{\left({ }^{362}\right)}$. Healthy controls usually have $\mathrm{nNO}$ levels above $300 \mathrm{ppb}$ (363). In allergic rhinitis, nasal nitric oxide is elevated compared to healthy controls and correlates with the severity of the inflammation, as long as the ostia to the sinuses are open ${ }^{(364)}$. In nonallergic rhinitis, the level of $\mathrm{nNO}$ is reported to be comparable to healthy controls ${ }^{(364)}$. Measurement of $\mathrm{nNO}$ in CRSwNP and CRSsNP is hampered by the opposing effects of

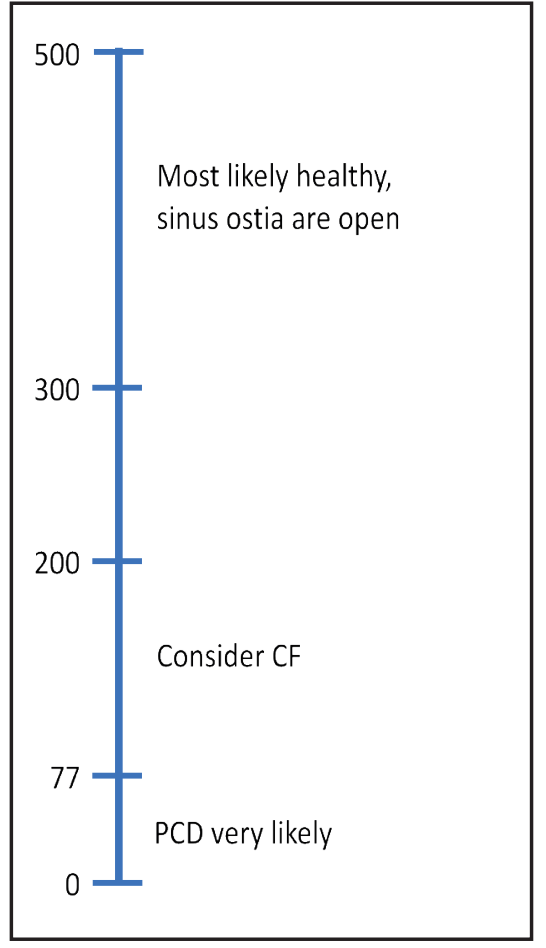

Figure 26. nNO level in the diagnosis of airway disease (in ppb). increased nNO due to inflammation and decreased nNO due to obstruction of the sinus ostia ${ }^{(355)}$.

\section{Diagnostic use of nNO}

$P C D$ is a rare disorder causing chronic otosinopulmonary disease, generally diagnosed through evaluation of respiratory ciliary ultrastructure and/or genetic testing (see section on 'Tests of mucociliary clearance'). Nasal NO is a sensitive and specific test for PCD in cooperative patients (generally over five years old) with a high clinical suspicion for the disease. Nasal NO testing using palatal closure manoeuvres has diagnostic accuracy similar to electron microscopy and/or genetic testing for PCD when CF has been ruled out ${ }^{(365)}$. Nasal NO values below $77 \mathrm{ppb}$ are very suggestive of PCD but higher values are occasionally found (Figure 26) ${ }^{(363)}$. CF also has generally low values (70-300 ppb), and the presence of nasal polyps is associated with significantly lower nNO levels than in CF patients without nasal polyps ${ }^{(366)}$.

Nasal NO values in patients with allergic rhinitis, CRSsNP, CRSwNP, asthma and chronic obstructive pulmonary disease can be in the normal range or increased ${ }^{(361,367)}$ but when sinus ostia are closed nNO may also decrease. For that reason, nNO measurements are not very helpful in these patient groups. After endoscopic sinus surgery for nasal polyposis, nNO levels increase significantly, but usually not to normal levels ${ }^{(366,368,369)}$.

\section{Recommendations}

Nasal NO is a sensitive and specific test for PCD in cooperative patients (generally over five years old) with a high clinical suspicion for this disease. To a lesser extent it may also be a useful adjunct in a potential diagnosis of CF. Whilst not commonly used as a specific diagnostic tool in allergic rhinitis and CRS, it may be used to monitor the response to treatment in these conditions.

\section{Tests of mucociliary clearance}

\author{
Rationale \\ In paediatric patients presenting with a long history of \\ uncontrolled CRS with bilateral anterior rhinorrhoea and \\ otitis media with effusion, one should consider evaluating the \\ mucociliary clearance system for exclusion or diagnosis of PCD \\ (370,371). \\ By their coordinated movement, the cilia lining the respiratory \\ epithelium transport the mucus layer with entrapped inhaled \\ particles from the nasal cavity towards the hypopharynx. \\ In physiological circumstances, about $10 \mathrm{ml}$ of mucus is \\ transported daily from the sinonasal cavities towards the \\ hypopharynx, ultimately being swallowed and cleared from \\ the upper airways. Normal mucociliary transport (MCT) is
}


essential for the maintenance of healthy sinonasal cavities. With infection or congenital dysfunction of the cilia as in PCD, MCT is inadequate or absent. In PCD, lack of MCT may lead to CRS and bronchiectasis. Mucostasis, hypoxia, microbial products and toxic inflammatory mediators in CRS may induce secondary ciliary changes, i.e. secondary ciliary dyskinesia (SCD), with subsequent inadequate MCT.

\section{Objectives}

Objective evaluation of the mucociliary clearance of the upper airways in order to quantify the ciliary function of the upper respiratory tract epithelium.

\section{Techniques}

\section{Mucociliary clearance time}

The MCT mechanism ensures the clearance of entrapped particles in the mucus lining the nasal mucosa towards the hypopharynx. Several non-absorbable substances have been used for the evaluation of MCT in patients.

The saccharine test evaluates the time taken to experience a sweet taste after placement of a 1-2 mm particle of saccharine on the inferior turbinate mucosa, $1 \mathrm{~cm}$ from the anterior end. The patient must sit quietly with the head bent forward and without sniffing, coughing, sneezing, drinking or eating during the investigation. Alternatively, one can monitor the time needed for a dye such as methylene blue to be transported from the mucosa of the anterior third of the nasal cavity towards the hypopharynx. Other substances including technetium$99 \mathrm{~m}$-labeled iron oxide have also been used. The mucociliary clearance (MCC) time is considered to be normal below 15 minutes and should be less than one hour.

As the MCC time can only be measured in cooperative patients with patent nasal cavities and in the absence of severe mucosal disease, it has limited diagnostic value in certain patients. It also has low sensitivity and specificity and requires significant time investment. In the context of the clinical relevance of MCT, it has recently been demonstrated that nasal lavages, a commonly recommended treatment for many sinonasal conditions, reduce the MCC time ${ }^{(372) \text {. }}$

\section{Electron microscopy}

Harvesting epithelial cells is performed by scraping along the inferior and middle turbinates with a sterile cytology brush (see section on 'Nasal sampling'). These epithelial cells can be used for either structural investigation of the cilia with electron microscopy (EM) or for measuring ciliary beat frequency (CBF) in vitro.

In primary and secondary ciliary dysfunction, several abnormalities may be observed in the ciliary ultrastructure including total or partial absence of dynein arms, aberrant organization of the dynein arms and/or disorientation. PCD is associated with the latter abnormalities but SCD may also present with these structural abnormalities. Therefore, EM evaluation of harvested epithelial cells may aid in the diagnosis of PCD but is not $100 \%$ sensitive or specific.

\section{Ciliary beat frequency measurement}

Harvested epithelial cells can be evaluated for ciliary beat frequency (CBF) and the ciliary wave form analysed in detail by digital high-speed video imaging. The evaluation of the $\mathrm{CBF}$ as well as assessment of their coordinated movement can be performed by computerized programs using a Fast Fourier analysis. Normal values of CBF vary depending on the methodology used, the age of the patient and the culture conditions. The demonstration of normal CBF and beat pattern excludes the diagnosis of PCD.

Recently, a novel technique for quantification of CBF has been reported using phase-contrast microscopy images, estimating ciliary motion by means of an optical flow algorithm ${ }^{(373)}$. A ciliary motility index might discriminate between healthy and infected epithelial cultures ${ }^{(374)}$.

\section{Ciliogenesis in vitro}

The evaluation of ciliogenesis in vitro is considered the gold standard for diagnosis of PCD, allowing the differentiation between primary and secondary ciliary dyskinesia ${ }^{(375)}$. A biopsy of the nasal mucosa is taken, nasal epithelial cells are dissociated by enzymatic digestion and incubated for six to eight weeks until cilia reappear on the apical side of the epithelial cells. The new cilia can be evaluated for their electron microscopic structure and coordinated activity. In PCD patients, no ciliogenesis takes place whereas patients with ciliary dysfunction due to infection/inflammation develop properly functioning cilia after ciliogenesis.

\section{Recommendations}

No ideal test is available for the diagnosis of PCD in routine practice ${ }^{(376)}$. In cases of suspected PCD in a patient with CRS since birth, a family history of PCD and/or associated features of Kartagener syndrome (situs inversus and infertility), one should consider diagnostic tests of ciliary function by evaluation of CBF, $E M$ evaluation of the dynein arms of the cilia and/or evaluation of the cilia after ciliogenesis in vitro. In a tertiary referral centre, one third of patients referred with suspected PCD are eventually diagnosed with the condition ${ }^{(377)}$.

As these techniques are not available in routine ENT practice, one should rely on measuring nNO levels in cases of suspected PCD; low nNO levels have been associated with PCD and therefore represent an excellent screening tool (see section on 'Nasal nitric oxide'). In addition, screening for genetic mutations known to be associated with PCD, as well as genetic counselling, is recommended ${ }^{(378)}$. 
1. Scadding G, Hellings P, Alobid I, Bachert C, Fokkens W, van Wijk RG, et al. Diagnostic tools in Rhinology EAACI position paper. Clin Transl Allergy. 2011 Jun 10;1(1):2.

2. Hopkins C, Rimmer J, Lund VJ. Does time to endoscopic sinus surgery impact outcomes in Chronic Rhinosinusitis? Prospective findings from the National Comparative Audit of Surgery for Nasal Polyposis and Chronic Rhinosinusitis. Rhinol J. 2015 Mar 1;53(1):10-7.

3. Fokkens WJ, Lund VJ, Mullol J, Bachert C, Alobid I, Baroody F, et al. European Position Paper on Rhinosinusitis and Nasal Polyps 2012. Rhinol Suppl. 2012;23:3 p preceding table of contents, 1-298.

4. Rosenfeld RM, Piccirillo JF, Chandrasekhar SS, Brook I, Ashok Kumar K, Kramper M, et al. Clinical Practice Guideline (Update): Adult Sinusitis. Otolaryngol Neck Surg. 2015 Apr;152(2_suppl):S1-39.

5. Hughes RG, Jones NS. The role of nasal endoscopy in outpatient management. Clin Otolaryngol Allied Sci. 1998 Jun;23(3):224-6.

6. Bhattacharyya $N$, Lee LN. Evaluating the diagnosis of chronic rhinosinusitis based on clinical guidelines and endoscopy. Otolaryngol Neck Surg. 2010 Jul;143(1):14751.

7. Amine $M$, Lininger $L$, Fargo KN, Welch KC. Outcomes of endoscopy and computed tomography in patients with chronic rhinosinusitis. Int Forum Allergy Rhinol. 2013 Jan;3(1):73-9.

8. Villwock JA, Kuppersmith RB. Diagnostic Algorithm for Evaluating Nasal Airway Obstruction. Otolaryngol Clin North Am. 2018 Oct:51(5):867-72.

9. Grymer LF, Hilberg O, Pedersen OF. Prediction of nasal obstruction based on clinical examination and acoustic rhinometry. Rhinology. 1997 Jun;35(2):53-7.

10. Jones NS. The prevalence of facial pain and purulent sinusitis. Curr Opin Otolaryngol Head Neck Surg. 2009 Feb;17(1):38-42.

11. Rosbe KW, Jones KR. Usefulness of patient symptoms and nasal endoscopy in the diagnosis of chronic sinusitis. Am J Rhinol. 12(3):167-71.

12. Hsueh WD, Conley DB, Kim H, ShintaniSmith S, Chandra RK, Kern RC, et al. Identifying clinical symptoms for improving the symptomatic diagnosis of chronic rhinosinusitis. Int Forum Allergy Rhinol. 2013 Apr;3(4):307-14.

13. Wise SK, Lin SY, Toskala E, Orlandi RR, Akdis CA, Alt JA, et al. International Consensus Statement on Allergy and Rhinology: Allergic Rhinitis. Int Forum Allergy Rhinol. 2018 Feb;8(2):108-352.

14. Bousquet J, Van Cauwenberge P, Khaltaev N, Aria Workshop Group, World Health Organization. Allergic rhinitis and its impact on asthma. J Allergy Clin Immunol. 2001 Nov;108(5 Suppl):S147-334.

15. Bonaparte JP, Campbell R. A prospective cohort study assessing the clinical utility of the Cottle maneuver in nasal septal surgery. J Otolaryngol - Head Neck Surg. 2018 Jul 11;47(1):45.

16. Autio TJ, Koskenkorva T, Närkiö M, Leino TK, Koivunen P, Alho OP. Diagnostic accuracy of history and physical examination in bacterial acute rhinosinusitis. Laryngoscope. 2015 Jul;125(7):1541-6.

17. Bolger WE, Kennedy DW. Nasal endoscopy in the outpatient clinic. Otolaryngol Clin North Am. 1992 Aug;25(4):791-802.

18. Batra PS. The role of endoscopy in the allergist's office. Curr Allergy Asthma Rep. 2006 May;6(3):228-31.

19. Druce HM. Diagnosis of sinusitis in adults: history, physical examination, nasal cytology, echo, and rhinoscope. J Allergy Clin Immunol. 1992 Sep;90(3 Pt 2):436-41.

20. Shargorodsky J, Bhattacharyya N. What is the role of nasal endoscopy in the diagnosis of chronic rhinosinusitis? Laryngoscope. 2013 Jan;123(1):4-6.

21. Lund VJ, Kennedy DW. Quantification for staging sinusitis. The Staging and Therapy Group. Ann Otol Rhinol Laryngol Suppl. 1995 Oct;167:17-21.

22. Psaltis AJ, Li G, Vaezeafshar R, Cho K-S, Hwang $\mathrm{PH}$. Modification of the lund-kennedy endoscopic scoring system improves its reliability and correlation with patientreported outcome measures. Laryngoscope. 2014 Oct;124(10):2216-23.

23. Annamalai S, Davis J, Kubba H. How Subjective is Nasal Endoscopy? A Study of Interrater Agreement using the Lund and Mackay Scoring System. Am J Rhinol. 2004 Sep 9;18(5):301-3.

24. McCoul ED, Smith TL, Mace JC, Anand VK, Senior BA, Hwang PH, et al. Interrater agreement of nasal endoscopy in patients with a prior history of endoscopic sinus surgery. Int Forum Allergy Rhinol. 2012 Nov;2(6):453-9.

25. Raithatha R, Anand VK, Mace JC, Smith TL, Schaberg MR, Nyquist GG, et al. Interrater agreement of nasal endoscopy for chronic rhinosinusitis. Int Forum Allergy Rhinol. 2012 Mar 1:2(2):144-50

26. Eren E, Aktaş A, Arslanoğlu S, Kopar A, Ciğer $E$, Özkul Y, et al. Diagnosis of allergic rhinitis: inter-rater reliability and predictive value of nasal endoscopic examination: a prospective observational study. Clin Otolaryngol. 2013 Dec;38(6):481-6.

27. Larsen $\mathrm{KL}$, Lange $B$, Darling $P$, Jørgensen $G$, Kjeldsen AD. The validity of nasal endoscopy in patients with chronic rhinosinusitisAn inter-rater agreement study. Clin Otolaryngol. 2018 Feb;43(1):144-50.
28. Bousquet J, Khaltaev N, Cruz AA, Denburg J, Fokkens WJ, Togias A, et al. Allergic Rhinitis and its Impact on Asthma (ARIA) 2008. Allergy. 2008 Apr;63:8-160.

29. Rudmik L, Smith TL, Mace JC, Schlosser RJ, Hwang PH, Soler ZM. Productivity costs decrease after endoscopic sinus surgery for refractory chronic rhinosinusitis. Laryngoscope. 2016 Mar;126(3):570-4.

30. DeConde AS, Mace JC, Bodner T, Hwang $\mathrm{PH}$, Rudmik L, Soler ZM, et al. SNOT-22 quality of life domains differentially predict treatment modality selection in chronic rhinosinusitis. Int Forum Allergy Rhinol. 2014 Dec:4(12):972-9.

31. Fitzpatrick R. Surveys of patients satisfaction: I--Important general considerations. BMJ. 1991 Apr 13;302(6781):887-9.

32. Gliklich RE, Metson R. The health impact of chronic sinusitis in patients seeking otolaryngologic care. Otolaryngol Head Neck Surg. 1995 Jul;113(1):104-9.

33. Banglawala SM, Schlosser RJ, Morella K Chandra R, Khetani J, Poetker DM, et al. Qualitative development of the sinus control test: A survey evaluating sinus symptom control. Int Forum Allergy Rhinol. 2016 May 1;6(5):491-9.

34. Remenschneider AK, D'Amico L, Gray ST, Holbrook EH, Gliklich RE, Metson R. The EQ5D: A new tool for studying clinical outcomes in chronic rhinosinusitis. Laryngoscope. 2015 Jan;125(1):7-15.

35. Brooks R, De Charro F. EuroQol: The current state of play. Health Policy (New York). 1996 Jul;37(1):53-72.

36. Passalacqua G, Pasquali $M$, Ariano $R$, Lombardi C, Giardini A, Baiardini I, et al. Randomized double-blind controlled study with sublingual carbamylated allergoid immunotherapy in mild rhinitis due to mites. Allergy. 2006 Jul;61(7):849-54.

37. Ang M, Fenwick E, Wong TY, Lamoureux E, Luo N. Utility of EQ-5D to Assess Patients Undergoing Cataract Surgery. Optom Vis Sci. 2013 Aug;90(8):861-6.

38. Stewart MG. Outcomes and patient-based hearing status in conductive hearing loss. Laryngoscope. 2001 Oct 20;111(11 II):1-21.

39. McDonough CM, Grove MR, Tosteson TD, Lurie JD, Hilibrand AS, Tosteson ANA. Comparison of EQ-5D, HUI, and SF-36derived societal health state values among spine patient outcomes research trial (SPORT) participants. Qual Life Res. 2005 Jun;14(5):1321-32.

40. Rudmik L, Hopkins C, Peters A, Smith TL, Schlosser RJ, Soler ZM. Patient-reported outcome measures for adult chronic rhinosinusitis: A systematic review and quality assessment. J Allergy Clin Immunol. 2015 Dec;136(6):1532-1540.e2.

41. Morley AD, Sharp HR. A review of sinonasal 
outcome scoring systems - which is best? Clin Otolaryngol. 2006 Apr;31(2):103-9.

42. van Oene CM, van Reij EJF, Sprangers MAG, Fokkens WJ. Quality-assessment of diseasespecific quality of life questionnaires for rhinitis and rhinosinusitis: a systematic review. Allergy. 2007 Dec;62(12):1359-71.

43. Hopkins C, Browne JP, Slack R, Lund V, Topham J, Reeves B, et al. The national comparative audit of surgery for nasal polyposis and chronic rhinosinusitis. Clin Otolaryngol. 2006 Oct;31(5):390-8.

44. Hopkins C, Gillett S, Slack R, Lund VJ, Browne JP. Psychometric validity of the 22-item Sinonasal Outcome Test. Clin Otolaryngol. 2009 Oct;34(5):447-54.

45. Juniper EF, Thompson AK, Ferrie PJ, Roberts JN. Development and validation of the mini Rhinoconjunctivitis Quality of Life Questionnaire. Clin Exp Allergy. 2000 Jan;30(1):132-40.

46. Segboer CL, Terreehorst I, Gevorgyan A, Hellings PW, van Drunen CM, Fokkens WJ. Quality of life is significantly impaired in nonallergic rhinitis patients. Allergy. 2018 May;73(5):1094-100.

47. Stewart $M$, Witsell $D L$, Smith $T L$, Weaver EM, Yueh B, Hannley MT. Development and validation of the nasal obstruction symptom evaluation (NOSE) scale1, *1. Otolaryngol Head Neck Surg. 2004 Feb;130(2):157-63.

48. Buckland JR, Thomas S, Harries PG. Can the Sino-nasal Outcome Test (SNOT-22) be used as a reliable outcome measure for successful septal surgery? Clin Otolaryngol Allied Sci. 2003 Feb;28(1):43-7.

49. Kosowski TR, McCarthy C, Reavey PL, Scott AM, Wilkins EG, Cano SJ, et al. A Systematic Review of Patient-Reported Outcome Measures after Facial Cosmetic Surgery and/ or Nonsurgical Facial Rejuvenation. Plast Reconstr Surg. 2009 Jun;123(6):1819-27.

50. Copas JB, Robin AA. The Facial Appearance Sorting Test (FAST): an aid to the selection of patients for rhinoplasty. Br J Plast Surg. 1989 Jan;42(1):65-9.

51. Hellings PW, Trenité GJN. Long-Term Patient Satisfaction After Revision Rhinoplasty. Laryngoscope. 2007 Jun;117(6):985-9.

52. Meningaud J-P, Lantieri L, Bertrand J-C. Rhinoplasty: An Outcome Research. Plast Reconstr Surg. 2008 Jan;121(1):251-7.

53. Abergel A, Fliss DM, Margalit N, Gil Z. A prospective evaluation of short-term healthrelated quality of life in patients undergoing anterior skull base surgery. Skull Base. 2010 Jan 22;20(1):27-33.

54. Cho JH, Suh JD, Kim JK, Hong SC, Park IH, Lee HM. Correlation between skin-prick testing, individual specific lgE tests, and a multiallergen IgE assay for allergy detection in patients with chronic rhinitis. Am J Rhino Allergy. 2014 Sep;28(5):388-91.

55. Haxel BR, Huppertz T, Boessert P, Bast F, Fruth K. Correlation of Skin Test Results and Specific Immunoglobulin E Blood Levels with Nasal Provocation Testing for House-
Dust Mite Allergies. Am J Rhinol Allergy 2016 Jan;30(1):60-4.

56. Lewis AF, Franzese C, Stringer SP. Diagnostic Evaluation of Inhalant Allergies: A Costeffectiveness Analysis. Am J Rhinol. 2008 May;22(3):246-52.

57. Gera C, Kumar N. Otolaryngologic Manifestations of Various Rheumatic Diseases: Awareness and Practice Among Otolaryngologists. Indian J Otolaryngol Head Neck Surg. 2015 Dec;67(4):366-9.

58. Lutalo PMK, D'Cruz DP. Diagnosis and classification of granulomatosis with polyangiitis (aka Wegener's granulomatosis). J Autoimmun. 2014 Feb;48-49:94-8.

59. Greco A, Marinelli C, Fusconi M, Macr GF, Gallo A, De Virgilio A, et al. Clinic manifestations in granulomatosis with polyangiitis. Int J Immunopathol Pharmacol. 2016 Jun;29(2):151-9.

60. Eren E, Kalkan T, Arslanoğlu S, Özmen M, Önal K, Tarhan EF, et al. Clinical Factors Associated with the Diagnosis of Granulomatosis with Polyangiitis. Otolaryngol Neck Surg. 2017 Mar 10;156(3):484-8.

61. Cornec D, Gall EC-L, Fervenza FC, Specks U. ANCA-associated vasculitis - clinical utility of using ANCA specificity to classify patients. Nat Rev Rheumatol. 2016 Oct 28;12(10):5709.

62. Seccia V, Baldini C, Latorre M, Gelardi M Dallan I, Cristofani-Mencacci L, et al. Focus on the Involvement of the Nose and Paranasal Sinuses in Eosinophilic Granulomatosis with Polyangiitis (Churg-Strauss Syndrome): Nasal Cytology Reveals Infiltration of Eosinophils as a Very Common Feature. Int Arch Allergy Immunol. 2018;175(1-2):61-9.

63. Oommen E, Hummel A, Allmannsberger L, Cuthbertson D, Carette S, Pagnoux C, et al. IgA antibodies to myeloperoxidase in patients with eosinophilic granulomatosis with polyangiitis (Churg-Strauss). Clin Exp Rheumatol. 35 Suppl 103(1):98-101.

64. Gungor S, Ozseker F, Yalcinsoy M, Akkaya E, Can G, Eroglu H, et al. Conventional markers in determination of activity of sarcoidosis. Int Immunopharmacol. 2015 Mar;25(1):174-9.

65. Thi Hong Nguyen C, Kambe N, Kishimoto I, Ueda-Hayakawa I, Okamoto H. Serum soluble interleukin-2 receptor level is more sensitive than angiotensin-converting enzyme or lysozyme for diagnosis of sarcoidosis and may be a marker of multiple organ involvement. J Dermatol. 2017 Jul:44(7):789-97.

66. Brook CD, Maxfield AZ, Stankovic K, Metson RB. The Impact of AngiotensinModulating Antihypertensives on Time Interval to Revision Surgery for Nasal Polyps. Otolaryngol - Head Neck Surg (United States). 2016 Dec 3;155(6):1046-52.

67. Izuhara K, Ohta S, Ono J. Using Periostin as a Biomarker in the Treatment of Asthma. Allergy Asthma Immunol Res. 2016 Nov:8(6):491-8.

68. Izuhara $\mathrm{K}$, Matsumoto $\mathrm{H}$, Ohta S, Ono J,
Arima K, Ogawa M. Recent developments regarding periostin in bronchial asthma. Allergol Int. 2015 Sep 1;64:S3-10.

69. Baenkler H-W. Functional-eicosanoid-test (FET) and disease. J Physiol Pharmacol. 2006 Dec;57(S1):65-72

70. Kim MS, Cho YJ. Flow Cytometry-Assisted Basophil Activation Test as a Safe Diagnostic Tool for Aspirin/NSAID Hypersenstivity. Allergy Asthma Immunol Res. 2012 May;4(3):137-42.

71. Kerkhof M, Droste JH, de Monchy JG, Schouten JP, Rijcken B. Distribution of total serum $\lg E$ and specific IgE to common aeroallergens by sex and age, and their relationship to each other in a random sample of the Dutch general population aged 20-70 years. Dutch ECRHS Group, European Community Respiratory Health Study. Allergy. 1996 Nov;51(11):770-6.

72. From the Board of Directors. Allergen skin testing. J Allergy Clin Immunol. 1993 Nov 1;92(5):636-7.

73. Bernstein IL, Li JT, Bernstein DI, Hamilton $R_{\text {, }}$ Spector SL, Tan R, et al. Allergy diagnostic testing: an updated practice parameter [Internet]. Vol. 100, Annals of Allergy, Asthma and Immunology. 2008. p. S1-148.

74. Heinzerling L, Mari A, Bergmann K-C, Bresciani M, Burbach G, Darsow U, et al. The skin prick test - European standards. Clin Transl Allergy. 2013 Dec 1;3(1):3.

75. Klimek L, Werfel T, Vogelberg C, Jung K. Authorised allergen products for intracutaneous testing may no longer be available in Germany: Allergy textbooks have to be re-written. Allergo J Int. 2015;24(3):8493.

76. The European Academy of Allergology and Clinical Immunology. Position paper: Allergen standardization and skin tests. Allergy. 1993;48(14 Suppl):48-82.

77. Cardona V, Demoly P, Dreborg S, Kalpaklioglu AF, Klimek L, Muraro A, et al. Current practice of allergy diagnosis and the potential impact of regulation in Europe. Allergy Eur J Allergy Clin Immunol. 2018 Feb;73(2):323-7.

78. Klimek L, Hoffmann HJ, Renz H, Demoly P, Werfel T, Matricardi PM, et al. Diagnostic test allergens used for in vivo diagnosis of allergic diseases are at risk: a European Perspective. Allergy. 2015 Oct;70(10):1329-31.

79. CommitteeforMedicinal Products for Human Use (CHMP) Guideline on Allergen Products: Production and Quality Issues. Draft Agreed by Biologics Working Party Adoption by CHMP for Release for Consultation [Internet]. 2008. Available at https://www.ema.europa. eu/en/documents/scientific-guideline/ guideline-clinical-development-productsspecific-immunotherapy-treatmentallergic-diseases_en.pdf

80. Zuberbier T, Werfel T. Is European legislation killing allergy diagnostics? Curr Opin Allergy Clin Immunol. 2012 Oct;12(5):475-6.

81. Bousquet J, Heinzerling L, Bachert C, Papadopoulos NG, Bousquet PJ, Burney 
$P G$, et al. Practical guide to skin prick tests in allergy to aeroallergens. Allergy Eur J Allergy Clin Immunol. 2012 Jan;67(1):1824.

82. Engler DB, DeJarnatt AC, Sim TC, Lee JL, Grant JA. Comparison of the sensitivity and precision of four skin test devices. J Allergy Clin Immunol. 1992 Dec;90(6 Pt 1):985-91.

83. Heinzerling LM, Burbach GJ, Edenharter G, Bachert C, Bindslev-Jensen C, Bonini S et al. GA 2 LEN skin test study l: GA2LEN harmonization of skin prick testing: novel sensitization patterns for inhalant allergens in Europe. Allergy. 2009 Oct;64(10):1498506.

84. Nelson HS, Rosloniec DM, McCall LI, Iklé D. Comparative performance of five commercial prick skin test devices. J Allergy Clin Immunol. 1993 Nov 1;92(5):750-6.

85. Burbach GJ, Heinzerling LM, Edenharter $G$ Bachert C, Bindslev-Jensen C, Bonini S, et al. GA2LEN skin test study II: Clinical relevance of inhalant allergen sensitizations in Europe. Allergy Eur J Allergy Clin Immunol. 2009 Oct;64(10):1507-15.

86. Ruëff $F$, Bergmann $K-C$, Brockow $K$ Fuchs T, Grübl A, Jung K, et al. Hauttests zur Diagnostik von allergischen Soforttypreaktionen. Allergo J. 2010 Sep 2;19(6):402-15.

87. Möbs C, Wiedemann D, Pfützner W Evaluation of a modified skin prick test for diagnosis of Hymenoptera venom allergy. Allergo J Int. 2018 Jun 13;1-7.

88. Dreborg S. Histamine reactivity of the skin. Allergy. 2001 May;56(5):359-64.

89. Interdisziplinare Arbeitsgruppe "Allergische Rhinitis" der Sektion HNO. Allergische Rhinokonjunktivitis - Leitlinie der Deutschen Gesellschaft für Allergologie und klinische Immunologie (DGAl). Allergo J Int. 2003:12:182-94.

90. Fisher MM, Bowey CJ. Intradermal compared with prick testing in the diagnosis of anaesthetic allergy. $\mathrm{Br} \mathrm{J}$ Anaesth. 1997 Jul;:79(1):59-63.

91. Jeep S, Reiprich G, Kunkel G. Yellow jacket allergy. Comparison of skin prick tests and intradermal tests with three different yellow jacket venom extracts. Allergy. 1992 Feb;47(1):35-40.

92. McKay SP, Meslemani D, Stachler RJ, Krouse $\mathrm{JH}$. Intradermal positivity after negative prick testing for inhalants. Otolaryngol Neck Surg. 2006 Aug 17;135(2):232-5.

93. Wood RA, Phipatanakul W, Hamilton RG, Eggleston PA. A comparison of skin prick tests, intradermal skin tests, and RASTs in the diagnosis of cat allergy. J Allergy Clin Immunol. 1999 May:103(5 Pt 1):773-9.

94. Augé J, Vent J, Agache I, Airaksinen L, Campo Mozo P, Chaker A, et al. EAACl Position paper on the standardization of nasal allergen challenges. Allergy. 2018 Aug 1;73(8):1597-608.

95. Pelikan Z. Cellular changes in tears associated with keratoconjunctival responses induced by nasal allergy. Eye (Lond). 2014 Apr;28(4):430-8

96. Fauquert J-L, Jedrzejczak-Czechowicz M, Rondon C, Calder V, Silva D, Kvenshagen BK, et al. Conjunctival allergen provocation test: guidelines for daily practice. Allergy. 2017 Jan;72(1):43-54.

97. Riechelmann H, Epple B, Gropper G. Comparison of Conjunctival and Nasal Provocation Test in Allergic Rhinitis to House Dust Mite. Int Arch Allergy Immunol. 2003 Jan;130(1):51-9.

98. Gronemeyer U. Der konjunktivale Provokationstest (CPT). In: Fuchs E, Schulz $\mathrm{KH}$, editors. Manuale allergologicum. Dustri-Verlag; 1994. p. 1-6.

99. Worm M, Higenbottam T, Pfaar O, Mösges R, Aberer W, Gunawardena K, et al. Randomized controlled trials define shape of dose response for Pollinex Quattro Birch allergoid immunotherapy. Allergy. 2018 Sep;73(9):1812-22

100. Ishizaka K, Ishizaka T. Identification of gamma-E-antibodies as a carrier of reaginic activity. J Immunol. 1967 Dec;99(6):118798.

101. Matricardi PM, Kleine-Tebbe J, Hoffmann HJ, Valenta R, Hilger C, Hofmaier S, et al. EAACI Molecular Allergology User's Guide. Pediatr Allergy Immunol. 2016 May;27:1250.

102. Wide L, Bennich H, Johansson SG. Diagnosis of allergy by an in-vitro test for allergen antibodies. Lancet (London, England). 1967 Nov 25;2(7526):1105-7.

103. Hamilton RG. Clinical laboratories worldwide need to report lgE antibody results on clinical specimens as analytical results and not use differential positive thresholds. J Allergy Clin Immunol. 2015 Sep 1;136(3):811-2.

104. Kleine-Tebbe J, Jakob T. Molecular allergy diagnostics using lgE singleplex determinations: methodological and practical considerations for use in clinical routine. Allergo J Int. 2015 Oct 28;24(6):185-97.

105. Stemeseder T, Hemmer W, Hawranek T, Gadermaier G. Marker allergens of weed pollen - basic considerations and diagnostic benefits in the clinical routine: Part 16 of the Series Molecular Allergology. Allergo J Int. 2014;23(8):274-80.

106. Valenta R, Lidholm J, Niederberger V, Hayek $B$, Kraft $D$, Grönlund $H$. The recombinant allergen-based concept of componentresolved diagnostics and immunotherapy (CRD and CRIT). Clin Exp Allergy. 1999 Jul;29(7):896-904.

107. Gangl K, Niederberger V, Valenta R, Nandy A. Marker allergens and panallergens in tree and grass pollen allergy. Allergo J Int. 2015 Aug 5;24(5):158-69

108. Matricardi PM, Kleine-Tebbe J. Molecular Allergology between Precision Medicine and the Choosing Wisely initiative. Clin Exp Allergy. 2016 May 1;46(5):664-7.
109. Mirnezami R, Nicholson J, Darzi A. Preparing for Precision Medicine. N Engl J Med. 2012 Feb 9;366(6):489-91.

110. Mari A. Importance of Databases in Experimental and Clinical Allergology. Int Arch Allergy Immunol. 2005 Sep;138(1):8896.

111. Mari A, Scala E. Allergome: a unifying platform. Arb Paul Ehrlich Inst Bundesamt Sera Impfstoffe Frankf AM. 2006;(95):29-39; discussion 39-40.

112. De Knop KJ, Bridts $\mathrm{CH}$, Verweij MM, Hagendorens MM, De Clerck LS, Stevens WJ, et al. Component-resolved allergy diagnosis by microarray: potential, pitfalls, and prospects. Adv Clin Chem. 2010;50:87101

113. Thorpe SJ, Heath A, Fox B, Patel D, Egner W. The 3rd International Standard for serum IgE: international collaborative study to evaluate a candidate preparation. Clin Chem Lab Med. 2014 Jan 1;52(9):1283-9.

114. Powe DG, Jagger C, Kleinjan A, Carney AS, Jenkins D, Jones NS. "Entopy": localized mucosal allergic disease in the absence of systemic responses for atopy. Clin Exp Allergy. 2003 Oct;33(10):1374-9.

115. Rondón C, Romero JJ, López S, Antúnez C, Martín-Casañez E, Torres MJ, et al. Local lgE production and positive nasal provocation test in patients with persistent nonallergic rhinitis. J Allergy Clin Immunol. 2007 Apr;119(4):899-905.

116. Eberlein B, Santos AF, Mayorga C, Nopp A, Ferrer M, Rouzaire P, et al. Basophil activation testing in diagnosis and monitoring of allergic disease - an overview. Allergo J Int. 2016 Jun 25:25(4):106-13.

117. Hoffmann HJ, Santos AF, Mayorga C, Nopp A, Eberlein B, Ferrer $M$, et al. The clinical utility of basophil activation testing in diagnosis and monitoring of allergic disease. Allergy. 2015 Nov;70(11):1393-405.

118. Leach AJ, Stubbs E, Hare K, Beissbarth J, Morris PS. Comparison of Nasal Swabs with Nose Blowing for Community-Based Pneumococcal Surveillance of Healthy Children. J Clin Microbiol. 2008 Jun 1;46(6):2081-2.

119. van den Bergh MR, Bogaert D, Dun L, Vons J, Chu ML, Trzcinski K, et al. Alternative sampling methods for detecting bacterial pathogens in children with upper respiratory tract infections. J Clin Microbiol. 2012;50(12):4134-7.

120. Benninger MS, Payne SC, Ferguson BJ, Hadley JA, Ahmad N. Endoscopically directed middle meatal cultures versus maxillary sinus taps in acute bacterial maxillary rhinosinusitis: a metaanalysis. Otolaryngol Head Neck Surg. 2006;134(1):3-9.

121. Dubin MG, Ebert CS, Coffey CS, Melroy CT, Sonnenburg RE, Senior BA. Concordance of middle meatal swab and maxillary sinus aspirate in acute and chronic sinusitis: a meta-analysis. Am J Rhinol. 2005;19(5):462- 
70.

122. Hsin $\mathrm{CH}$, Su MC, Tsao $\mathrm{CH}$, Chuang $\mathrm{CY}$, Liu CM. Bacteriology and antimicrobial susceptibility of pediatric chronic rhinosinusitis: a 6-year result of maxillary sinus punctures. Am J Otolaryngol. 2010;31(3):145-9.

123. Ikeda K, Ono N, lizuka T, Kase K, Minekawa A, Inoshita A, et al. Bacteriologic evaluation of sinus aspirates taken by balloon catheter devices in chronic rhinosinusitis: preliminary study. ORL J Otorhinolaryngol Relat Spec. 2011;73(5):271-4.

124. Miller C, Davis GE. Are multiple sinus cultures necessary during sinus surgery for chronic rhinosinusitis? Int Forum Allergy Rhinol. 2018;8(4):504-8,

125. Bassiouni A, Cleland EJ, Psaltis AJ, Vreugde $\mathrm{S}$, Wormald PJ. Sinonasal microbiome sampling: a comparison of techniques. PLoS One. 2015;10(4):e0123216.

126. Hauser LJ, Feazel LM, Ir D, Fang R, Wagner $\mathrm{BD}$, Robertson CE, et al. Sinus culture poorly predicts resident microbiota. Int Forum Allergy Rhinol. 2015;5(1):3-9.

127. Ahovuo-Saloranta A, Rautakorpi UM, Borisenko $O V$, Liira $H$, Williams Jr. JW, Makela M. Antibiotics for acute maxillary sinusitis in adults. Cochrane Database Syst Rev. 2014;(2):CD000243.

128. Landis BN, Hummel $T$, Hugentobler $M$, Giger R, Lacroix JS. Ratings of overall olfactory function. Chem Senses. 2003 Oct;28(8):691-4.

129. Philpott C, Wolstenholme C, Goodenough P, Clark A, Murty G. Comparison of Subjective Perception with Objective Measurement of Olfaction. Otolaryngol - Head Neck Surg. 2006 Mar;134(3):488-90.

130. Haxel BR, Bertz-Duffy S, Fruth K, Letzel S, Mann WJ, Muttray A. Comparison of subjective olfaction ratings in patients with and without olfactory disorders. J Laryngol Otol. 2012 Jul 16:126(07):692-7.

131. Delank KW, Stoll W. Olfactory function after functional endoscopic sinus surgery for chronic sinusitis. Rhinology. 1998 Mar;36(1):15-9.

132. Welge-Luessen A, Hummel $T$, Stojan $T$, Wolfensberger M. What is the Correlation between Ratings and Measures of Olfactory Function in Patients with Olfactory Loss? Am J Rhinol. 2005 Nov 9;19(6):567-71.

133. Soter A, Kim J, Jackman A, Tourbier I, Kaul A, Doty RL. Accuracy of SelfReport in Detecting Taste Dysfunction. Laryngoscope. 2008 Apr;1 18(4):611-7.

134. Hummel $T$, Whitcroft $K L$, Andrews $P$, Altundag A, Cinghi C, Costanzo RM, et al. Position paper on olfactory dysfunction. Rhinol Suppl. 2017;54(26):1-30.

135. Cain WS. To know with the nose: Keys to odor identification. Science (80- ). 1979 Feb 2;203(4379):467-70

136. Doty RL, Shaman P, Kimmelman CP, Dann MS. University of Pennsylvania Smell Identification Test: a rapid quantitative olfactory function test for the clinic Laryngoscope. 1984 Feb;94(2 Pt 1):176-8.

137. Cain WS, Goodspeed RB, Gent JF, Leonard G. Evaluation of olfactory dysfunction in the Connecticut Chemosensory Clinical Research Center. Laryngoscope. 1988 Jan;98(1):83-8

138. Cardesín A, Alobid I, Benítez P, Sierra E, de Haro J, Bernal-Sprekelsen M, et al. Barcelona Smell Test - 24 (BAST-24): validation and smell characteristics in the healthy Spanish population. Rhinology. 2006 Mar;44(1):839

139. Doty RL, Shaman P, Dann M Development of the University of Pennsylvania Smell Identification Test: a standardized microencapsulated test of olfactory function. Physiol Behav. 1984 Mar;32(3):489-502

140. Haehner A, Mayer A-M, Landis BN Pournaras I, Lill K, Gudziol V, et al. High TestRetest Reliability of the Extended Version of the \&quot;Sniffin' Sticks\&quot; Test. Chem Senses. 2009 Oct 1;34(8):705-11.

141. Freiherr J, Gordon AR, Alden EC, Ponting AL, Hernandez MF, Boesveldt S, et al. The 40-item Monell Extended Sniffin' Sticks Identification Test (MONEX-40). J Neurosci Methods. 2012 Mar 30;205(1):10-6

142. Klimek L, Hummel T, Moll B, Kobal G, Mann WJ. Lateralized and bilateral olfactory function in patients with chronic sinusitis compared with healthy control subjects. Laryngoscope. 1998 Jan;108(1 Pt 1):111-4.

143. Menashe I, Man O, Lancet D, Gilad Y Different noses for different people. Nat Genet. 2003 Jun 5:34(2):143-4.

144. Kobal G, Hummel T, Sekinger B, Barz S, Roscher S, Wolf S. "Sniffin' sticks": screening of olfactory performance. Rhinology. 1996 Dec;34(4):222-6.

145. Doty RL, Gregor TP, Settle RG. Influence of intertrial interval and sniff-bottle volume on phenyl ethyl alcohol odor detection thresholds. Chem Senses. 1986 May 1;11(2):259-64.

146. Hummel T, Kobal G, Gudziol H, Mackay-Sim A. Normative data for the "Sniffin' Sticks" including tests of odor identification, odor discrimination, and olfactory thresholds: an upgrade based on a group of more than 3,000 subjects. Eur Arch Oto-RhinoLaryngology. 2007 Feb 2;264(3):237-43.

147. Landis BN, Negoias S, Friedrich $H$ Chemosensorisch evozierte Potenziale Chemosensory Event Related Potentials [Internet]. Vol. 33, Epileptologie. 2016.

148. Deems DA, Doty RL, Settle RG, MooreGillon V, Shaman P, Mester AF, et al. Smell and taste disorders, a study of 750 patients from the University of Pennsylvania Smell and Taste Center. Arch Otolaryngol Head Neck Surg. 1991 May;117(5):519-28.

149. Pfaar $\mathrm{O}$, Landis BN, Frasnelli J, Hüttenbrink K-B, Hummel T. Mechanical Obstruction of the Olfactory Cleft Reveals Differences Between Orthonasal and Retronasal
Olfactory Functions. Chem Senses. 2006 Jan 1;31(1):27-31.

150. Landis BN, Giger R, Ricchetti A, Leuchter I, Hugentobler M, Hummel T, et al. Retronasal olfactory function in nasal polyposis. Laryngoscope. 2003 Nov;113(11):1993-7.

151. Güttich H. Intravenös verabreichte Riechstoffe: Gustatorisches Riechen. HNO. 1965;13(2):42-5.

152. Heilmann S, Strehle G, Rosenheim K, Damm M, Hummel T. Clinical assessment of retronasal olfactory function. Arch Otolaryngol Head Neck Surg. 2002 Apr;128(4):414-8.

153. Croy I, Hoffmann H, Philpott C, Rombaux P, Welge-Luessen A, Vodicka J, et al. Retronasal testing of olfactory function: an investigation and comparison in seven countries. Eur Arch Oto-RhinoLaryngology. 2014 May 3;271(5):1087-95.

154. Hedner M, Larsson M, Arnold N, Zucco GM, Hummel T. Cognitive factors in odor detection, odor discrimination, and odor identification tasks. J Clin Exp Neuropsychol. 2010 Dec 8;32(10):1062-7.

155. Lotsch J, Reichmann H, Hummel T. Different Odor Tests Contribute Differently to the Evaluation of Olfactory Loss. Chem Senses. 2008 Jan 1;33(1):17-21.

156. Bromley SM, Doty RL. Odor Recognition Memory Is Better Under Bilateral Than Unilateral Test Conditions. Cortex. 1995 Mar;31(1):25-40

157. Frank RA, Dulay MF, Gesteland RC. Assessment of the Sniff Magnitude Test as a clinical test of olfactory function. Physiol Behav. 2003 Feb;78(2):195-204

158. Gudziol H, Wächter R. Gibt es olfaktorisch evozierte Atemänderungen? LaryngoRhino-Otologie. 2004 Jun;83(6):367-73.

159. van Spronsen E, Ebbens FA, Fokkens WJ. Olfactory Function in Healthy Children: Normative Data for Odor Identification. Am J Rhinol Allergy. 2013 May 1;27(3):197-201.

160. Schriever VA, Mori E, Petters W, Boerner C, Smitka M, Hummel T. The "Sniffin" Kids" Test - A 14-Item Odor Identification Test for Children." PLoS One. 2014:9(6).

161. Schriever VA, Agosin E, Altundag A, Avni H, Cao Van H, Cornejo C, et al. Development of an International Odor Identification Test for Children: The Universal Sniff Test. J Pediatr. 2018 Jul;198:265-272.e3.

162. Poncelet J, Rinck F, Bourgeat F, Schaal $B$ Rouby $C$, Bensafi $M$, et al. The effect of early experience on odor perception in humans: Psychological and physiological correlates. Behav Brain Res. 2010 Apr 2;208(2):458-65.

163. Hsieh JW, Keller A, Wong M, Jiang R-S, Vosshall LB. SMELL-S and SMELL-R: Olfactory tests not influenced by odorspecific insensitivity or prior olfactory experience. Proc Natl Acad Sci. 2017 Oct 24;114(43):11275-84

164. Oleszkiewicz A, Pellegrino $R$, Pusch $K$, Margot C, Hummel T. Chemical complexity of odors increases reliability of olfactory 
threshold testing. Sci Rep. 2017;7:39977.

165. Kobal G. Elektrophysiologische Untersuchungen des menschlichen Geruchssinns. Thieme Verlag; 1981. p. $1-161$

166. Rombaux P, Mouraux A, Collet S, Eloy $P_{i}$ Bertrand B. Usefulness and feasibility of psychophysical and electrophysiological olfactory testing in the rhinology clinic. Rhinology. 2009 Mar;47(1):28-35.

167. Rombaux P, Huart C, Mouraux A Assessment of chemosensory function using electroencephalographic techniques. Rhinology. 2012 Mar;50(1):1321.

168. Yarmolinsky DA, Zuker CS, Ryba NJP Common Sense about Taste: From Mammals to Insects. Cell. 2009 Oct 16;139(2):234-44.

169. Zocchi D, Wennemuth G, Oka Y. The cellular mechanism for water detection in the mammalian taste system. Nat Neurosci. 2017 May 29;20(7):927-33.

170. Pilková L, Nováková M, Pokorný J. Naming and identification of tastes in aqueous solutions. Food / Nahrung. 1991 Jan 1;35(9):999-1002.

171. Krarup B. On the Technique of Gustatory Examinations. Acta Otolaryngol. 1958 Jan 8:49(sup140):195-200.

172. Murphy C, Quiñonez C, Nordin S. Reliability and validity of electrogustometry and its application to young and elderly persons. Chem Senses. 1995 Oct;20(5):499-503.

173. Ahne G, Erras A, Hummel T, Kobal G. Assessment of Gustatory Function by Means of Tasting Tablets. Laryngoscope. 2000 Aug;110(8):1396-401.

174. Hummel T, Erras A, Kobal G. A test for the screening of taste function. Rhinology. 1997 Dec;35(4):146-8.

175. Mueller C, Kallert S, Renner B, Stiassny K, Temmel AFP, Hummel T, et al. Quantitative assessment of gustatory function in a clinical context using impregnated "taste strips". Rhinology. 2003 Mar;41(1):2-6.

176. Landis BN, Welge-Luessen $A$, Brämerson $A$ Bende M, Mueller CA, Nordin S, et al. "Taste Strips" - A rapid, lateralized, gustatory bedside identification test based on impregnated filter papers. J Neurol. 2009 Feb 7:256(2):242-8.

177. Kobal G. Gustatory evoked potentials in man. Electroencephalogr Clin Neurophysiol. 1985 Nov;62(6):449-54.

178. Hummel T, Genow A, Landis BN. Clinical assessment of human gustatory function using event related potentials. J Neurol Neurosurg Psychiatry. 2010 Apr 1;81(4):459-64.

179. Iannilli E, Noennig N, Hummel T, Schoenfeld AM. Spatio-temporal correlates of taste processing in the human primary gustatory cortex. Neuroscience. 2014 Jul 25:273:92-9.

180. Dalton P, Doolittle N, Nagata H, Breslin PAS. The merging of the senses: integration of subthreshold taste and smell. Nat Neurosci.
2000 May 1;3(5):431-2.

181. Daiber P, Genovese F, SchrieverVA, Humme T, Möhrlen F, Frings S. Neuropeptide receptors provide a signalling pathway for trigeminal modulation of olfactory transduction. Eur J Neurosci. 2013 Feb;37(4):572-82.

182. Landis BN, Scheibe M, Weber C, Berger R, Brämerson $\mathrm{A}$, Bende $\mathrm{M}$, et al. Chemosensory interaction: acquired olfactory impairment is associated with decreased taste function. J Neurol. 2010 Aug 11;257(8):1303-8.

183. Frasnelli J, Hummel T. Interactions between the chemical senses: Trigeminal function in patients with olfactory loss. Int Psychophysiol. 2007 Sep;65(3):177-81.

184. Scheibe M, Schulze S, Mueller CA, Schuster B, Hummel T. Intranasal trigeminal sensitivity: measurements before and after nasal surgery. Eur Arch Oto-RhinoLaryngology. 2014 Jan 9;271 (1):87-92.

185. Konstantinidis I, Tsakiropoulou $E_{4}$ Chatziavramidis A, Ikonomidis C, Markou K. Intranasal trigeminal function in patients with empty nose syndrome. Laryngoscope. 2017 Jun;127(6):1263-7.

186. Hummel T. Assessment of intranasal trigeminal function. Int J Psychophysiol. 2000 May:36(2):147-55.

187. Hummel $T$, Futschik $T$, Frasnelli J, Hüttenbrink K-B. Effects of olfactory function, age, and gender on trigeminally mediated sensations: a study based on the lateralization of chemosensory stimuli. Toxicol Lett. 2003 Apr 11;140-141:273-80.

188. HummelT, Kaehling C, Grosse F. Automated assessment of intranasal trigeminal function. Rhinology. 2016 Mar;54(1):27-31.

189. Naka A, Wolf A, Renner B, Mueller CA. A Novel Device for the Clinical Assessment of Intranasal Trigeminal Sensitivity. Ann Otol Rhinol Laryngol. 2014 Jun 1;123(6):428-33.

190. Rombaux P, Mouraux A, Keller T, Hummel T. Trigeminal event-related potentials in patients with olfactory dysfunction. Rhinology. 2008 Sep:46(3):170-4

191. Lund VJ, Stammberger H, Fokkens WJ, Beale $T$, Bernal-Sprekelsen $M$, Eloy $P_{\text {, }}$ et al. European position paper on the anatomical terminology of the internal nose and paranasal sinuses. Rhinol Suppl. 2014;24:1-34.

192. Wormald PJ, Bassiouni A, Callejas CA, Kennedy DW, Citardi MJ, Smith TL, et al. The International Classification of the radiological Complexity (ICC) of frontal recess and frontal sinus. Int Forum Allergy Rhinol. 2017 Apr;7(4):332-7.

193. Zinreich SJ, Kennedy DW, Rosenbaum AE, Gayler BW, Kumar AJ, Stammberger $H$. Paranasal sinuses: $\mathrm{CT}$ imaging requirements for endoscopic surgery. Radiology. 1987 Jun;163(3):769-75.

194. Savy L, Lloyd G, Lund VJ, Howard D. Optimum imaging for inverted papilloma. J Laryngol Otol. 2000 Nov; 1 14(11):891-3.

195. Orlandi RR, Kingdom TT, Hwang PH, Smith
TL, Alt JA, Baroody FM, et al. International Consensus Statement on Allergy and Rhinology: Rhinosinusitis. Int Forum Allergy Rhinol. 2016 Feb;6(S1):S22-209.

196. Sodickson A. CT radiation risks coming into clearer focus. BMJ. 2013 May 21;346(may21 1):f3102-f3102.

197. Bulla S, Blanke P, Hassepass F, Krauss T, Winterer JT, Breunig C, et al. Reducing the radiation dose for low-dose $\mathrm{CT}$ of the paranasal sinuses using iterative reconstruction: Feasibility and image quality. Eur J Radiol. 2012 Sep;81(9):224650.

198. Bologna M, Montin E, Corino VDA, Bossi P, Calareso G, Licitra L, et al. Use of apparent diffusion coefficient images to predict response to induction chemotherapy in sinonasal cancer. In: 2018 40th Annual International Conference of the IEEE Engineering in Medicine and Biology Society (EMBC). IEEE; 2018. p. 782-5.

199. Jiang J, Xiao Z, Tang Z, Zhong Y, Qiang J. Differentiating between benign and malignant sinonasal lesions using dynamic contrast-enhanced MRI and intravoxel incoherent motion. Eur J Radiol. 2018 Jan;98:7-13.

200. Stankiewicz JA, Chow JM. Nasal Endoscopy and the Definition and Diagnosis of Chronic Rhinosinusitis. Otolaryngol Neck Surg. 2002 Jun;126(6):623-7.

201. LundVJ, MackayIS. Staging in rhinosinusitus. Rhinology. 1993 Dec;31 (4):183-4

202. Metson R, Gliklich RE, Stankiewicz JA, Kennedy DW, Duncavage JA, Hoffman $\mathrm{SR}$, et al. Comparison of Sinus Computed Tomography Staging Systems. Otolaryngol Neck Surg. 1997 Oct 21;117(4):372-9.

203. Oluwole M, Russell N, Tan L, Gardiner Q White P. A comparison of computerized tomographic staging systems in chronic sinusitis. Clin Otolaryngol Allied Sci. 1996 Feb:21(1):91-5.

204. Lloyd GAS, Lund VJ, Scadding GK. CT of the paranasal sinuses and functional endoscopic surgery: a critical analysis of 100 symptomatic patients. J Laryngol Otol. 1991 Mar 29;105(03):181-5.

205. Jones NS, Strobl A, Holland I. A study of the CT findings in 100 patients with rhinosinusitis and 100 controls. Clin Otolaryngol Allied Sci. 1997 Feb;22(1):4751.

206. Reittner P, Doerfler O, Goritschnig T, Tillich M, Koele W, Stammberger $\mathrm{H}$, et al. Magnetic resonance imaging patterns of the development of the sphenoid sinus: a review of 800 patients. Rhinology. 2001 Sep;39(3):121-4.

207. Gwaltney JM, Phillips CD, Miller RD, Riker DK. Computed Tomographic Study of the Common Cold. N Engl J Med. 1994 Jan 6:330(1):25-30

208. Leopold AD, Stafford TC, Sod WE, Szeverenyi MN, Allison DJ, Phipps JR, et al. Clinical Course of Acute Maxillary Sinusitis 
Documented by Sequential MRI Scanning Am J Rhinol. 1994 Jan 1;8(1):19-28.

209. Ashraf N, Bhattacharyya N. Determination of the "Incidental" Lund Score for the Staging of Chronic Rhinosinusitis. Otolaryngol Neck Surg. 2001 Nov;125(5):483-6.

210. Bhattacharyya N, Fried MP. The accuracy of computed tomography in the diagnosis of chronic rhinosinusitis. Laryngoscope. 2003 Jan;113(1):125-9.

211. Lin HW, Bhattacharyya N. Diagnostic and Staging Accuracy of Magnetic Resonance Imaging for the Assessment of Sinonasal Disease. Am J Rhinol Allergy. 2009 Jan;23(1):36-9.

212. Varonen $H$, Savolainen S, Kunnamo I, Heikkinen R, Revonta M. Acute rhinosinusitis in primary care: a comparison of symptoms, signs, ultrasound, and radiography. Rhinology. 2003 Mar;41(1):3743.

213. Hamizan AW, Loftus PA, Alvarado R, Ho J, Kalish L, Sacks R, et al. Allergic phenotype of chronic rhinosinusitis based on radiologic pattern of disease. Laryngoscope. 2018 Sep;128(9):2015-21.

214. Lloyd G, Howard D, Lund V, Savy L. Imaging for juvenile angiofibroma. J Laryngol Otol. 2000 Sep 8;114(09):727-30.

215. Bhalla RK, Wright ED. Predicting the site of attachment of sinonasal inverted papilloma. Rhinology. 2009 Dec 1:47(4):345-8.

216. Lund VJ, Howard DJ, Lloyd GA, Cheesman AD. Magnetic resonance imaging of paranasal sinus tumors for craniofacial resection. Head Neck. 11(3):279-83.

217. Rombaux P, Duprez T, Hummel T. Olfactory bulb volume in the clinical assessment of olfactory dysfunction. Rhinology. 2009 Mar:47(1):3-9

218. Veyseller B, Aksoy F, Yildirim YS, Bayraktar FGl, Gurbuz D, Savas Y, et al. Reduced olfactory bulb volume in total laryngectomy patients: a magnetic resonance imaging study. Rhinology. 2011 Mar;49(1):112-6.

219. Hopkins C, Browne JP, Slack R, Lund V, Brown P. The Lund-Mackay staging system for chronic rhinosinusitis: How is it used and what does it predict? Otolaryngol Neck Surg. 2007 Oct 17;137(4):555-61.

220. Brooks SG, Trope M, Blasetti M, Doghramji L, Parasher A, Glicksman JT, et al. Preoperative Lund-Mackay computed tomography score is associated with preoperative symptom severity and predicts qualityof-life outcome trajectories after sinus surgery. Int Forum Allergy Rhinol. 2018 Jun;8(6):668-75.

221. Videler WJM, Georgalas C, Menger DJ, Freling NJM, van Drunen CM, Fokkens WJ. Osteitic bone in recalcitrant chronic rhinosinusitis. Rhinology. 2011 Jun:49(2):139-47.

222. Sacks $P-L$, Snidvongs $K$, Rom $D$, Earls $P$, Sacks R, Harvey RJ. The impact of neoosteogenesis on disease control in chronic rhinosinusitis after primary surgery. Int Forum Allergy Rhinol. 2013 Oct;3(10):8237.

223. Bayonne E, Kania R, Tran P, Huy B, Herman P. Intracranial complications of rhinosinusitis. A review, typical imaging data and algorithm of management*. Rhinology. 2009:47(1):59-65.

224. Jaume F, Quintó L, Alobid I, Mullol J. Overuse of diagnostic tools and medications in acute rhinosinusitis in Spain: a populationbased study (the PROSINUS study). BMJ Open. 2018 Jan 31;8(1):e018788.

225. Leung RM, Chandra RK, Kern RC, Conley DB, Tan BK. Primary care and upfront computed tomography scanning in the diagnosis of chronic rhinosinusitis: A costbased decision analysis. Laryngoscope. 2014 Jan;124(1):12-8.

226. Agius AM. Chronic sinusitis in Maltacorrelation between symptoms and CT scan. Rhinology. 2010;48(1):65-70.

227. Leung $R$, Kern R, Jordan N, Almassian $S$, Conley D, Tan BK, et al. Upfront computed tomography scanning is more costbeneficial than empiric medical therapy in the initial management of chronic rhinosinusitis. Int Forum Allergy Rhinol. 2011 Nov; 1 (6):471-80.

228. Tan BK, Chandra RK, Conley DB, Tudor RS, Kern RC. A randomized trial examining the effect of pretreatment point-of-care computed tomography imaging on the management of patients with chronic rhinosinusitis symptoms. Int Forum Allergy Rhinol. 2011 May 1;1(3):229-34.

229. Madani G, Lund VJ. Imaging of Sinonasal Tumors. Semin Ultrasound, CT MRI. 2009 Feb 1;30(1):25-38.

230. Lund VJ, Stammberger $H$, Nicolai $P$ Castelnuovo P, Beal T, Beham A, et al. European position paper on endoscopic management of tumours of the nose paranasal sinuses and skull base. Rhino Suppl. 2010;22:1-143.

231. Beiersdorf $N$, Schien $M$, Hentschel J, Pfister W, Markert UR, Mainz JG. Soluble inflammation markers in nasal lavage from CF patients and healthy controls. J Cyst Fibros. 2013 May 1;12(3):249-57.

232. Castelli S, Arasi S, Pawankar R, Matricardi PM. Collection of nasal secretions and tears and their use in allergology [Internet]. Vol. 18, Current Opinion in Allergy and Clinical Immunology. 2018. p. 1-9.

233. Al Ahmari MD, Sapsford RJ, Wedzicha JA, Hurst JR. Intersession repeatability of a novel nasal lavage technique. Transl Res. 2011 Sep 1;158(3):163-8

234. Tomazic PV, Birner-Gruenberger $R$, Leitner A, Obrist B, Spoerk S, Lang-Loidolt D. Nasal mucus proteomic changes reflect altered immune responses and epithelial permeability in patients with allergic rhinitis. J Allergy Clin Immunol. 2014 Mar;133(3):741-50.

235. Wolf $A$, Liesinger $L$, Spoerk $S$, Schittmayer
M, Lang-Loidolt D, Birner-Gruenberger R, et al. Olfactory cleft proteome does not reflect olfactory performance in patients with idiopathic and postinfectious olfactory disorder: A pilot study. Sci Rep. 2018 Dec 3;8(1):17554.

236. Watelet J-B, Gevaert P, Holtappels G, Van Cauwenberge P, Bachert C. Collection of nasal secretions for immunological analysis. Eur Arch Oto-Rhino-Laryngology. 2004 May 1;261(5):242-6.

237. Lü FX, Esch RE. Novel nasal secretion collection method for the analysis of allergen specific antibodies and inflammatory biomarkers. J Immunol Methods. 2010 Apr;356(1-2):6-17.

238. Mosler K, Coraux C, Fragaki K, Zahm J-M, Bajolet O, Bessaci-Kabouya K, et al. Feasibility of nasal epithelial brushing for the study of airway epithelial functions in CF infants. J Cyst Fibros. 2008 Jan;7(1):4453.

239. Pipolo C, Bianchini S, Barberi S, Landi M, D'auria E, Fuccillo E, et al. Nasal cytology in children: scraping or swabbing?*

240. Fokkens WJ, Vroom TM, Gerritsma V, Rijntjes E. A biopsy method to obtain high quality specimens of nasal mucosa. Rhinology. 1988 Dec;26(4):293-5.

241. Prior AJ, Calderon MA, Lavelle RJ, Davies RJ. Nasal biopsy: indications, techniques and complications. Respir Med. 1995 Mar;89(3):161-9.

242. Segal N, Osyntsov L, Olchowski J, Kordeluk S, Plakht Y. Nose biopsy: a comparison between two sampling techniques. Eur Arch Oto-Rhino-Laryngology. 2016 Jun 29;273(6):1445-8.

243. Fokkens WJ, Holm AF, Rijntjes E, Mulder PG, Vroom TM. Characterization and quantification of cellular infiltrates in nasal mucosa of patients with grass pollen allergy, non-allergic patients with nasal polyps and controls. Int Arch Allergy Appl Immunol. 1990;93(1):66-72.

244. Ingels K, Durdurez JP, Cuvelier C, van Cauwenberge P. Nasal biopsy is superior to nasal smear for finding eosinophils in nonallergic rhinitis. Allergy. 1997 Mar;52(3):338-41.

245. Hellings PW, Klimek L, Cingi C, Agache I, Akdis C, Bachert C, et al. Non-allergic rhinitis: Position paper of the European Academy of Allergy and Clinical Immunology. Allergy. 2017 Nov;72(11):1657-65.

246. Andrews P, Poirrier A-L, Lund V, Choi D. Safety of human olfactory mucosal biopsy for the purpose of olfactory ensheathing cell harvest and nerve repair: a prospective controlled study in patients undergoing endoscopic sinus surgery. Rhinology. 2016 Jun 1:54(2):183-91.

247. Corey JP, Houser SM, Ng BA. Nasal congestion: a review of its etiology, evaluation, and treatment. Ear Nose Throat J. 2000 Sep;79(9):690-3, 696, 698 passim.

248. Ottaviano G, Scadding GK, lacono V, Scarpa 
B, Martini A, Lund VJ. Peak nasal inspiratory flow and peak expiratory flow. Upright and sitting values in an adult population. Rhinol J. 2016 Dec 1;54(2):160-3.

249. Valero A, Navarro A, del Cuvillo A, Alobid I, Benito J, Colás C, et al. Position Paper on Nasal Obstruction: Evaluation and Treatment. J Investig Allergol Clin Immunol. 2018 Apr 16;28(2):67-90

250. Lara-Sánchez H, Álvarez Nuño C, GilCarcedo Sañudo E, Mayo Iscar A, Vallejo Valdezate LÁ. Evaluación de la obstrucción nasal mediante rinomanometría y escalas subjetivas y medición del éxito terapéutico médico y quirúrgico. Acta Otorrinolaringológica Española. 2017 May;68(3):145-50.

251. Sipilä J, Suonpää J, Laippala P. Sensation of nasal obstruction compared to rhinomanometric results in patients referred for septoplasty. Rhinology. 1994 Sep;32(3):141-4.

252. Salihoglu M, Cekin E, Altundag A, Cesmeci E. Examination versus subjective nasal obstruction in the evaluation of the nasal septal deviation. Rhinol J. 2014 Jan 1;52(2):122-6.

253. Sipilä J, Suonpää J, Silvoniemi P, Laippala P. Correlations between Subjective Sensation of Nasal Patency and Rhinomanometry in both Unilateral and Total Nasal Assessment. ORL. 1995;57(5):260-3.

254. Roithmann R, Cole P, Chapnik J, Barreto SM, Szalai JP, Zamel N. Acoustic rhinometry, rhinomanometry, and the sensation of nasal patency: a correlative study. J Otolaryngol. 1994 Dec;23(6):454-8.

255. Mozzanica F, Gera R, Bulgheroni C, Ambrogi F, Schindler A, Ottaviani F. Correlation between Objective and Subjective Assessment of Nasal Patency. Iran J Otorhinolaryngol. 2016 Sep;28(88):313-9.

256. Simola M, Malmberg $H$. Sensation of nasal airflow compared with nasal airway resistance in patients with rhinitis Clin Otolaryngol Allied Sci. 1997 Jun 1;22(3):260-2.

257. Tompos T, Garai T, Zemplén B, Gerlinger I. Sensation of nasal patency compared to rhinomanometric results after septoplasty. Eur Arch Oto-Rhino-Laryngology. 2010 Dec 11;267(12):1887-91.

258. Hirschberg A, Rezek Ö. Correlation between Objective and Subjective Assessments of Nasal Patency. ORL. 1998;60(4):206-11.

259. Andrews P, Joseph J, Li C-H, Nip L, Jacques T, Leung T. A UK survey of current ENT practice in the assessment of nasal patency. J Laryngol Otol. 2017 Aug 27;131(08):7026.

260. Occasi F, Duse M, Vittori T, Rugiano A, Tancredi G, De Castro G, et al. Primary school children often underestimate their nasal obstruction. Rhinology. 2016;54:1649.

261. Bousquet J, Clark TJH, Hurd S, Khaltaev N, Lenfant $C$, O'Byrne $P$, et al. GINA guidelines on asthma and beyond. Allergy Eur J Allergy Clin Immunol. 2007 Feb;62(2):102-12.

262. Gordon ASD, McCaffreyTV., Kern EB, Pallanch JF. Rhinomanometry for Preoperative and Postoperative Assessment of Nasal Obstruction. Otolaryngol Neck Surg. 1989 Jul 25;101(1):20-6.

263. Hopkins C, Hettige R, Soni-Jaiswal A, Lakhani R, Carrie S, Cervin A, et al. CHronic Rhinosinusitis Outcome MEasures (CHROME), developing a core outcome set for trials of interventions in chronic rhinosinusitis. Rhinol J. 2018 Mar 1;56(1):22-32.

264. Ottaviano G, Fokkens WJ. Measurements of nasal airflow and patency: a critical review with emphasis on the use of peak nasal inspiratory flow in daily practice. Allergy. 2016 Feb;71(2):162-74.

265. Mendes AIS, Wandalsen GF, Solé D. Objective and subjective assessments of nasal obstruction in children and adolescents with allergic rhinitis. J Pediatr (Rio J). 2012 Sep 22;88(5):389-95.

266. Wandalsen GF, Mendes Al, Solé D. Correlation between nasal resistance and different acoustic rhinometry parameters in children and adolescents with and without allergic rhinitis. Braz J Otorhinolaryngol. 2012 Nov 1;78(6):81-6.

267. Zhang G, Solomon P, Rival R, Fenton RS, Cole P. Nasal Airway Volume and Resistance to Airflow. Am J Rhinol. 2008 Jul 1;22(4):371-5.

268. Yepes-Nuñez JJ, Bartra J, MuñozCano R, Sánchez-López J, Serrano C, Mullol J, et al. Assessment of nasal obstruction: Correlation between subjective and objective techniques. Allergol Immunopathol (Madr). 2013 Nov;41(6):397-401.

269. Van Spronsen $E$, Ingels KJAO, Jansen AH, Graamans K, Fokkens WJ. Evidencebased recommendations regarding the differential diagnosis and assessment of nasal congestion: using the new GRADE system. Allergy. 2008 Jun 28;63(7):820-33.

270. Ottaviano G, Scadding GK, Coles S, Lund VJ. Peak nasal inspiratory flow; normal range in adult population. Rhinology. 2006 Mar:44(1):32-5.

271. Chaves C, Ibiapina C da C, de Andrade CR, Godinho R, Alvim CG, Cruz ÁA. Correlation between peak nasal inspiratory flow and peak expiratory flow in children and adolescents. Rhinology. 2012 Dec;50(4):381-5.

272. Åkerlund A, Millqvist E, Öberg D, Bende $M$. Prevalence of upper and lower airway symptoms: the Skövde populationbased study. Acta Otolaryngol. 2006 Jan 26;126(5):483-8.

273. Bouzgarou MD, Saad H Ben, Chouchane A, Cheikh I Ben, Zbidi A, Dessanges JF, et al. North African reference equation for peak nasal inspiratory flow. J Laryngol Otol. 2011 Jun 28;125(6):595-602.

274. Pité H, Pimenta L, Cristina Henriques A,
Marques I, Camarinha C, Verónica Lourenço A, et al. Lower airway flow influences peak nasal inspiratory flow in school-aged children*. Rhinology. 2018:56:288-96.

275. Ottaviano G, Lund VJ, Coles S, Staffieri A, Scadding GK. Does peak nasal inspiratory flow relate to peak expiratory flow? Rhinology. 2008 Sep;46(3):200-3.

276. Papachristou A, Bourli E, Aivazi D, Futzila E, Papastavrou T, Konstandinidis T, et al. Normal peak nasal inspiratory flow rate values in Greek children and adolescents. Hippokratia. 2008;12(2):94-102.

277. Da Cunha Ibiapina C, Ribeiro De Andrade C, Augusto P, Camargos M, Alvim CG, Cruz ÁA. Reference values for peak nasal inspiratory flow in children and adolescents in Brazil*.

278. van Spronsen E, Ebbens FA, Fokkens WJ. Normal peak nasal inspiratory flow rate values in healthy children aged 6 to 11 years in the Netherlands. Rhinology. 2012;50(1).

279. Klossek J-M, Lebreton J-P, Delagranda A, Dufour X. PNIF measurement in a healthy French population. A prospective study about 234 patients*.

280. Ottaviano G, Scadding GK, Scarpa B, Accordi D, Staffieri A, Lund VJ. Unilateral peak nasal inspiratory flow, normal values in adult population. Rhinology. 2012 Dec;50(4):386-92.

281. Wieslander G, Kumlin A, Norbäck D. Dampness and 2-Ethyl-1-hexanol in Floor Construction of Rehabilitation Center: Health Effects in Staff. Arch Environ Occup Health. 2010 Jan 29;65(1):3-11.

282. Wilson A, Dempsey OJ, Sims EJ, Coutie WJ, Paterson MC, Lipworth BJ. Evaluation of treatment response in patients with seasonal allergic rhinitis using domiciliary nasal peak inspiratory flow. Clin Exp Allergy. 2000 Jun;30(6):833-8.

283. Nathan R, Eccles R, Howarth P, Steinsvag $S$, Togias A. Objective monitoring of nasal patency and nasal physiology in rhinitis. J Allergy Clin Immunol. 2005 Mar;115(3):S442-59.

284. Teixeira RUF, Zappelini CEM, Alves FS, Costa EA da. Peak nasal inspiratory flow evaluation as an objective method of measuring nasal airflow. Braz J Otorhinolaryngol. 2011 Aug;77(4):473-80.

285. Cho S II, Hauser R, Christiani DC. Reproducibility of nasal peak inspiratory flow among healthy adults: Assessment of epidemiologic utility. Chest. 1997 Dec;112(6):1547-53.

286. Starling-Schwanz R, Peake HL, Salome CM, Toelle BG, Ng KW, Marks GB, et al. Repeatability of peak nasal inspiratory flow measurements and utility for assessing the severity of rhinitis. Allergy. 2005 Jun;60(6):795-800.

287. Barnes ML, Lipworth BJ. Removing nasal valve obstruction in peak nasal inspiratory flow measurement. Ann Allergy, Asthma Immunol. 2007 Jul;99(1):59-60. 
288. Balikci HH, Gurdal MM. Use of peak nasal inspiratory flowmetry and nasal decongestant to evaluate outcome of septoplasty with radiofrequency coblation of the inferior turbinate. Rhinology. 2014 Jan 1;52(2):112-5.

289. Larsen K, Oxhøj H, Grøntved A, Kristensen S. Peak flow nasal patency indices in patients operated for nasal obstruction. Eur Arch Oto-Rhino-Laryngology. 1990;248(1):21-4.

290. Poirrier AL, Ahluwalia S, Kwame I, Chau H, Bentley M, Andrews P. External nasal valve collapse: validation of novel outcome measurement tool. Rhinology. 2014 Jun;52(2):127-32.

291. Hellings PW, Nolst Trenite GJ. Improvement of nasal breathing and patient satisfaction by the endonasal dilator Airmax ${ }^{\oplus}$. Rhinology. 2014 Mar;52(1):31-4.

292. Ottaviano G, Ermolao A, Nardello E, Muci $F$, Favero $V$, Zaccaria $M$, et al. Breathing parameters associated to two different external nasal dilator strips in endurance athletes. Auris Nasus Larynx. 2017 Dec;44(6):713-8.

293. Lekakis G, Dekimpe E, Steelant B, Steelant PW. Managing nasal valve compromise patients with nasal dilators: objective vs. subjective parameters. Rhinol J. 2016 Dec 1;54(4):348-54.

294. Johnson SM, Hamilton AM, Lauersen LA. A phase IV, single-center, crossover evaluation of the efficacy of an external nasal dilator strip in children with nasal congestion. Allergy Asthma Proc. 2016 May 1;37(3):242-7.

295. Dinardi RR, de Andrade CR, Martins-Costa HC, da Cunha Ibiapina C. Does the Airmax internal nasal dilator increase peak nasal inspiratory flow (PNIF) in adolescent athletes? Int J Pediatr Otorhinolaryngol. 2016 May:84:37-42

296. van den Broek SJAC, van Heerbeek N. The effect of the titanium butterfly implant on nasal patency and quality of life. Rhinol J. 2018 Sep 1;0(0):364-9.

297. Elsayed Al, Fouad YA, El Malt A, Sweed AH. External Nasal Valve Repair in Children: Alar Batten Graft Reinforced by External Temporary Suspensory Suture. Ann Otol Rhinol Laryngol. 2018 Sep 28;127(9):598603.

298. Clement PA. Committee report on standardization of rhinomanometry. Rhinology. 1984 Sep;22(3):151-5.

299. Vogt K, Bachmann-Harildstad G, Lintermann A, Nechyporenko A, Peters F, Wernecke KD. The new agreement of the international RIGA consensus conference on nasal airway function tests. Rhinology. 2018 Jun 1;56(2):133-43

300. Tugrul S, Dogan R, Senturk E, Eren SB, Meric A, Ozturan O. A prospective randomized blinded clinical trial: large-volume nasal irrigation with fluticasone propionate in the early postoperative period following septoplasty. Int Forum Allergy Rhinol. 2015
Jul;5(7):610-5.

301. Ottaviano G, Marioni G, Giacomelli L, La Torre FB, Staffieri C, Marchese-Ragona R, et al. Smoking and chronic rhinitis: effects of nasal irrigations with sulfurous-arsenicalferruginous thermal water: A prospective, randomized, double-blind study. Am J Otolaryngol. 2012 Nov 1;33(6):657-62.

302. Vogt K, Jalowayski AA, Althaus W, Cao C, Han D, Hasse W, et al. 4-Phase-Rhinomanometry (4PR)--basics and practice 2010. Rhino Suppl. 2010;21:1-50.

303. Vogt K, Zhang L. Airway assessment by four-phase rhinomanometry in septal surgery. Curr Opin Otolaryngol Head Neck Surg. 2012 Feb;20(1):33-9.

304. Wong EHC, Eccles R. Comparison of classic and 4-phase rhinomanometry methods, is there any difference? Rhinology. 2014 Dec;52(4):360-5.

305. Laine-Alava MT, Murtolahti S, Crouse UK, Warren DW. Upper airway resistance during growth: A longitudinal study of children from 8 to 17 years of age. Angle Orthod. 2016 Jul 6;86(4):610-6.

306. Merkle J, Kohlhas L, Zadoyan G, Mosges R, Hellmich M. Rhinomanometric reference intervals for normal total nasal airflow resistance. Rhinology. 2014;52:292-9.

307. Ren L, Zhang L, Duan S, Zhang W, Zhang $Y$. Nasal airflow resistance measured by rhinomanometry in a healthy population of China. Int Forum Allergy Rhinol. 2018 Nov;8(11):1308-14.

308. Peksis K, Unger J, Paulauska S, Emsina1 A Blumbergs $M$, Vogt $K$, et al. Relationships among nasal resistance, age and anthropometric parameters of the nose during growth. Rhinol Online. 2018;1:11221.

309. VogtK,Wernecke K-D, Behrbohm H, Gubisch W, Argale M. Four-phase rhinomanometry: a multicentric retrospective analysis of 36,563 clinical measurements. Eur Arch Oto-Rhino-Laryngology. 2016 May 22:273(5):1185-98

310. Jackson AC, Butler JP, Millet EJ, Hoppin FG, Dawson S V. Airway geometry by analysis of acoustic pulse response measurements. J Appl Physiol. 1977 Sep;43(3):523-36.

311. Giotakis A, Tomazic P, Riechelmann H, Vent J. Objective Assessment of Nasal Patency. Facial Plast Surg. 2017 Aug 28;33(04):37887.

312. Clement PAR, Gordts F, Standardisation Committee on Objective Assessment of the Nasal Airway, IRS and E. Consensus report on acoustic rhinometry and rhinomanometry. Rhinology. 2005 Sep:43(3):169-79.

313. Grymer LF, Hilberg O, Pedersen OF Rasmussen TR. Acoustic rhinometry: values from adults with subjective normal nasa patency. Rhinology. 1991 Mar;29(1):35-47.

314. Holmström M. The use of objective measures in selecting patients for septal surgery. Rhinology. 2010;48:387-93.
315. Straszek SP, Schlünssen $V$, Sigsgaard $T$, Pedersen OF. Reference values for acoustic rhinometry in decongested school children and adults: the most sensitive measurement for change in nasal patency. Rhinology. 2007:45(1):36-9.

316. Mishima $H$, Kase $Y$, Hiraiwa $F$, linuma $T$. The Influence of Septal Perforation on Measurement by Acoustic Rhinometry. Nippon Jibiinkoka Gakkai Kaiho. 2001 Aug 20;104(8):815-23.

317. Munoz-Cano R, Salvador $R$, Valero $A$, Berenguer J, Alobid I, Bartra J, et al. Accuracy of acoustic rhinometry versus computed tomography in the evaluation of nasal cavity in patients with nasal polyposis. Rhinol J. 2010 Jun 1;48(2):224-7.

318. Alobid I, Benitez P, Valero A, Munoz R, Langdon C, Mullol J. Oral and intranasal steroid treatments improve nasal patency and paradoxically increase nasal nitric oxide in patients with severe nasal polyposis. Rhinology. 2012 Jun;50(2):171-7.

319. Lund VJ, Flood J, Sykes AP, Richards DH. Effect of fluticasone in severe polyposis. Arch Otolaryngol Head Neck Surg. 1998 May;124(5):513-8.

320. Van Zele T, Gevaert P, Holtappels G, Beule A Wormald PJ, Mayr S, et al. Oral steroids and doxycycline: Two different approaches to treat nasal polyps. J Allergy Clin Immunol. 2010 May;125(5):1069-1076.e4

321. Ottaviano G, Lund VJ, Nardello $E_{i}$ Scarpa B, Frasson G, Staffieri A, et al. Comparison between unilateral PNIF and rhinomanometry in healthy and obstructed noses. Rhinology. 2014;52(1):25-30.

322. Ottaviano G, Marioni G, Staffieri C, Giacomelli L, Marchese-Ragona R, Bertolin A, et al. Effects of sulfurous, salty, bromic, iodic thermal water nasal irrigations in nonallergic chronic rhinosinusitis: a prospective, randomized, double-blind, clinical, and cytological study. Am J Otolaryngol. 2011 May;32(3):235-9.

323. Varvyanskaya A, Lopatin A. Efficacy of long-term low-dose macrolide therapy in preventing early recurrence of nasal polyps after endoscopic sinus surgery. Int Forum Allergy Rhinol. 2014 Jul;4(7):533-41.

324. Martins de Oliveira GM, Rizzo JÂ, Camargos PA, Sarinho ES. Are measurements of peak nasal flow useful for evaluating nasal obstruction in patients with allergic rhinitis? Rhinology. 2015;53:160-6.

325. Kirtsreesakul V, Leelapong J, Ruttanaphol S. Nasal Peak Inspiratory and Expiratory Flow Measurements for Assessing Nasal Obstruction in Allergic Rhinitis. Am J Rhinol Allergy. 2014 Mar;28(2):126-30.

326. Neighbour H, Soliman M, Steacy LM, Hickey $P$, Forbes $B$, Larché $M$, et al. The Allergic Rhinitis Clinical Investigator Collaborative (AR-CIC): verification of nasal allergen challenge procedures in a study utilizing an investigational immunotherapy for cat allergy. Clin Trans| Allergy. 2018;8:15. 
327. Kirtsreesakul V, Hararuk K, Leelapong J Ruttanaphol S. Clinical Efficacy of Nasal Steroids on Nonallergic Rhinitis and the Associated Inflammatory Cell Phenotypes. Am J Rhinol Allergy. 2015 Sep;29(5):343-9.

328. Scadding GW, Eifan AO, Lao-Araya M, Penagos M, Poon SY, Steveling $E$, et al. Effect of grass pollen immunotherapy on clinical and local immune response to nasal allergen challenge. Allergy. 2015 Jun;70(6):689-96.

329. de Souza Campos Fernandes S, Ribeiro de Andrade C, da Cunha Ibiapina C. Application of Peak Nasal Inspiratory Flow reference values in the treatment of allergic rhinitis. Rhinology. 2014 Jun;52(2):133-6.

330. Jordana G, Dolovich J, Briscoe MP, Day $J H$, Drouin MA, Gold M, et al. Intranasal fluticasone propionate versus loratadine in the treatment of adolescent patients with seasonal allergic rhinitis. J Allergy Clin Immunol. 1996 Feb 1:97(2):588-95.

331. Gomes DDL, Camargos PAM, Ibiapina CDC, de Andrade CR. Nasal peak inspiratory flow and clinical score in children and adolescents with allergic rhinitis. Rhinology. 2008;46(4):276-80

332. Chin D, Marcells G, Malek J, Pratt E, Sacks $R$, Snidvongs $K$, et al. Nasal peak inspiratory flow (NPIF) as a diagnostic tool for differentiating decongestable from structural nasal obstruction. Rhinology. 2014 Jun;52(2):116-21.

333. Ciprandi G, Cirillo I, Vizzaccaro A, Pallestrini $\mathrm{E}$, Tosca MA. Decongestion test in patients with allergic rhinitis: functional evaluation of nasal aifflow. Am J Rhinol. 20(2):224-6.

334. Ozkul HM, Balikci HH, Gurdal MM, Celebi S, Yasar H, Karakas M, et al. Normal Range of Peak Nasal Inspiratory Flow and Its Role in Nasal Septal Surgery. J Craniofac Surg. 2013 May;24(3):900-2.

335. Sandhu AS, Temple RH, Timms MS. Partia laser turbinectomy: two year outcomes in patients with allergic and non-allergic rhinitis. Rhinology. 2004 Jun;42(2):81-4.

336. Xavier R, Azeredo-Lopes S, Papoila A. Spreader grafts: functional or just aesthetical? Rhinol J. 2015 Dec 1;53(4):3329.

337. Whitcroft KL, Andrews PJ, Randhawa PS. Peak nasal inspiratory flow correlates with quality of life in functional endoscopic sinus surgery. Clin Otolaryngol. 2017 Dec;42(6):1187-92.

338. Fuller JC, Gadkaree SK, Levesque PA, Lindsay RW. Peak nasal inspiratory flow is a useful measure of nasal airflow in functional septorhinoplasty. Laryngoscope. 2018 Oct 16;

339. Fuller JC, Levesque PA, Lindsay RW. Functional septorhinoplasty in the pediatric and adolescent patient. Int J Pediatr Otorhinolaryngol. 2018 Aug:111:97-102.

340. Haavisto LE, Sipilä Jl. Acoustic rhinometry, rhinomanometry and visual analogue scale before and after septal surgery: a prospective 10-year follow-up. Clin Otolaryngol. 2013 Feb 1;38(1):23-9.

341. Tasca I, Ceroni Compadretti G, Losano $\mathrm{TI}$, Lijdens $Y$, Boccio C. Extracorporeal septoplasty with internal nasal valve stabilisation La chirurgia extracorporea del setto nasale con stabilizzazione della valvola nasale interna. ACTA Otorhinolaryngol Ital. 2018:38:331-7.

342. Lund $\vee \mathrm{J}$. Measuring the breath of life. Rhinology. 2014;52(2):97-8.

343. Pendolino $A L$, Nardello $E_{1}$ Lund $V J$, Maculan P, Scarpa B, Martini A, et al. Comparison between unilateral PNIF and rhinomanometry in the evaluation of nasal cycle. Rhinol J. 2018 Jun 1;56(2):122-6.

344. Pendolino AL, Lund VJ, Nardello E, Ottaviano G. The nasal cycle: a comprehensive review. Rhinol Online. 2018;2:67-76.

345. Ottaviano G, Cosmi E, lacono V, Scarpa B, Staffieri A, Scadding GK. Does the contraceptive pill influence peak nasal inspiratory flow values? Rhinology. 2014 Dec;52(4):355-9.

346. Yıldırım YS, Senturk E, Tugrul S, Ozturan O. Evaluation of the nasal contractility capacity in postmenopausal women*.

347. Scadding GW, Calderon MA, Bellido V, Koed GK, Nielsen N-C, Lund K, et al. Optimisation of grass pollen nasal allergen challenge for assessment of clinical and immunological outcomes. J Immunol Methods. 2012 Oct 31;384(1-2):25-32.

348. Miller B, Mirakian R, Gane S, Larco J, Sannah AA, Darby $Y$, et al. Nasal lysine aspirin challenge in the diagnosis of aspirin exacerbated respiratory disease. Clin Exp Allergy. 2013 Aug;43(8):874-80.

349. Shamji MH, Bellido V, Scadding GW, Layhadi $J A$, Cheung DKM, Calderon MA, et al. Effector cell signature in peripheral blood following nasal allergen challenge in grass pollen allergic individuals. Allergy. 2015 Feb;70(2):171-9.

350. Celikel S, Stevenson D, Erkorkmaz U, White AA. Use of nasal inspiratory flow rates in the measurement of aspirin-induced respiratory reactions. Ann Allergy, Asthma Immunol. 2013 Oct;111(4):252-5.

351. Gosepath J, Amedee RG, Mann WJ. Nasal Provocation Testing as an International Standard for Evaluation of Allergic and Nonallergic Rhinitis. Laryngoscope. 2005 Mar;1 15(3):512-6.

352. Dordal MT, Lluch-Bernal M, Sánchez MC, Rondón C, Navarro A, Montoro J, et al. Allergen-specific nasal provocation testing: review by the rhinoconjunctivitis committee of the Spanish Society of Allergy and Clinical Immunology. J Investig Allergol Clin Immunol. 2011;21(1):1-12; quiz follow 12

353. Kim YH, Jang TY. Proposed diagnostic standard using visual analogue scale and acoustic rhinometry in nasal provocation test in allergic patients. Auris Nasus Larynx. 2011 Jun 1;38(3):340-6.
354. Serrano CD, Valero A, Bartra J, Roca-Ferrer J, Muñoz-Cano R, Sánchez-López J, et al. Nasal and bronchial inflammation after nasal allergen challenge: assessment using noninvasive methods. J Investig Allergol Clin Immunol. 2012;22(5):351-6.

355. Maniscalco M, Bianco A, Mazzarella G, Motta A. Recent Advances on Nitric Oxide in the Upper Airways. Curr Med Chem. 2016 Aug 30;23(24):2736-45.

356. Coumou H, Bel EH. Improving the diagnosis of eosinophilic asthma. Expert Rev Respir Med. 2016 Oct 2;10(10):1093-103.

357. Horváth I, Barnes PJ, Loukides S, Sterk PJ, Högman $M$, Olin A-C, et al. A European Respiratory Society technical standard: exhaled biomarkers in lung disease. Eur Respir J. 2017 Apr;49(4):1600965.

358. American Thoracic Society, European Respiratory Society. ATS/ERS Recommendations for Standardized Procedures for the Online and Offline Measurement of Exhaled Lower Respiratory Nitric Oxide and Nasal Nitric Oxide, 2005. Am J Respir Crit Care Med. 2005 Apr 15;171(8):912-30.

359. de Winter-de Groot KM, van der Ent CK. Measurement of nasal nitric oxide: evaluation of six different sampling methods. Eur J Clin Invest. 2009 Jan 1;39(1):72-7.

360. Struben VMD, Wieringa MH, Mantingh CJ, Jongste JC, Feenstra L. Nasal NO measurement by direct sampling from the nose during breathhold: aspiration flow, nasal resistance and reproducibility. Eur Arch Oto-Rhino-Laryngology. 2006 Aug 19;263(8):723-8.

361. Struben VMD, Wieringa $M H$, Feenstra $L$, de Jongste JC. Nasal nitric oxide and nasal allergy. Allergy. 2006 Jun;61 (6):665-70.

362. Struben VMD, Sewbalak WV., Wieringa MH, Mantingh CJ, van den Toorn LM, Bakker M, et al. Nasal nitric oxide in cystic fibrosis with and without humming. Eur J Clin Invest. 2007 Feb 1;37(2):140-4.

363. Boon M, Meyts I, Proesmans M, Vermeulen FL, Jorissen M, De Boeck K. Diagnostic accuracy of nitric oxide measurements to detect primary ciliary dyskinesia. Eur J Clin Invest. 2014 May:44(5):477-85.

364. Suojalehto $H$, Vehmas $T$, Lindström I, Kennedy DW, Kilpeläinen M, Plosila T, et al. Nasal nitric oxide is dependent on sinus obstruction in allergic rhinitis. Laryngoscope. 2014 Jun;124(6):E213-8.

365. Shapiro AJ, Josephson M, Rosenfeld M, Yilmaz O, Davis SD, Polineni D, et al. Accuracy of Nasal Nitric Oxide Measurement as a Diagnostic Test for Primary Ciliary Dyskinesia: A Systematic Review and Meta-Analysis. Ann Am Thorac Soc. 2017 May 8;14(7):AnnalsATS.201701062SR.

366. de Winter-de Groot KM, van Haren Noman S, Speleman L, Schilder AGM, van der Ent CK. Nasal Nitric Oxide Levels and Nasal 
Polyposis in Children and Adolescents With Cystic Fibrosis. JAMA Otolaryngol Neck Surg. 2013 Sep 1;139(9):931.

367. Alexanderson C, Olin A-C, DahlmanHöglund A, Finizia C, Torén K. Nasal nitric oxide in a random sample of adults and its relationship to sensitization, cat allergen rhinitis, and ambient nitric oxide. Am J Rhinol Allergy. 2012;26(3):e99-103.

368. Fu C-H, Huang C-C, Chen Y-W, Chang $\mathrm{P}-\mathrm{H}$, Lee T-J. Nasal Nitric Oxide in Relation to Quality-of-life Improvements after Endoscopic Sinus Surgery. Am J Rhinol Allergy. 2015 Nov;29(6):e187-91.

369. Lee JM, McKnight CL, Aves T, Yip J, Grewal AS, Gupta S. Nasal nitric oxide as a marker of sinus mucosal health in patients with nasal polyposis. Int Forum Allergy Rhinol. 2015 Oct;5(10):894-9.

370. Rimmer J. Congenital problems of mucociliary clearance: primary ciliary dyskinesia. Rhinology. 2012 Dec;50(4):353-
371. Braun JJ, Boehm N, Metz-Favre C, Koscinsk I, Teletin M, Debry C. Diagnosis of primary ciliary dyskinesia: When and how? Eur Ann Otorhinolaryngol Head Neck Dis. 2017 Dec;134(6):377-82.

372. Sauvalle M, Alvo A. Effect of the temperature of nasal lavages on mucociliary clearance: a randomised controlled trial. Eur Arch Oto-Rhino-Laryngology. $2018 \quad$ Sep 13;275(9):2403-6.

373. Parrilla $E$, Armengot M, Mata M, SánchezVílchez JM, Cortijo J, Hueso JL, et al. Primary ciliary dyskinesia assessment by means of optical flow analysis of phase-contrast microscopy images. Comput Med Imaging Graph. 2014 Apr 1;38(3):163-70.

374. Parrilla $E$, Armengot $M$, Mata $M$, Carda C, Cortijo J, Moratal D, et al. A Ciliary Motility Index for Activity Measurement in Cell Cultures With Respiratory Syncytia Virus. Am J Rhinol Allergy. 2018 Nov 20;194589241881132.

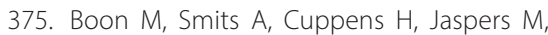

Proesmans M, Dupont $L$, et al. Primary ciliary dyskinesia: Critical evaluation of clinical symptoms and diagnosis in patients with normal and abnormal ultrastructure. Orphanet J Rare Dis. 2014 Jan 22;9(1):11.

376. Takeuchi K, Kitano M, Ishinaga H, Kobayashi M, Ogawa S, Nakatani K, et al. Recent advances in primary ciliary dyskinesia. Auris Nasus Larynx. 2016 Jun;43(3):229-36.

377. Kouis $\mathrm{P}$, Yiallouros PK, Middleton N, Evans JS, Kyriacou K, Papatheodorou SI. Prevalence of primary ciliary dyskinesia in consecutive referrals of suspect cases and the transmission electron microscopy detection rate: a systematic review and meta-analysis. Pediatr Res. 2017 Mar 9;81(3):398-405.

378. Olbrich H, Cremers C, Loges NT, Werner C, Nielsen KG, Marthin JK, et al. Loss-ofFunction GAS8 Mutations Cause Primary Ciliary Dyskinesia and Disrupt the NexinDynein Regulatory Complex. Am J Hum Genet. 2015 Oct 1;97(4):546-54. 


\title{
CONTENT
}

\author{
Abstract \\ Introduction \\ History and examination \\ Quality of life instruments \\ Patient-rated outcome measures (PROMs) \\ Generic PROMs \\ Disease-specific PROMs
}

\section{Blood tests}

Epistaxis

Rhinitis

Granulomatous and vasculitic rhinological conditions

Infectious conditions

Immunoglobulin deficiencies

Miscellaneous blood tests

Allergy tests

Skin tests

Provocation tests

In vitro allergy testing (lgE)

Microbiology

Culture-dependent techniques

Culture-independent techniques

\section{Chemosensory assessment}

Olfactory testing

Gustatory testing

Trigeminal testing

Imaging

Computed tomography (CT) and cone beam CT (CBCT)

Magnetic resonance imaging (MRI)

\section{Nasal sampling for inflammatory markers}

Techniques

\section{Objective measures of nasal airflow and patency}

Peak nasal inspiratory flow (PNIF)

Rhinomanometry

Acoustic rhinometry (AR)

Nasal nitric oxide ( $\mathrm{nNO}$ )

Technique

Diagnostic accuracy

Tests of mucociliary clearance

Mucociliary clearance time

Electron microscopy

Ciliary beat frequency measurement

Ciliogenesis in vitro

\section{References}

